\title{
META-ANÁLISE DE ESTIMATIVAS DA CORRELAÇÃO GENÉTICA ENTRE PESOS AO NASCER E DESMAMA DE BOVINOS
}

\section{JULIANA DI GIORGIO GIANNOTTI}

Engenheiro Agrônomo

Orientador: Prof. Dr. IRINEU UMBERTO PACKER

\begin{abstract}
Dissertação apresentada à Escola Superior de Agricultura "Luiz de Queiroz", Universidade de São Paulo, para obtenção do título de Mestre em Agronomia, Área de Concentração: Estatística e Experimentação Agronômica.
\end{abstract}

P I R A C I C A B A

Estado de São Paulo - Brasil

Dezembro - 2000 


\title{
Dados Internacionais de catalogação na Publicação 〈OP DIVISÃO DE BIBLIOTECA E DOCUMENTAÇÃO •Campus uluiz de Oueiroz"/USP
}

\author{
Giannotti, Juliana Di Giorgio \\ Meta-análise de estimativas da correlação genética entre pesos ao nascer e desmama \\ de bovinos/ Juliana Di Giorgio Giannotti. - - Piracicaba, 2000. \\ $85 \mathrm{p}$. \\ Dissertação (mestrado) - - Escola Superior de Agricultura Luiz de Queiroz, 2000. \\ Bibliografia. \\ 1. Bovino 2. Correlação genética 3. Desmama 4. Método estatístico 5. Peso 6. \\ Revisão 1 Título
}

CDD636.2

Permifila a copia total ou pareial deste locumento, desde que citadh a fonte - O autor 
Aos meus pais Edegar e Thais, pelo

amor e apoio que sempre me deram,

OFEREÇO.

Ao meu avô Washington (in

memorian), por todos os seus

ensinamentos,

DEDICO. 


\section{A GRA D E CIM ENT OS}

Ao meu orientador, Professor Irineu Umberto Packer, pela sua amizade, incentivo e orientação.

Aos Professores Paulo Afonso Bracarense Costa e Domingo Marcolino Braile, pelo interesse, atenção, gentileza e materiais cedidos.

À amiga e Pesquisadora Maria Eugênia Zerlotti Mercadante, pelas valiosas sugestões e pelos dados cedidos para a realização desta meta-análise.

Ao Departamento de Produção Animal da ESALQ/USP, que sempre me acolheu, assim como aos funcionários Cláudia, Vera e Henrique.

Aos Professores do Departamento de Ciências Exatas da ESALQ/USP, em especial aos Professores Décio Barbin e Antônio Francisco Iemma, pelos ensinamentos transmitidos.

Ao Departamento de Ciências Exatas da ESALQ/USP, pela oportunidade, e aos funcionários, pelo atendimento.

Aos funcionários e bibliotecárias da Biblioteca Central da ESALQ/USP pelos serviços prestados, em especial à Eliana, à Cristina e à Ângela.

Aos colegas de curso, em especial à Ana Carolina e ao Cláudio, pela amizade, companheirismo e discussões, que muito auxiliaram na realização deste trabalho.

Aos Meus Pais e Irmão, pela confiança, paciência e dedicação.

Ao Alexandre, pela ajuda inesperada e bem-vinda no momento certo, além da força, da compreensão e do carinho sempre presente.

A todos aqueles que de maneira direta ou indireta tornaram possível a concretização deste trabalho. 


\section{SUMÁRIO}

Página

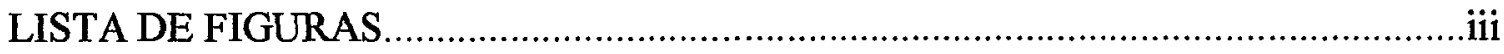

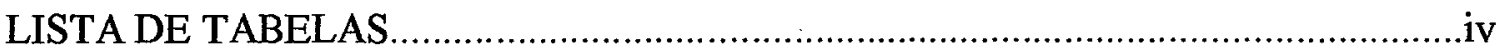

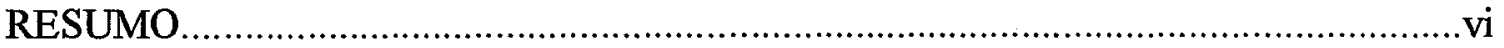

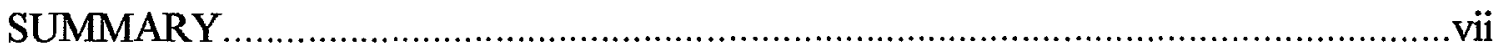

1 INTRODUÇÃ

2 REVISÃO DE LITERATURA ............................................................... 4

2.1 Pesquisa bibliográfica e seleção dos estudos ........................................... 5

2.2 Conversão dos resultados a uma medida comum ..................................... 6

2.2.1 Diferenças médias padronizadas.................................................. 7

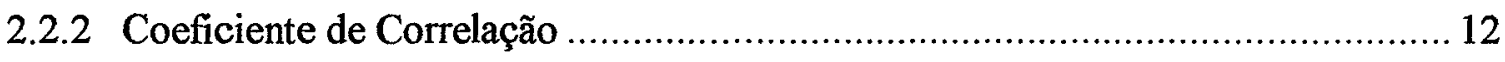

2.2.3 Testes de significância estatística para resultados combinados........................ 15

2.2.3.1 Métodos baseados na distribuição uniforme ............................................. 16

2.2.3.2 Método do qui-quadrado inverso ................................................ 16

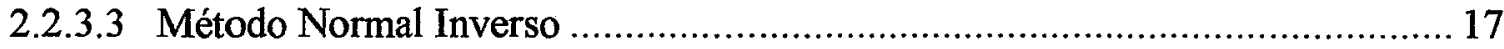

2.3 Modelagem da variação na meta-análise ............................................ 17

2.3.1 Modelos de efeitos fixos (MEF) .......................................................... 18

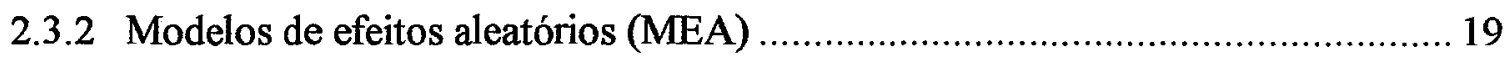

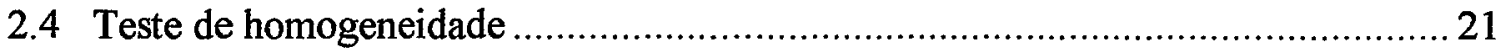

2.4.1 Analogia à análise de variância em meta-análise para Modelos de efeitos fixos

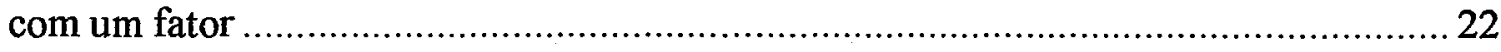

2.4.2 Analogia à análise de variância em meta-análise para modelos de efeitos aleatórios com um fator 
2.4.2.1 Método da Máxima Verossimilhança (MV)............................................ 26

2.4.2.2 Método da Máxima Verossimilhança Restrita (MVR) ................................. 27

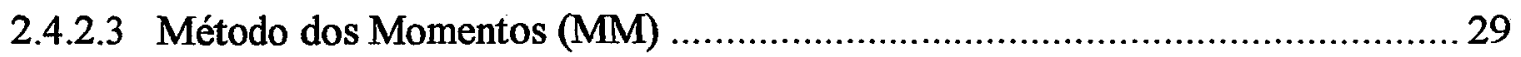

2.4.3 Modelo de Regressão para meta-análise .............................................. 30

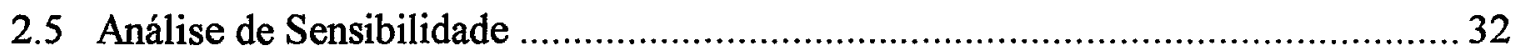

2.6 Principais Problemas em Meta-análise ...................................................... 33

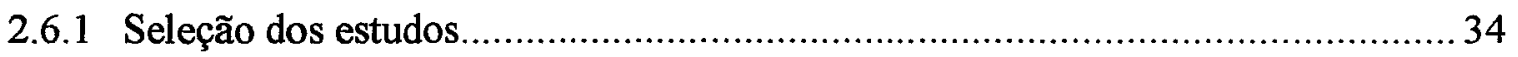

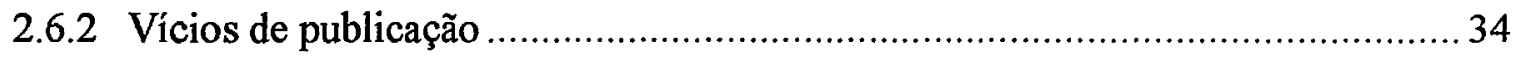

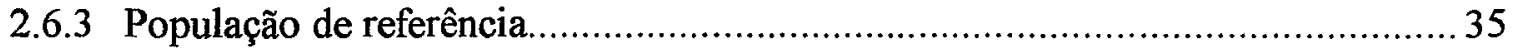

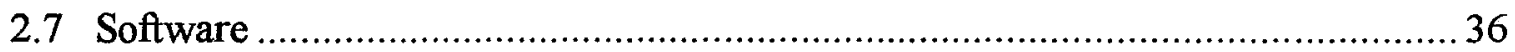

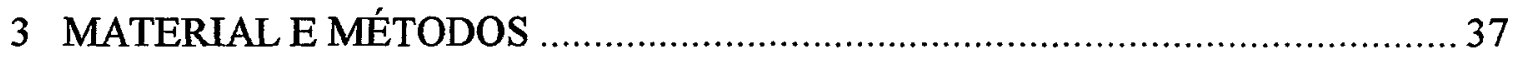

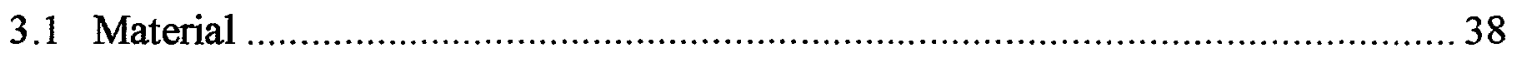

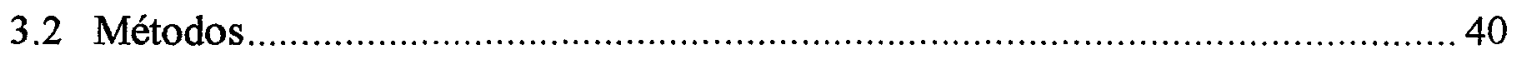

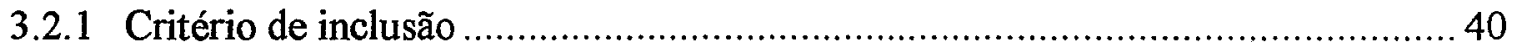

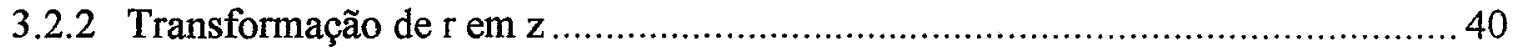

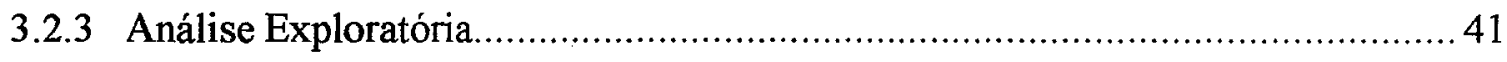

3.2.4 Teste de homogeneidade ............................................................ 41

3.2.5 Modelo de Efeitos Fixos (MEF) ...................................................... 42

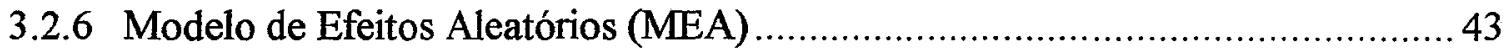

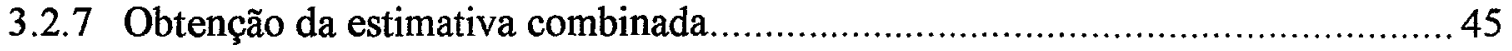

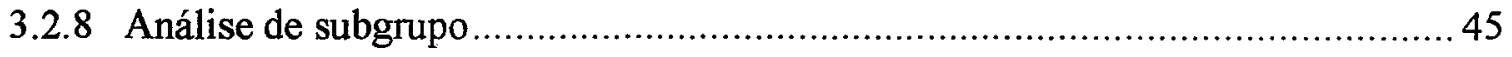

3.2.9 Análise de Sensibilidade ................................................................. 47

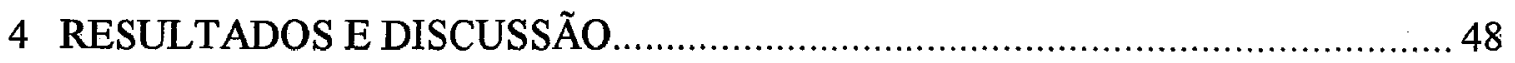

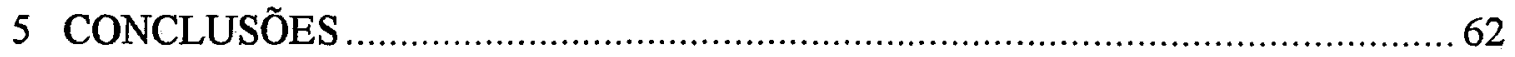

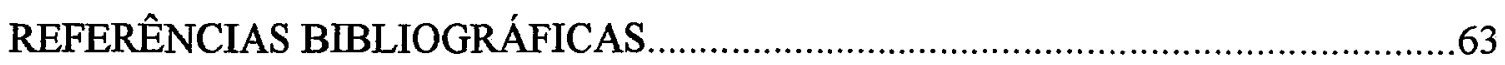

REFERÊNCIAS BIBLIOGRÁFICAS UTILIZADAS NA META-ANÁLISE .............67

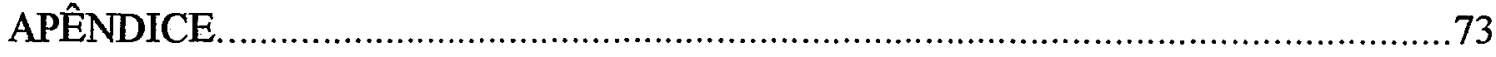




\section{LISTA DE FIGURAS}

Página

1 Fluxograma da meta-análise aplicada para as correlações genéticas. ...................... 37

2 "Dot plot" para a correlação entre peso ao nascimento e peso à desmama. .............. 50

3 Estatísticas descritivas dos coeficientes de correlação genética transformados..........51

4 "Box plot" para os intervalos de confiança dos MEF e MEA. ................................ 56

5 "Box plot" para os IC dos MEF e MEA, para a análise de sensibilidade................. 59 


\section{LISTA DE TABELAS}

1 Representação esquemática das observações com suas respectivas médias e

Página variâncias 8

2 Representação esquemática das duas variáveis contínuas e suas correlações. 12

3 Estimativas do tamanho do efeito e variâncias amostrais para os $p$ grupos de estudos.

4 Heterogeneidade resumida para um modelo de efeitos fixos com um fator. 25

5 Relação completa dos trabalhos sobre correlação genética entre peso ao nascer e desmama em bovinos de corte. 39

6 Representação esquemática das observações com suas respectivas correlações. ..... 40

7 Análise da Heterogeneidade entre e dentro dos grupos de estudo. 47

8 Estimativas de correlações genéticas entre peso ao nascimento e peso à desmama com a transformação $z$.

9 Teste de homogeneidade das 34 estimativas transformadas dos coeficientes de correlação entre peso ao nascer e à desmama em bovinos de corte. 52

10 Estimativa combinada para o modelo de efeitos fixos $\left(w_{i}=1 / s_{i}^{2}\right)$ 52

11 Estimação do componente de variância pelo MVR, pelo PROC MIXED 53

12 Estimativa combinada para o modelo de efeitos aleatórios $\left[\mathrm{w}_{\mathrm{i}}^{*}=1 /\left(\mathrm{s}_{\mathrm{i}}^{2}+\tau_{\mathrm{DL}}^{2}\right)\right] \ldots . .54$

13 Estimativa combinada para o modelo de efeitos aleatórios $\left[\mathrm{w}_{\mathrm{i}}^{*}=1 /\left(\mathrm{s}_{\mathrm{i}}^{2}+\tau_{\mathrm{MVR}}^{2}\right)\right] \ldots . .55$

14 Resultado da análise da heterogeneidade para os grupos de estudo. 57

15 Resultados das estimativas combinadas para os subgrupos e intervalos de confiança. 
16 Resultados resumidos da análise de sensibilidade. 58

17 Resultado da análise da heterogeneidade para os grupos de estudo na análise de sensibilidade. 60

18 Resultados das estimativas combinadas para os subgrupos e intervalos de confiança, para a análise de sensibilidade. 60 


\title{
META-ANÁLISE DE ESTIMATIVAS DA CORRELAÇÃO GENÉTICA ENTRE PESOS AO NASCER E DESMAMA DE BOVINOS
}

\author{
Autora: Juliana Di Giorgio Giannotti \\ Orientador: Prof. Dr. Irineu Umberto Packer
}

\section{RESUMO}

Uma meta-análise foi conduzida com o objetivo de resumir de modo mais apropriado as estimativas da correlação genética entre pesos ao nascer e desmama de bovinos de corte de origem zebuína. Foi usado um conjunto de estimativas obtidas em 39 trabalhos publicados no período de 1968 a 2000.

Estes dados foram analisados de acordo com modelos fixo e aleatório, este último sob as técnicas da máxima verossimilhança restrita e método dos momentos. Para a situação específica deste estudo, observou-se que o modelo fixo não foi apropriado em virtude da falta de homogeneidade das estimativas de correlação, sendo portanto recomendável o modelo aleatório. A análise de subgrupo indicou heterogeneidades dos estudos. Conclui-se que a meta-análise constitui-se em técnica que deve ser implementada para esta e outras finalidades. 


\title{
META-ANALYSIS OF ESTIMATES OF GENETIC CORRELATION BETWEEN BIRTH AND WEANING WEIGTHS IN ZEBU CATTLE
}

\author{
Author: Juliana Di Giorgio Giannotti \\ Adviser: Prof. Dr. Irineu Umberto Packer
}

\section{SUMMARY}

A meta-analysis was conducted to summarize published estimates of genetic correlation between birth and weaning weight of zebu cattle. It was used a collection of estimates from 39 reports from 1968 to 2000 .

Data were analyzed under fixed and random effect models. Components of variance were obtained by the method of moments and restricted maximum likelihood techniques. For the actual case it was verified a strong lack of homogeneity among the studies considered. As a consequence fixed model estimates of combined results were inappropriate. Results suggest random effects model produced better estimates. Subgroup comparisons showed heterogeneity of estudies. It was conclude that metaanalysis techniques were recommended for quantitative reviews of genetic parameters. 


\section{INTRODUÇÃo}

A meta-análise é um procedimento que utiliza métodos estatísticos para combinar ou comparar resultados de estudos distintos, mas relacionados (Kirby, 1993).

A necessidade de combinar informações provenientes de dados coletados sob diferentes condições e diferentes níveis de precisão, para produzir conclusões mais fortes do que aquelas disponiveis em cada fonte de informação, é muito antiga. Stiler $^{1}$, citado por Gaver et al. (1992), descreve a origem do método dos mínimos quadrados por Legrenge em 1805 e Gauss em 1809, como uma tentativa de resolver o problema do uso de observações astronômicas coletadas em diferentes observatórios para estimar a órbita de cometas e determinar arcos meridianos em Geodesia (Gaver et al., 1992).

No início do século XX, o pesquisador Karl Pearson, utilizou técnicas formais de estatística para combinar dados de amostras distintas. A meta-análise de Pearson consistiu em calcular a média de cinco estimativas baseadas na amostra populacional da correlação entre febre entérica e mortalidade. A lógica utilizada por Pearson, pode ser considerada como uma das principais razões, para realizar a meta-análise: "Muitos dos grupos... são muito pequenos para permitir que qualquer opinião definitiva seja formada do todo" (Dickersin \& Berlin, 1992).

Dickesin \& Berlin (1992) citam também outros pesquisadores que promoveram a combinação de resultados de estudos separados, dentre eles: Tippett ${ }^{2}$ (1931) que produziu um método baseado no "p-value" mínimo; Fisher (1932) que criou um método

\footnotetext{
'STIGLER, E.A. The brief history of Statistics: the measurement of uncertainty before 1900. Cambrige, MA: Harvard Universty Press, 1986.

${ }^{2}$ TIPPET, L.H.H. The method of statistics. London: Willian \& Norgate, 1931.
} 
baseado no produto dos valores de probabilidade dos testes e Yates e $\operatorname{Cochran}^{3}$ (1938) que, motivados pela necessidade de combinar os resultados de experimentos agronômicos discutiram métodos e problemas de meta-análise.

Existem alguns poucos artigos entre 1945 e 1960, seguido por uma ausência total de publicação de artigos nessa área até o início dos anos setenta e, em seguida um aumento no número de artigos sobre a combinação de dados (Olkin, 1995).

Nessa época, no campo das ciências sociais, mais precisamente na pesquisa educacional, o desenvolvimento de técnicas estatísticas mais sofisticadas para combinar estudos começou a tomar espaço. Glass (1976) criou o termo meta-análise, o qual é apropriado, pois "meta" implica em algo que ocorre depois ou em sucessão, algo mais organizado ou realizado de uma maneira mais especializada (Egger \& Smith, 1997).

Além de criar o termo, Glass (1976), definiu a meta-análise como "a análise das análises" ou "a análise estatística de uma grande coleção de resultados de análises de estudos individuais com o propósito de completar as descobertas". E advertiu como sendo clara a necessidade da meta-análise pelo aumento assombroso de artigos sobre o mesmo tópico em todas as áreas das ciências.

Deste modo, a motivação principal para a condução de uma meta-análise, está no grande número de estudos similares publicados nas diversas áreas da pesquisa, gerando interesse no desenvolvimento de métodos para combinar informações provenientes daqueles estudos distintos.

A meta-análise obteve aceitação imediata na área médica pois, ao possibilitar reunião de informações dos dados existentes pela combinação de estudos menores, o tamanho da amostra aumenta. Assim, a importância maior da meta-análise reside, principalmente, na possibilidade de obtenção de tamanho grande da amostra, pela combinação de vários estudos pequenos, permitindo uma resposta mais precisa do que a obtida em estudos individuais.

\footnotetext{
${ }^{3}$ YATES, F.; COCHRAN, W.G. The analysis of groups of experiments. Journal of Agricultural Science., v.28, p.556-580, 1938.
} 
Além de estar sendo muito utilizada na área da saúde, a meta-análise é também adotada em agronomia, zootecnia, biologia, ecologia, genética, fisica, estatística, entre outras. Apesar de abranger várias áreas da ciência, tem sido pouco utilizada no Brasil.

No contexto do melhoramento animal são frequentes as revisões bibliográficas sobre estimativas dos parâmetros genéticos de populações bovinas, herdabilidade e correlações genéticas, como pode ser observado nos trabalhos de Mohiuddin et al. (1993), Koots et al. (1994b), Mercadante (1995), e Lôbo et al. (2000). Nestes trabalhos os autores têm usado vários critérios para combinar os resultados individuais.

Deste modo, Koots et al. (1994b) e Lôbo et al. (2000), utilizaram, para obter uma medida comum dos coeficientes de correlação, a transformação proposta por Fisher (transforma-se $r$ em $z$ ), e a ponderação utilizando o inverso da variância de $z$.

$\mathrm{Na}$ revisão realizada por Mercadante et al. (1995) os autores usaram como medida resumida a média, ponderada pelo inverso do erro padrão, das estimativas do coeficiente de correlação.

De modo geral tais revisões seguem alguns fundamentos da meta-análise, a saber, pesquisa bibliográfica abrangente e obtenção de uma medida resumida comum dos vários estudos. Porém, não utilizaram de outros aspectos que são considerados imprescindiveis na proposta da meta-análise.

De qualquer modo fica evidente que a meta-análise pode contribuir grandemente para a questão de combinar diferentes estudos na genética e em outras áreas do conhecimento humano.

Desta maneira os objetivos gerais deste trabalho consistem no desenvolvimento da metodologia da meta-análise e a sua aplicação ao problema específico de resumir estimativas da correlação genética entre pesos ao nascer e desmama em bovinos de origem indiana. 


\section{REVISÃO DE LITERATURA}

Conforme definida por Glass (1976), a meta-análise é uma técnica estatística que consiste de uma revisão quantitativa e resumida de resultados de estudos relacionados, mas independentes.

Os seus propósitos são aumentar o número de observações e o poder estatístico; avaliar a possibilidade de generalizações de conclusões para uma amplitude variada de estudos; examinar a variabilidade entre os ensaios ou estudos; resolver incertezas quando certas conclusões destoam; realizar análise de subgrupo; identificar a necessidade e planejar ensaios ou estudos maiores; responder questões que não foram atribuídas de início aos estudos individuais (Fagard et al., 1996).

Apesar de oferecer muitos atrativos ela não deve ser vista como substituta para a análise dos dados originais. Mesmo quando meticulosamente realizada, os resultados da meta-análise devem ser interpretados com atenção, principalmente devido ao inevitável vício de publicação ("file drawer problem") e à influência do critério de inclusão. Além disso, a meta-análise infringe um dos princípios essenciais da pesquisa científica, de que as hipóteses devem preceder os testes e análises (Fagard et al., 1996).

Houwelingen (1997) refere-se à meta-análise como um pesadelo e uma solução humana pobre para o problema de analisar medidas resumidas de publicações selecionadas. Ele defende a situação ideal de ter acesso os dados originais, e assim realizar uma análise, sob um modelo de efeitos aleatórios, considerando tanto a variação dentro de cada estudo como a entre os estudos. Porém, este mesmo autor admite ser dificil analisar os dados originais de todas as pesquisas. Ao apoiar a idéia de combinar evidências provenientes de origens distintas, considera a hipótese de realizar uma meta- 
análise, porém, da melhor maneira possível, e necessariamente modelando a variação entre os estudos.

DerSimonian \& Laird (1986) citam a natureza diversa dos diferentes estudos, tanto em termos de delineamento como em métodos empregados na realização de cada um deles, como sendo a principal dificuldade para combinar os resultados. Para solucionar esta questão, esses autores sugerem que a variação entre os estudos seja incorporada na análise.

Apesar das críticas e problemas enfrentados pela meta-análise, as evidências indicam que ela é um procedimento estatístico que vem sendo aceito gradativamente pela comunidade científica, e sua aplicação tem aumentado em todos campos das ciências (Cooper, 1989).

Os principais passos envolvidos na meta-análise são:

1. Revisão de literatura;

2. Converter os resultados de cada estudo para uma métrica comum;

3. Modelar a variação;

4. Verificar se os resultados dos estudos são homogêneos;

5. Realizar uma análise de sensibilidade.

\subsection{Pesquisa Bibliográfica e seleção dos estudos}

A revisão de literatura deve ser a mais completa possível, incluindo trabalhos publicados e não publicados (trabalhos em andamento, comunicações pessoais etc) sobre o assunto, com a finalidade de obter o máximo de informação e minimizar os erros que possam influenciar na análise dos dados (Normand, 1999).

A escolha dos estudos a serem incluídos na meta-análise é um ponto crucial que irá influenciar o restante da análise e os resultados finais. Esta seleção tem dois aspectos, às vezes conflitantes, ou seja, incluir apenas aqueles válidos ou apropriados, ou incluir tantos quanto possíveis. A defínição de um critério objetivo de inclusão ajuda o processo 
de seleção dos estudos (Pickard et al., 1998). Tais estudos devem conter obrigatoriamente os dados básicos necessários para o início da meta-análise. Por exemplo, os artigos que não contêm informações que permitam o cálculo dos desvios padrões dos grupos tratamento e controle devem ser descartados, assim como experimentos de baixa qualidade. Entretanto, detectar experimentos de baixa qualidade não é tarefa fácil para o pesquisador que utiliza a meta-análise.

De acordo com Egger \& Smith (1998), o meio mais apropriado para examinar a influência da publicação é através de um gráfico de funil, que é um "scatterplot" dos efeitos estimados dos ensaios contra o tamanho da amostra. Este gráfico é baseado no fato de que a precisão da estimativa do efeito básico do tratamento aumenta com o aumento do tamanho da amostra do componente em estudo. Resultados de estudos pequenos serão plotados na parte inferior do gráfico. Na ausência de influência, a forma do gráfico assemelhar-se-á a um funil invertido e simétrico. Se existir uma forma assimétrica no gráfico, então poderá haver influência dos estudos selecionados.

\subsection{Conversão dos resultados a uma medida comum}

De posse dos resultados dos estudos individuais incluídos é necessário converter os mesmos para uma métrica comum para serem analisados. Esta métrica comum recebe o nome de tamanho do efeito ("effect size").

Foi também Glass (1976) um dos primeiros a sugerir o uso de uma escala invariante de índices do tamanho do efeito - diferenças médias padronizadas e coeficiente de correlação - para combinar informações de estudos distintos nas ciências sociais. $\mathrm{O}$ termo tamanho do efeito tem sido usado para se referir a diferenças médias padronizadas porém, com experimentação mais elaborada e aplicações mais diversas, as diferenças entre tratamentos podem depender não apenas de médias, mas também de variâncias, correlações, medianas, estatísticas de ordem, distâncias etc... Então é conveniente utilizar esse termo para se referir a qualquer destes índices (Hedges \& Olkin, 1985). 
Duas medidas do tamanho do efeito são comumente utilizadas: as diferenças médias padronizadas $d$ de Cohen e o coeficiente de correlação $r$ de Pearson (Hwang \& Thorn, 1999). Quando os estudos se referem a comparar dois grupos (tratamento versus controle) o tamanho do efeito é frequentemente expresso na forma de diferenças médias padronizadas. E quando se trata de duas variáveis contínuas, então o indicador do tamanho do efeito utilizado com mais freqüência é o coeficiente de correlação.

Além dessas duas medidas do tamanho do efeito emprega-se com frequência os testes de significância estatística para resultados combinados, que foram os primeiros procedimentos para a síntese de pesquisa quantitativa.

\subsubsection{Diferenças médias padronizadas}

Seja, segundo Hedges \& Olkin (1985), uma coleção de $k$ estudos cada um

consistindo de dois grupos: tratamento $(\mathrm{T})$ e controle $(\mathrm{C})$, e sendo $\mathrm{n}_{\mathrm{i}}^{\mathrm{T}}$ ○ tamanho da amostra do grupo tratamento e $n_{i}^{c}$ o tamanho da amostra do grupo controle (com $\mathrm{i}=1,2, \ldots \mathrm{k})$, podendo ser iguais, ou não, para os $k$ estudos.

Denota-se a j-ésima $\left(\mathrm{j}=1,2, \ldots, \mathrm{n}_{\mathrm{i}}\right)$ observação nos grupos tratamento e controle do i-ésimo $(i=1,2, \ldots, k)$ estudo por $Y_{i j}^{T}$ e $Y_{i j}^{C}$, respectivamente, assumindo que esses estudos são independentes. Os dados podem ser representados esquematicamente como na Tabela 1. 
Tabela 1. Representação esquemática das observações com suas respectivas médias e variâncias.

\begin{tabular}{|c|c|c|c|c|c|c|}
\hline \multirow[b]{2}{*}{ Estudo } & \multicolumn{2}{|c|}{ Dados } & \multicolumn{2}{|c|}{ Tratamento } & \multicolumn{2}{|c|}{ Controle } \\
\hline & Tratamento & Controle & Média & Variância & Média & Variância \\
\hline 1 & $Y_{11}^{T}, \ldots, Y_{1 n_{1}^{T}}^{T}$ & $\mathrm{Y}_{11}^{\mathrm{C}}, \ldots, \mathrm{Y}_{1_{1}^{\mathrm{C}}}^{\mathrm{C}}$ & $\mu_{1}^{T}$ & $\sigma_{1}^{2}$ & $\mu_{1}^{\mathrm{C}}$ & $\sigma_{1}^{2}$ \\
\hline 2 & $Y_{21}^{T}, \ldots, Y_{2 n_{2}^{T}}^{T}$ & $Y_{21}^{\mathrm{C}}, \ldots, Y_{2 n_{2}}^{\mathrm{C}}$ & $\mu_{2}^{\mathrm{T}}$ & $\sigma_{2}^{2}$ & $\mu_{2}^{\mathrm{C}}$ & $\sigma_{2}^{2}$ \\
\hline K & $\mathbf{Y}_{\mathbf{k} 1}^{\mathbf{T}}, \ldots, \mathbf{Y}_{\mathbf{k n}_{\mathbf{k}}^{\mathrm{T}}}^{\mathrm{T}}$ & $\mathbf{Y}_{\mathrm{k} 1}^{\mathrm{c}}, \ldots, \mathrm{Y}_{\mathrm{kn}_{\mathrm{ckk}}^{\mathrm{c}}}^{\mathrm{c}}$ & $\mu_{\mathrm{k}}^{\mathrm{T}}$ & $\sigma_{k}^{2}$ & $\mu_{\mathrm{k}}^{\mathrm{c}}$ & $\sigma_{k}^{2}$ \\
\hline
\end{tabular}

Assume-se, para o i-ésimo estudo, que as observações dos tratamentos $Y_{i 1}^{T}, \ldots, Y_{i i_{i}^{T}}^{T}$ são normalmente distribuídas com uma média comum $\mu_{i}^{T}$ e variância $\sigma_{i}^{2}$, e as observações dos grupos controle $Y_{\mathrm{i} 1}^{\mathrm{C}}, \ldots, \mathrm{Y}_{\mathrm{in}_{\mathrm{i}}^{\mathrm{C}}}^{\mathrm{C}}$ são normalmente distribuídas com uma média comum $\mu_{i}^{C}$ e variância $\sigma_{i}^{2}$. Admitindo-se homogeneidade de variâncias para os grupos tratamento e controle, para o i-ésimo experimento, têm-se,

$$
\begin{array}{cc}
Y_{i j}^{T} \sim N\left(\mu_{i}^{T}, \sigma_{i}^{2}\right), & j=1, \ldots, n_{i}^{T}, \quad i=1, \ldots, k \\
Y_{i j}^{c} \sim N\left(\mu_{i}^{c}, \sigma_{i}^{2}\right), & j=1, \ldots, n_{i}^{c}, \quad i=1, \ldots, k
\end{array} .
$$

Assim, o indicador do parâmetro do tamanho do efeito $\delta_{i}$ para o i-ésimo experimento, quando este se refere a diferenças médias padronizadas, é dado por:

$$
\delta_{i}=\frac{\mu_{i}^{T}-\mu_{i}^{c}}{\sigma_{i}}, \quad i=1, \ldots, k
$$

Um estimador do parâmetro $\delta$ do tamanho do efeito proposto, por Glass et al. (1981), é baseado no valor amostral da diferença média padronizada. Se, $\overline{\mathrm{Y}}^{\mathrm{T}}$ e $\overline{\mathrm{Y}}^{\mathrm{C}}$, 
são, respectivamente, as médias estimadas dos grupos tratamento e controle, existem várias maneiras de produzir estimativa da diferença média padronizada, entre as quais estão:

$$
\mathrm{g}_{\mathrm{i}}=\frac{\overline{\mathrm{Y}}_{\mathrm{i}}^{\mathrm{T}}-\overline{\mathrm{Y}}_{\mathrm{i}}^{\mathrm{c}}}{\mathrm{s}^{*}}, \quad \mathrm{i}=1, \ldots, \mathrm{k}
$$

onde $s^{*}$ é um desvio padrão estimado. As diferentes escolhas de $s^{*}$ produzem diferentes estimadores, podendo-se definir $s^{*}$ como $s^{T}$, desvio padrão estimado do grupo tratamento, ou como $s^{\mathrm{C}}$, desvio padrão estimado do controle ou, alternativamente, podese usar um desvio padrão que combine $s^{T}$ e $s^{\mathrm{C}}$, chamado desvio padrão combinado, simbolizado por $s_{\mathrm{p}}$, dado pela seguinte expressão,

$$
s_{p i}=\sqrt{\frac{\left(n_{i}^{T}-1\right) s_{T i}^{2}+\left(n_{i}^{c}-1\right) s_{C i}^{2}}{n_{i}^{T}+n_{i}^{C}-2}}, \quad i=1, \ldots, k,
$$

onde:

$\mathrm{s}_{\mathrm{Ti}}^{2}$ é a estimativa da variância do grupo tratamento;

$\mathrm{s}_{\mathrm{Ci}}^{2}$ é a estimativa da variância do grupo controle;

A variância estimada de $g_{\mathrm{i}}$ é dada por:

$$
\hat{\sigma}^{2}\left(g_{i}\right)=\frac{n_{i}^{T}+n_{i}^{c}}{n_{i}^{T} n_{i}^{C}}+\frac{g_{i}^{2}}{2\left(n_{i}^{T}+n_{i}^{C}\right)}, \quad i=1, \ldots, k,
$$

onde:

$g_{\mathrm{i}}$ é definido em (2). 
Outro estimador não-viesado do tamanho do efeito foi proposto por Hedges (1982), e é dado por:

$$
d_{i} \cong\left(1-\frac{3}{4 N_{i}-9}\right) g_{i}, \quad i=1, \ldots, k,
$$

onde:

$N_{i}=n_{i}^{T}+n_{i}^{c}$.

O estimador $d_{i}$ tem menores variância e vício do que $g_{\mathrm{i}}$ (Hedges \& Olkin, 1985).

Cohen (1988) fornece uma interpretação convencional da magnitude do tamanho do efeito para diferenças médias padronizadas, como segue: 0,2 é um efeito pequeno, 0,5 é médio e 0,8 é grande e, qualquer efeito maior do que 1,0 pode ser considerado muito grande.

$\mathrm{Na}$ revisão quantitativa de meta-análise o que se pretende é combinar os indicadores das estimativas dos tamanhos do efeito dos $k$ estudos. Suponha que cada um dos $k$ estudos tenha um tamanho de amostra grande, para que desta maneira a suposição de normalidade seja válida, e também que tais estimativas sejam homogêneas. Sejam, respectivamente, $\hat{\delta}_{\mathrm{i}}$ e $\hat{\sigma}^{2}\left(\hat{\delta}_{\mathrm{i}}\right)$ uma estimativa do tamanho do efeito e sua correspondente estimativa da variância amostral.

Assim, o estimador combinado dos tamanhos do efeito para os $k$ estudos é,

$$
\hat{\delta}_{+}=\frac{\sum_{i=1}^{k} w_{i} \hat{\delta}_{i}}{\sum_{i=1}^{k} w_{i}},
$$

onde cada estimativa individual do tamanho do efeito é ponderada pelo inverso da sua variância, 


$$
w_{i}=\frac{1}{\hat{\sigma}^{2}\left(\hat{\delta}_{i}\right)}, \quad i=1, \ldots, k
$$

e $\hat{\sigma}^{2}\left(\hat{\delta}_{\mathrm{i}}\right)$ é a variância de $d_{\mathrm{i}}$ dada pela fórmula,

$$
\hat{\sigma}^{2}\left(\hat{\delta}_{i}\right)=\frac{n_{i}^{T}+n_{i}^{C}}{n_{i}^{T} n_{i}^{C}}+\frac{\hat{\delta}_{i}^{2}}{2\left(n_{i}^{T}+n_{i}^{C}\right)}, \quad i=1, \ldots, k
$$

A estimativa da variância do tamanho do efeito combinado, $\hat{\sigma}\left(\hat{\delta}_{+}\right)$, é dada por,

$$
\hat{\sigma}^{2}\left(\hat{\delta}_{+}\right)=\frac{1}{\sum_{i=1}^{k} \frac{1}{\hat{\sigma}^{2}\left(\hat{\delta}_{i}\right)}}, \quad i=1, \ldots, k
$$

Segundo Hedges \& Olkin (1985) o melhor estimador de $\delta$ é $\hat{\delta}_{+}$, pois para grandes amostras ele fornece uma variância tão pequena quanto possível. Assim, nenhum outro estimador tem variância assintótica menor do que a de $\hat{\delta}_{+}$.

O intervalo de confiança, a $100(1-\alpha) \%$, para este tamanho do efeito, é dado por:

$$
\delta_{\text {inf. }}=\hat{\delta}_{+}-c_{\frac{\alpha}{2}} \hat{\sigma}\left(\hat{\delta}_{+}\right) \text {e } \delta_{\text {sup. }}=\hat{\delta}_{+}+c_{\frac{\alpha}{2}} \hat{\sigma}\left(\hat{\delta}_{+}\right)
$$

onde $c_{\alpha / 2}$ é o valor tabelado da distribuição normal padronizada a um nível $\frac{\alpha}{2}$ de probabilidade. 


\subsubsection{Coeficiente de Correlação}

Considere, segundo Hedges \& Olkin (1985), uma coleção de $k$ estudos independentes, cada um dos quais produz um coeficiente de correlação entre as variáveis que têm distribuição bivariada normal. Especificamente, suponha que o i-ésimo estudo consiste de pares de medidas $U_{i}, V_{i}$ que têm uma distribuição bivariada normal com correlações:

$$
\rho_{i}=\frac{\operatorname{Cov}\left(U_{i}, V_{i}\right)}{\sqrt{\operatorname{Var}\left(U_{i}\right) \operatorname{Var}\left(V_{i}\right)}} \quad i=1, \ldots, k
$$

Os tamanhos das amostras, $\mathrm{n}_{1}, \ldots, \mathrm{n}_{\mathrm{k}}$, são tomados dos $k$ estudos. Se $u_{\mathrm{ij}} \mathrm{e} \boldsymbol{v}_{\mathrm{ij}}$ é o jésimo par de observações no i-ésimo estudo, então as observações para os $k$ estudos podem ser arranjados conforme exposto na Tabela 2 .

Tabela 2. Representação esquemática das duas variáveis contínuas e suas correlações.

\begin{tabular}{|c|c|c|c|c|}
\hline & \multicolumn{4}{|c|}{ Estudo } \\
\hline & 1 & 2 & $\ldots$ & $\mathrm{K}$ \\
\hline Observações & $\begin{array}{l}\left(u_{11}, v_{11}\right) \\
\left(u_{12}, v_{12}\right)\end{array}$ & $\begin{array}{l}\left(u_{21}, v_{21}\right) \\
\left(u_{22}, v_{22}\right)\end{array}$ & $\ldots$ & $\begin{array}{l}\left(u_{k 1}, v_{k 1}\right) \\
\left(u_{k 2}, v_{k 2}\right)\end{array}$ \\
\hline & $\left(\mathrm{u}_{1 \mathrm{n}_{1}}, \mathrm{v}_{1 \mathrm{n}_{1}}\right)$ & $\left(\mathrm{u}_{2 \mathrm{n}_{2}}, \mathrm{v}_{2 \mathrm{n}_{2}}\right)$ & $\begin{array}{l}\cdots \\
\cdots\end{array}$ & $\left(\mathrm{u}_{\mathrm{kn}_{\mathrm{k}}}, \mathrm{v}_{\mathrm{kn}_{\mathrm{k}}}\right)$ \\
\hline Correlações & $\mathbf{r}_{1}$ & $\mathrm{r}_{2}$ & $\ldots$ & $\mathbf{r}_{\mathrm{k}}$ \\
\hline
\end{tabular}

O coeficiente de correlação $r_{\mathrm{i}}$ para o i-ésimo estudo é: 


$$
r_{i}=\frac{\sum_{j=1}^{n_{i}}\left(u_{i j}-\bar{u}_{i}\right)\left(v_{i j}-\bar{v}_{i}\right)}{\sqrt{\sum_{j=1}^{n_{i}}\left(v_{i j}-\bar{v}_{i}\right)^{2} \sum_{j=1}^{n_{i}}\left(u_{i j}-\bar{u}_{i}\right)^{2}}}, \quad i=1, \ldots, k,
$$

onde $\bar{u}_{i}$ e $\bar{v}_{i}$ são as médias de $u_{1}, u_{2}, \ldots, u_{n_{i}}$ e $v_{1}, v_{2}, \ldots, v_{n_{i}}$, (com $\left.i=1, \ldots, k\right)$, respectivamente.

De acordo com Cooper (1989), o tamanho do efeito é, neste caso, o próprio coeficiente de correlação quando se dispõe deste índice da relação entre duas variáveis.

Cohen (1988) fornece uma interpretação convencional da magnitude do tamanho do efeito quando se utiliza o coeficiente de correlação: 0,1 é um efeito pequeno, 0,3 é médio e 0,5 é grande.

Numa revisão quantitativa de meta-análise o que se pretende é combinar as estimativas dos tamanhos do efeito, neste caso, as correlações dos $k$ estudos. Porém, combinar os coeficientes de correlação é um pouco mais complicado pelo fato de sua distribuição não ser normal quando $\rho \neq 0$. Para remediar este problema, Fisher ${ }^{4}$, citado por Hedges \& Olkin (1985), propôs uma transformação de $r$ para a quantidade $z$ que apresenta distribuição aproximadamente normal com variância aproximada de $1 /(n-3)$. A relação entre $r$ e $z$ é dada por:

$$
\mathrm{z}=\frac{1}{2} \ln \frac{1+\mathrm{r}}{1-\mathrm{r}}
$$

Suponha que as correlações amostrais são homogêneas. Para obter uma média ponderada das correlações amostrais, $r_{+}$, primeiro é preciso obter a média ponderada dos valores correspondentes de $z$ :

\footnotetext{
${ }^{4}$ FISHER, R. A. On the probable error of a coefficient of correlation deduced from a small sample, Metron, 1: 1-32, 1921.
} 


$$
z_{+}=\frac{\sum_{i=1}^{k} w_{i} z_{i}}{\sum_{i=1}^{k} w_{i}},
$$

onde:

$w_{\mathrm{i}}$ é a ponderação, que neste caso é $\mathrm{w}_{\mathrm{i}}=\mathrm{n}_{\mathrm{i}}-3 \mathrm{e}$,

$n_{\mathrm{i}}$ é o tamanho da amostra do i-ésimo estudo.

A variância estimada para $z_{+}$é:

$$
\operatorname{Var}\left(\mathrm{z}_{+}\right)=\frac{1}{\mathrm{~N}-3 \mathrm{k}}
$$

$\operatorname{com} N=n_{1}+\ldots+n_{k}$

Para se obter, finalmente a estimativa combinada do coeficiente de correlação deve-se aplicar a função inversa expressa pela equação (16) (Kirby, 1993).

$$
r_{+}=\frac{\exp \left\{2 z_{+}\right\}-1}{\exp \left\{2 z_{+}\right\}+1}
$$

A ponderação por $\left(n_{i}-3\right)$, na equação (14), se dá pois $\left(n_{i}-3\right)$ é o inverso da variância para a transformação de $r$ em $z$ de Fisher (as estimativas do tamanho do efeito são frequentemente ponderadas pelo inverso de suas variâncias).

Os limites do intervalo de confiança, a $100(1-\alpha) \%$, para este tamanho do efeito, são dados por: 


$$
\zeta_{\mathrm{inf} .}=z-\frac{\mathrm{c}_{\alpha / 2}}{\sqrt{\mathrm{n}-3}} \text { e } \zeta_{\text {sup. }}=\mathrm{z}+\frac{\mathrm{c}_{\alpha / 2}}{\sqrt{\mathrm{n}-3}}
$$

onde $c_{\alpha / 2}$ é o valor da distribuição normal padronizada a um nível $\frac{\alpha}{2}$ de probabilidade.

Para obter o intervalo de confiança referente a variável $r$ utiliza-se primeiramente a eq. (17), e posteriormente a eq. (16) para transformar $z$ em $r$.

\subsubsection{Testes de significância estatística para resultados combinados}

Segundo Normand (1999), quando os dados dos estudos a serem combinados forem provenientes de testes estatísticos, pode-se estimar o tamanho do efeito se algumas informações também estiverem disponíveis nos artigos.

Se os trabalhos fornecem os valores das probabilidades, ou meios para calculálos, pode-se combiná-los e avaliar sua significância estatística utilizando testes de significância. Tais testes, que avaliam a significância de resultados combinados foram, possivelmente, o primeiro procedimento estatístico desenvolvido para combinar os resultados provenientes de diferentes estudos de pesquisa (Hedges \& Olkin, 1985). A referência mais antiga a um procedimento estatístico para combinar testes de significância está presente em um livro de Tippett ${ }^{5}$, citado por Hedges \& Olkin (1985). O problema de reunir as informações provenientes de testes de significância, também chamou a atenção de Fisher (1932) e Pearson ${ }^{6}$, citado por Hedges \& Olkin (1985).

Neste tópico, serão apresentados, alguns métodos que visam combinar informações provenientes de testes de significância. Para tanto, deve-se considerar, segundo Hedges e Olkin (1985), uma coleção de $k$ estudos independentes caracterizados pelos parâmetros $\theta_{1}, \ldots, \theta_{k}$, que podem ser médias, diferenças médias ou correlações e

\footnotetext{
${ }^{5}$ TIPPET, L.H.H. The method of statistics. London: Willian \& Norgate, 1931.

${ }^{6}$ PEARSON, $\mathrm{K}$. On a method of determining whether a sample of given size $n$ supposed to have been drawn from a parent population having a known probability integral has probably been drawn at random. Harvard Education Review, 50: 176-195, 1933.
} 
também que o i-ésimo estudo produz uma estatística $T_{\mathrm{i}}$ que será usada para testar a hipótese de nulidade:

$H_{0}: \theta_{1}=\theta_{2}=\ldots=\theta_{k}=0$

versus uma das seguintes hipóteses alternativas:

$\mathrm{H}_{1}: \theta_{\mathrm{i}} \geq 0, \mathrm{i}=1, \ldots, \mathrm{k}$, e ao menos um $\theta_{\mathrm{i}}>0$;

$\mathrm{H}_{2}: \theta_{\mathrm{i}} \leq 0$ ou $\theta_{\mathrm{i}} \geq 0, \mathrm{i}=1, \ldots, \mathrm{k}$, e ao menos um $\theta_{\mathrm{i}} \neq 0 ;$

$\mathrm{H}_{3}$ : pelo menos um $\theta_{\mathrm{i}} \neq 0, \mathrm{i}=1, \ldots, \mathrm{k}$.

\subsubsection{Métodos baseados na distribuição uniforme}

O primeiro método para testar a significância de resultados combinados foi proposto por Tippett (1931), citado por Hedges e Olkin (1985), e indicou que se os $\mathrm{p}_{1}, \ldots, \mathrm{p}_{\mathrm{k}}$ são os valores das probabilidades independentes, então eles têm uma

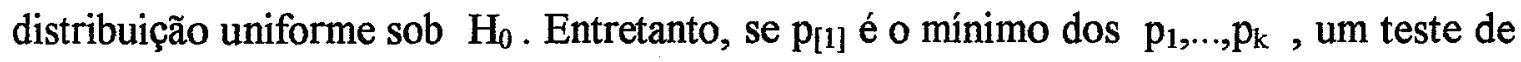
$\mathrm{H}_{0}$ ao nível $\alpha$ de significância é obtido comparando $\mathrm{p}_{[1]} \operatorname{com} 1-(1-\alpha)^{1 / 1}$, então:

$$
\text { rejeita-se } \mathrm{H}_{0} \text { se } \mathrm{p}_{[1]}<1-(1-\alpha)^{1 / k} \text {. }
$$

\subsubsection{Método do qui-quadrado inverso}

Tal procedimento foi desenvolvido por Fisher (1932) e é o mais utilizado para realizar a combinação de informações provenientes de testes de significância. Dados $k$ estudos independentes e os valores das probabilidades $\mathrm{p}_{1}, \ldots, \mathrm{p}_{\mathrm{k}}, \mathrm{o}$ procedimento proposto por Fisher utiliza o produto $\mathrm{p}_{1} \mathrm{p}_{2} \ldots \mathrm{p}_{\mathrm{k}}$ para combinar os valores das probabilidades. Devido à soma das variáveis independentes de qui-quadrado terem uma distribuição de qui-quadrado, resulta que se $H_{0}$ é verdadeira, então: $-2 \log \left(p_{1} p_{2} \ldots p_{k}\right)=2 \log p_{1}-\ldots-2 \log p_{k}$ tem uma distribuição de qui-quadrado com $2 \mathrm{k}$ graus de liberdade. Assim: 


$$
\text { Rejeita-se } H_{0} \text { se } p=-2 \sum_{i=1}^{k} \log p_{i} \geq c
$$

onde $c$ é obtido da cauda superior da distribuição de qui-quadrado com $2 \mathrm{k}$ graus de liberdade.

\subsubsection{Método Normal Inverso}

Outro procedimento para combinar valores das probabilidades é o método normal inverso proposto por Lipták ${ }^{7}$, citado por Hedges e Olkin (1985), e é dado por:

$$
Z=\frac{Z_{1}+\ldots+Z_{k}}{\sqrt{k}}=\frac{\phi^{-1}\left(p_{1}\right)+\ldots+\phi^{-1}\left(p_{k}\right)}{\sqrt{k}}
$$

onde $\phi^{-1}($ ) é a inversa da distribuição normal padronizada acumulada.

Quando $\mathrm{H}_{0}$ é verdadeira $\mathrm{Z}$ tem uma distribuição normal padronizada. Assim, rejeita-se $\mathrm{H}_{0}$ se $\mathrm{Z}$ excede o valor crítico da distribuição normal padronizada.

\subsection{Modelagem da variação na meta-análise}

Uma questão importante a ser considerada na combinação dos estudos é a heterogeneidade entre eles, pois podem ter sido encontrados estudos com qualidades diferentes, conduzindo, assim, a conclusões distintas, ou ainda ter estudos com doses distintas, diferentes tipos de tratamentos ou indivíduos, que necessitam ser combinados. Deste modo os pesquisadores que utilizam meta-análise tentam convencer o leitor que aqueles dados são homogêneos e justificar a combinação deles para a questão focada (Lau et al., 1997). Entretanto, se a variação nas estimativas dos tamanhos dos efeitos é

\footnotetext{
${ }^{7}$ LIPTÁK, T. On the combination of indepent tests. Magyar Tudomanyos Akademia Matematikai Kutato Intezetenek Kozlemenyei, 3: 1971-1977, 1958.
} 
maior do que se pode admitir pelo acaso, não se devem combinar todas elas. Pode-se testar se as estimativas dos tamanhos dos efeitos são muito heterogêneas para serem combinadas. $\mathrm{O}$ resultado significativo do teste estatístico implica que a variação nas estimativas do tamanho do efeito entre os estudos é maior do que aquela esperada pelo acaso (Wang \& Bushman, 1999).

As características dos estudos podem ser consideradas como variáveis fixas ou aleatórias e, de acordo com Egger et a.l. (1997), a diferença entre os dois modelos é a maneira com que a variabilidade dos resultados é tratada. Segundo Wang \& Bushman (1999), nos modelos de efeitos fixos assume-se que o tamanho do efeito populacional é um valor fixo, enquanto que nos modelos de efeitos aleatórios o tamanho do efeito populacional é uma variável aleatoriamente distribuída com média e variância próprias. Quando se utiliza um modelo de efeitos fixos pode-se fazer generalizações para um universo de estudos com características similares. Já quando se utiliza um modelo de efeitos aleatórios, pode-se fazer generalizações a um universo de estudos diversos. Deste modo, como a generalização é maior nos modelos de efeitos aleatórios, o poder estatístico deste modelo é menor do que o de efeitos fixos. Consequentemente, os intervalos de confiança são mais estreitos para os modelos de efeitos fixos do que para os de aleatórios.

Assim, numa meta-análise utiliza-se um modelo de efeitos fixos se a variação nos tamanhos dos efeitos entre estudos for resultante somente do erro amostral, e utiliza-se um modelo de efeitos aleatórios se a variação nos tamanhos dos efeitos entre estudos resultar tanto do erro amostral quanto na variabilidade do tamanho do efeito populacional.

\subsubsection{Modelos de efeitos fixos (MEF)}

Quando os resultados dos estudos diferem devido ao erro experimental adota-se então a estrutura de modelo de efeitos fixos, assumindo que existe apenas a variabilidade dentro dos estudos, não havendo variabilidade entre os estudos. Neste caso, a variância 
dentro dos estudos assume um dado valor e a entre os estudos é considerada nula (Lau et al., 1997).

Segundo Normand (1999) um modelo de efeito fixo assume que a estatística resumida $Y_{i}$ de cada estudo é a realização de uma população dos estudos estimados com uma média comum $\theta$.

Seja, segundo Normand (1995), $\theta$ um parâmetro central de interesse. Assumindo que existam $k$ estudos independentes, e também uma estatística resumida suficiente $\mathbf{Y}_{\mathbf{i}}$ correspondente a cada estudo tal que: $\mathrm{E}\left(\mathrm{Y}_{\mathrm{i}}\right)=\theta$ e $\mathrm{V}_{\mathrm{i}}=\operatorname{Var}\left(\mathrm{Y}_{\mathrm{i}}\right)=\mathrm{E}\left(\mathrm{Y}_{\mathrm{i}}-\mu\right)^{2}=\sigma_{\mathrm{i}}^{2}=\mathrm{s}_{\mathrm{i}}^{2}$. Para o tamanho do estudo moderadamente grande, cada $Y_{i}$, deve ser aproximadamente normalmente distribuído (pelo teorema central do limite) e aproximadamente nãoviesado. Então:

$$
\mathrm{Y}_{\mathrm{i}} \stackrel{\text { indep. }}{\sim} \mathrm{N}\left(\theta, \sigma_{\mathrm{i}}^{2}\right) \text { para } \mathrm{i}=1,2, \ldots, \mathrm{k}
$$

sendo $\sigma_{i}^{2}$ conhecido. $O$ parâmetro central de interesse é $\theta$ o qual quantifica o efeito médio do tratamento.

Pode-se, segundo Gaver et al. (1992), construir um modelo expresso como,

$$
Y_{i}=\theta+e_{i}
$$

onde:

$Y_{i}$ e $\theta$ foram definidos anteriormente $e$,

$\mathbf{e}_{\mathrm{i}} \stackrel{\text { indep. }}{\sim} \mathrm{N}\left(0, \sigma_{\mathrm{i}}^{2}\right)$.

\subsubsection{Modelos de efeitos aleatórios (MEA)}

Se as inferências serão generalizadas para a população na qual os estudos permitem ter efeitos e características diferentes, então os modelos de efeito aleatório 
poderiam ser apropriados (Normand, 1999), isto é, cada estudo é tratado como sendo proveniente de diferentes populações. Nesse tipo de modelo tem-se além da variância dentro dos estudos, como no modelo de efeito fixo, também a variância entre os estudos (Lau et al., 1997).

Assim, o modelo de efeito aleatório assume um efeito básico diferente para cada estudo e leva isto em consideração como uma causa de variação adicional, conduzindo, entretanto, a um intervalo de confiança um pouco maior do que no modelo de efeitos fíxos (Egger et al., 1997).

A estrutura de efeitos aleatórios postula, segundo Normand (1999), que a estatística resumida de cada estudo $Y_{i}$ é extraída de uma população com média $\theta_{i}$ e variância $\sigma_{i}^{2}$ específicas,

$$
\mathrm{Y}_{\mathrm{i}} \mid \theta_{\mathrm{i}}, \sigma_{\mathrm{i}}^{2} \stackrel{\text { indep. }}{\sim} \mathrm{N}\left(\theta_{\mathrm{i}}, \sigma_{\mathrm{i}}^{2}\right)
$$

Além disso, a média de cada estudo específico, $\theta_{i}$, é assumida ser retirada de alguma superpopulação de efeitos com média $\theta$ e variância $\tau^{2}$,

$$
\theta_{\mathrm{i}} \mid \theta, \tau^{2} \sim \mathrm{indep.} N\left(\theta, \tau^{2}\right)
$$

sendo $\theta$ e $\tau^{2}$ referidos como hiperparâmetros e representando, respectivamente, o efeito médio do tratamento e a variabilidade entre os estudos.

Pode-se então, segundo Gaver et al. (1992), construir um modelo de efeitos aleatórios expresso por,

$$
\begin{aligned}
& Y_{i}=\theta_{i}+e_{i} \\
& \theta_{i}=\theta+\varepsilon_{i}
\end{aligned}
$$


onde:

$Y_{i}$ e $\theta$ foram definidos anteriormente;

$\theta_{\mathrm{i}}$ é dado, neste caso, pela equação (27);

$$
\begin{aligned}
& \mathrm{e}_{\mathrm{i}} \stackrel{\text { indep. }}{\sim} \mathrm{N}\left(0, \sigma^{2}\right) ; \\
& \varepsilon_{\mathrm{i}} \sim \mathrm{N}\left(0, \tau^{2}\right) .
\end{aligned}
$$

Em contraste com o modelo de efeitos fixos, o modelo de efeitos aleatórios concebe os estudos observados como tendo sido retirados de uma grande população de estudos. O modelo de efeitos fixos é um caso especial do de efeitos aleatórios onde $\tau^{2}=0$. Nesse caso todos os $\theta_{\mathrm{i}}$ são constantes e iguais a $\theta$.

Alguns estatísticos consideram que outras estatísticas são mais apropriadas que as discutidas anteriormente. Uma op̧̧ão seria a aproximação Bayesiana onde os modelos estão disponíveis sob ambas as suposições: efeitos fixos e aleatórios.

\subsection{Teste de homogeneidade}

Com o intuito de avaliar as diferenças nos tamanhos das amostras e nos níveis dos estudos, estes são estratificados e então combinados. Isto é, melhor do que estimar um tamanho do efeito verdadeiro, é tomar uma média ponderada das estimativas de cada estudo. Similarmente, considerando tratamento e controle, poderia ser tomada uma média ponderada das estimativas dos efeitos do tratamento e uma das estimativas dos efeitos do grupo controle. Porém, permanece, ainda neste ponto da análise, a dúvida de se cada estudo (ou conjunto de estudos) compartilham um efeito comum. Portanto, a convenção é primeiro realizar um teste de homogeneidade de médias. Se não existe variação significativa entre estudos, então, um modelo de efeitos fixos é adotado, caso contrário ou adota-se um modelo de efeitos aleatórios ou identificam-se as 
características de estudo que estratificam os estudos dentro dos subgrupos com efeitos homogêneos (Normand, 1999).

\subsubsection{Analogia à análise de variância em meta-análise para Modelos de efeitos fixos com um fator}

Suponha, de acordo com Wang \& Bushman (1999), que o interesse é testar o efeito de um fator com $p$ grupos independentes, com $m_{1}$ efeitos no grupo $1, m_{2}$ efeitos no grupo $2, \ldots$, e $m_{\mathrm{p}}$ efeitos no grupo $p$. Seja $\theta_{\mathrm{ij}} \mathrm{o}$ j-ésimo parâmetro do tamanho do efeito no i-ésimo grupo, e seja $\hat{\theta}_{\mathrm{ij}}$ sua estimativa com variância amostral Vâr( $\left.\hat{\theta}_{\mathrm{ij}}\right)$. A Tabela 3 fornece a notação para um modelo de efeitos fixos com um fator.

Numa análise de variância para um experimento com um fator, a soma de quadrados total pode ser separada em dois componentes: soma de quadrados entre grupos e soma de quadrados dentro dos grupos, ou seja,

$$
\mathrm{SQ}_{\text {total }}=\mathrm{SQ}_{\text {entre }}+\mathrm{SQ}_{\text {dentro }}
$$

Similarmente, na análise de variância para meta-análise, a estatística da heterogeneidade total pode ser separada dentro de dois componentes: heterogeneidade entre os grupos de estudos e heterogeneidade dentro dos grupos de estudos, ou seja,

$$
\mathrm{Q}_{\text {total }}=\mathrm{Q}_{\text {entre }}+\mathrm{Q}_{\text {dentro. }}
$$


Tabela 3. Estimativas do tamanho do efeito e variâncias amostrais para os $p$ grupos de estudos.

\begin{tabular}{|c|c|c|}
\hline & Estimativas do Tamanho do Efeito & Estimativas das variâncias \\
\hline \multicolumn{3}{|l|}{ GRUPO 1} \\
\hline Estudo 1 & $\hat{\theta}_{11}$ & $\operatorname{Vâr}\left(\hat{\theta}_{11}\right)$ \\
\hline Estudo 2 & $\hat{\theta}_{12}$ & $\operatorname{Vâr}\left(\hat{\theta}_{12}\right)$ \\
\hline$\ldots$ & & $\ldots$ \\
\hline Estudo $\mathrm{m}_{1}$ & $\hat{\theta}_{1 m_{1}}$ & $\operatorname{Vâr}\left(\hat{\theta}_{1_{\mathrm{m}_{1}}}\right)$ \\
\hline \multicolumn{3}{|l|}{ GRUPO 2} \\
\hline Estudo 1 & $\hat{\theta}_{21}$ & $\operatorname{Vâr}\left(\hat{\theta}_{21}\right)$ \\
\hline Estudo 2 & $\hat{\theta}_{22}$ & $\operatorname{Vâr}\left(\hat{\theta}_{22}\right)$ \\
\hline${ }^{\cdots}$ Estudo $\mathrm{m}_{2}$ & $\hat{\theta}_{2 \mathrm{~m}_{2}}^{\cdots}$ & $\operatorname{Vâr}\left(\hat{\theta}_{2 m_{2}}\right)$ \\
\hline$\cdots$ & $\cdots$ & $\cdots$ \\
\hline \multicolumn{3}{|l|}{ GRUPO $\mathrm{p}$} \\
\hline Estudo 1 & $\hat{\theta}_{\mathrm{p} 1}$ & $\operatorname{Vâr}\left(\hat{\theta}_{\mathrm{p} 1}\right)$ \\
\hline Estudo 2 & $\hat{\theta}_{\mathrm{p} 2}$ & $\operatorname{Vâr}\left(\hat{\theta}_{\mathrm{p} 2}\right)$ \\
\hline Estudo $\mathrm{m}_{\mathrm{p}}$ & $\hat{\theta}_{\mathrm{pm}_{\mathrm{p}}}^{\cdots}$ & $\operatorname{Vâr}\left(\hat{\theta}_{\mathrm{pm}_{\mathrm{p}}}\right)$ \\
\hline
\end{tabular}

Para testar a hipótese de nulidade que não existe variação nos grupos, de tamanhos médios do efeito,

$$
\mathrm{H}_{0}: \theta_{1+}=\theta_{2+}=\ldots=\theta_{\mathrm{p}+}
$$

versus a hipótese alternativa de que pelo menos um tamanho do efeito difere dos demais,

$$
\mathrm{H}_{\mathrm{A}} \text { : ao menos um } \theta_{\mathrm{i}+} \text { difere dos demais, }
$$

utiliza-se a estatística, 


$$
\mathrm{Q}_{\text {entre }}=\sum \mathrm{w}_{\mathrm{i+}}\left(\hat{\theta}_{\mathrm{i}+}-\hat{\theta}_{++}\right)^{2} \quad \mathrm{i}=1,2, \ldots, \mathrm{k},
$$

onde:

$$
\begin{aligned}
& w_{i+}=\sum_{j=1}^{m_{j}} w_{i j}, \\
& w_{i j}=\frac{1}{\operatorname{Vâr}\left(\hat{\theta}_{i j}\right)}, \\
& \hat{\theta}_{i+}=\frac{\sum_{j=1}^{m_{i j}} w_{i j} \hat{\theta}_{i j}}{\sum_{j=1}^{m_{i}} w_{i j}}, \\
& \hat{\theta}_{++}=\frac{\sum_{i=1}^{p} \sum_{j=1}^{m_{i}} w_{i j} \hat{\theta}_{i j}}{\sum_{i=1}^{p} \sum_{j=1}^{m_{i}} w_{i j}}=\frac{\sum_{i=1}^{p} w_{i+1} \hat{\theta}_{i+}}{\sum_{i=1}^{p} w_{i+}} .
\end{aligned}
$$

Sendo que o estimador fornecido pela equação (22) é denominado estimador de máxima verossimilhança (Normand, 1999).

Rejeita-se a hipótese de nulidade ao nível de significância $\alpha$ se Qentre exceder o valor crítico de $100(1-\alpha) \%$ da distribuição de qui-quadrado a p-1 graus de liberdade.

Para testar a hipótese de nulidade de que não existe variação nos efeitos da população dentro do grupo de estudos, isto é, 


$$
\mathrm{H}_{0}:\left\{\begin{array}{c}
\theta_{11}=\ldots=\theta_{1 \mathrm{~m}_{1}}=\theta_{1+} \\
\ldots \\
\theta_{\mathrm{pl}}=\ldots=\theta_{\mathrm{pm}_{\mathrm{p}}}=\theta_{\mathrm{p}+}
\end{array}\right.
$$

utiliza-se a estatística,

$$
Q_{\text {dentro }}=\sum_{i=1}^{k} \sum_{j=1}^{m_{i}} w_{i j}\left(\hat{\theta}_{i j}-\hat{\theta}_{i+}\right)^{2},
$$

com distribuição de qui-quadrado com k-p graus de liberdade.

A Tabela 4 resume as várias causas de heterogeneidade numa meta-análise com uma categoria de estudo, assim como o teste estatístico e os correspondentes graus de liberdade.

Tabela 4. Heterogeneidade resumida para um modelo de efeitos fixos com um fator.

\begin{tabular}{lcc}
\hline \multicolumn{1}{c}{ Causas de Heterogeneidade } & Estatística Q & Graus de liberdade \\
\hline Entre grupos & Qentre & $\mathrm{p}-1$ \\
\hline Dentro de grupos & $\mathrm{Q}_{\text {dentro }}$ & $\mathrm{k}-\mathrm{p}$ \\
Dentro do grupo 1 & $\mathrm{Q}_{\text {dentro 1 }}$ & $\mathrm{m}_{1}-1$ \\
Dentro do grupo 2 & Qdentro 2 $^{-}$ & $\mathrm{m}_{2}-1$ \\
$\ldots$ & $\ldots$ & $\ldots$ \\
Dentro do grupo $\mathrm{p}$ & $\mathrm{Q}_{\text {dentro }}$ & $\mathrm{m}_{\mathrm{p}}-1$ \\
\hline Total & $\mathrm{Q}_{\text {total }}$ & $\mathrm{k}-1$ \\
\hline Nota: $\mathrm{k}=\mathrm{m}_{1}+\mathrm{m}_{2}+\ldots+\mathrm{m}_{\mathrm{p} .}$ & &
\end{tabular}

\subsubsection{Analogia à análise de variância em meta-análise para modelos de efeitos aleatórios com um fator}

Considerando, agora, um modelo de efeitos aleatórios, suponha que o interesse está em testar o efeito de um estudo com $p$ grupos independentes, com $m_{1}$ efeitos no 
grupo $1, m_{2}$ efeitos no grupo $2, \ldots, m_{\mathrm{p}}$ efeitos no grupo $p, \mathrm{e} \mathrm{k}=\mathrm{m}_{1}+\mathrm{m}_{2}+\ldots+\mathrm{m}_{\mathrm{p}}$. A única diferença nos procedimentos de cálculos entre os modelos de efeitos fixos e os de efeitos aleatórios para o modelo de ANOVA com um fator é que para o segundo caso a ponderação estimada na análise é dada por $\mathbf{w}_{\mathrm{i}}^{*}=\frac{1}{\left\{\operatorname{Vâr}\left(\hat{\theta}_{\mathrm{i}}\right)+\hat{\tau}^{2}\right\}}$.

Para testar a hipótese de nulidade, de que as variâncias dos efeitos aleatórios é zero, isto é,

$$
\mathrm{H}_{0}: \tau^{2}=0
$$

versus a hipótese alternativa, de que as variâncias são maiores do que zero,

$$
\mathrm{H}_{\mathrm{A}}: \tau^{2}>0,
$$

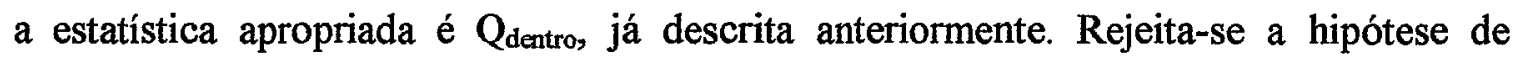
nulidade, a um nível $\alpha$ de significância, se $Q_{\text {dentro }}$ exceder o valor crítico de $100(1-\alpha) \%$, da distribuição de qui-quadrado com (k-p) graus de liberdade, onde $k$ é o número de estudos independentes e $p$ é o número de grupos independentes da categoria da característica do estudo.

Para estimar a variância entre estudos existem, segundo Normand (1999), quatro métodos Máxima Verossimilhança, Máxima Verossimilhança Restrita, Método dos Momentos e Método Bayesiano.

\subsubsection{Método da Máxima Verossimilhança (MV)}

Se a variância entre os estudos é conhecida, então o estimador de $\theta$ pelo MV é dado por, 


$$
\hat{\theta}(\tau)_{M V}=\frac{\sum_{i=1}^{k} w_{i}(\tau) \hat{\theta}_{i}}{\sum_{i=1}^{k} w_{i}(\tau)},
$$

onde: $\quad \mathrm{w}_{\mathrm{i}}(\tau)=\frac{1}{\operatorname{Vâr}\left(\hat{\theta}_{\mathrm{i}}\right)+\hat{\tau}^{2}}$.

Porém, no caso mais real onde não se conhece a variância entre os estudos, esta pode ser estimada utilizando-se o Método dos Momentos (MM), o Método da Máxima Verossimilhança Restrita (MVR) e o Método Bayesiano.

\subsubsection{Método da Máxima Verossimilhança Restrita (MVR)}

Este é um método para estimação dos componentes de variância que consiste em usar a distribuição marginal para y, e o log-verossimilhança a ser maximizado é:

$$
\begin{gathered}
\log \left(\mathrm{L}\left(\theta, \tau^{2} \mid \mathbf{s}^{2}, \mathrm{y}\right) \alpha \sum_{\mathrm{i}=1}^{\mathrm{k}}\left\{\log \left(\operatorname{Var}\left(\hat{\theta}_{\mathrm{i}}\right)+\hat{\tau}^{2}\right)+\frac{\left(\hat{\theta}_{\mathrm{i}}-\hat{\theta}_{\mathrm{MVR}}\right)^{2}}{\operatorname{Var}\left(\hat{\theta}_{\mathrm{i}}\right)+\tau^{2}}\right\}+\log \left[\sum\left(\operatorname{Var}\left(\hat{\theta}_{\mathrm{i}}\right)+\hat{\tau}^{2}\right)^{-1}\right]\right. \\
\text { O estimador de MVR de } \tau^{2} \text { é solução para, } \\
\hat{\tau}_{\mathrm{MVR}}^{2}=\frac{\sum_{\mathrm{i}=1}^{\mathrm{k}} \mathrm{w}_{\mathrm{i}}^{2}(\hat{\tau})\left[\frac{\mathrm{k}}{\mathrm{k}-1}\left(\mathrm{Y}_{\mathrm{i}}-\hat{\theta}_{\mathrm{MVR}}\right)^{2}-\operatorname{Var}\left(\hat{\theta}_{\mathrm{i}}\right)\right]}{\sum_{\mathrm{i}=1}^{\mathrm{k}} \mathrm{w}_{\mathrm{i}}^{2}(\hat{\tau})}
\end{gathered}
$$

O estimador para a média populacional é então calculado como 


$$
\hat{\theta}_{M V R}=\frac{\sum_{i=1}^{k} w_{i}\left(\hat{\tau}_{M V R}\right) \hat{\theta}_{i}}{\sum_{i=1}^{k} w_{i}\left(\hat{\tau}_{M V R}\right)},
$$

onde:

$$
\mathrm{w}_{\mathrm{i}}\left(\hat{\tau}_{\mathrm{MVR}}\right)=\frac{1}{\operatorname{Vâr}\left(\hat{\theta}_{\mathbf{i}}\right)+\hat{\tau}_{\mathrm{MVR}}},
$$

e as inferências são feitas utilizando: $\hat{\theta}_{\mathrm{MVR}} \sim \mathrm{N}\left(\theta,\left(\sum_{\mathrm{i}} \mathrm{w}_{\mathrm{i}}\left(\hat{\tau}_{\mathrm{MVR}}\right)\right)^{-1}\right)$.

Um estimador para $\theta_{i}$ pode ser calculado substituindo, na eq. 27 , as estimativas de MVR pelos hiperparâmetros. Este tipo de aproximação para uma distribuição $a$ posteriori é conhecida como empírica de Bayes ("Empirical Bayes") e resulta em

$$
\hat{\theta}_{i}^{M V R}=\left(1-\hat{B}_{i}^{M V R}\right) \hat{\theta}_{i}+\hat{B}_{i}^{M V R} \hat{\theta}_{M V R}
$$

onde:

$$
\hat{\mathbf{B}}_{\mathbf{i}}^{\mathrm{MVR}}=\frac{\operatorname{Vâr}\left(\hat{\theta}_{\mathbf{i}}\right)}{\operatorname{Vâr}\left(\hat{\theta}_{\mathbf{i}}\right)+\hat{\tau}_{\mathrm{MVR}}^{2}} .
$$

As inferências para um estudo específico são feitas usando: $\hat{\theta}_{i}^{\mathrm{MVR}} \sim \mathrm{N}\left(\theta_{\mathrm{i}}, \hat{\mathrm{B}}_{\mathrm{i}}^{\mathrm{MVR}}\right)$. A realização da estimação da variância entre os estudos, tanto o método MV como o da MVR, se dá utilizando-se o algoritmo "EM" ("Expectation Maximization") proposto por Dempster et al. (1977), que é um método iterativo apropriado para calcular estimativas de Máxima Verossimilhança quando as observações provém de dados incompletos. 


\subsubsection{Método dos Momentos (MM)}

Outro estimador, para a variância entre os estudos, foi proposto por DerSimonian \& Laird (1986), o qual é do tipo não iterativo, e obtido pelo cálculo da estatística $Q_{\text {dentro. }}$ Assim, tal estimador é definido como

$$
\hat{\tau}_{D L}^{2}=\operatorname{máx}\left\{0, \frac{Q_{\text {dentro }}-(k-1)}{\sum_{i=1}^{k} w_{i}-\frac{\sum_{i=1}^{2}}{\sum_{i=1}^{k} w_{i}}}\right\} \text {. }
$$

Conduzindo a,

$$
\hat{\theta}_{D L}=\frac{\sum_{i} w_{i}\left(\hat{\tau}_{D L}\right) \hat{\theta}_{i}}{\sum_{i} w_{i}\left(\hat{\tau}_{D L}\right)},
$$

onde,

$$
\mathrm{w}_{\mathrm{i}}\left(\hat{\tau}_{\mathrm{DL}}\right)=\frac{1}{\operatorname{Vâr}\left(\hat{\theta}_{\mathrm{i}}\right)+\hat{\tau}_{\mathrm{DL}}^{2}} .
$$

DerSimonian \& Laird (1986), compararam quatro métodos para a estimar o tamanho do efeito e a variância entre os estudos que são MV, MVR, MM com ponderações iguais e MM com ponderações refletindo as variâncias desiguais. Concluíram que os MV, MVR e MM com ponderações desiguais não deferiram muito quanto aos valores encontrados para da variação entre os estudos; e recomendam a 
utilização do $\mathrm{MM}$ com ponderações desiguais, para estimar a variância entre os estudos, em virtude da relativa facilidade dos cálculos envolvidos (eq. 28).

\subsubsection{Modelo de Regressão para meta-análise}

A análise de regressão pode ser usada para determinar a relação entre estudos com características contínuas e estimativas do tamanho do efeito.

Considere, segundo Hedges \& Olkin (1983), uma série de $k$ estudos independentes na qual o i-ésimo estudo produz uma estimativa $\hat{\theta}_{i}$ do tamanho do efeito $\theta_{\mathrm{i}}, \mathrm{i}=1, \ldots, \mathrm{k}$. Denote o vetor coluna com dimensão $k$ das estimativas e parâmetros por:

$$
\hat{\theta}=\left(\hat{\theta}_{1}, \hat{\theta}_{2}, \ldots, \hat{\theta}_{\mathrm{k}}\right) \quad \theta=\left(\theta_{1}, \theta_{2}, \ldots, \theta_{\mathrm{k}}\right) .
$$

Assume-se um modelo de regressão linear,

$$
\theta=X \beta
$$

onde:

$\mathrm{X}$ é uma matriz de delineamento $k x p$ com rank $p$; $\beta$ é um vetor de parâmetros $p x l$.

Suponha que cada $\hat{\theta}_{\mathrm{i}}$ está baseado no tamanho da amostra $n_{\mathrm{i}}, \mathrm{i}=1, \ldots, \mathrm{k}$ e que como $n=\sum_{i=1}^{k} n_{i} \rightarrow \infty$ com $n_{i} / n, i=1, \ldots, k$ fixo, a distribuição assintótica de $\left(\hat{\theta}_{1}, \hat{\theta}_{2}, \ldots, \hat{\theta}_{k}\right)$ é multivariada normal, isto é:

$$
\sqrt{\mathrm{n}}(\hat{\theta}-\theta) \sim \mathrm{N}(0, \Sigma)
$$


onde a matriz de covariâncias $\Sigma=\left(\sigma_{\mathrm{ij}}\right)$ pode depender do tamanho da amostra $\mathrm{n}_{1}, \mathrm{n}_{2}, \ldots, \mathrm{n}_{\mathrm{k}}$ e não dos parâmetros.

Segue, então, que um estimador consistente e assintoticamente eficiente de $\beta$ é,

$$
\hat{\beta}=\left(X^{\prime} \Sigma^{-1} X\right)^{-1} X^{\prime} \Sigma^{-1} \hat{\theta},
$$

cuja matriz de covariância é $\psi \equiv\left(X^{\prime} \Sigma^{-1} X\right)^{-1}$. Consequentemente

$$
\sqrt{\mathrm{n}}(\hat{\beta}-\beta) \sim \mathrm{N}(0, \psi)
$$

Sendo $\psi$ uma matriz conhecida, um elipsóide de confiança para $\beta$ pode ser obtido de:

$$
n(\hat{\beta}-\beta) \psi^{-1}(\hat{\beta}-\beta) \sim \chi_{p}^{2}
$$

Um intervalo de confiança a $100(1-\alpha) \%$ para os $\beta$ 's pode ser obtido das desigualdades,

$$
\hat{\beta}_{\mathrm{j}}-\mathrm{c}_{\frac{\alpha}{2}} \sqrt{\frac{\psi_{\mathrm{jj}}}{\mathrm{n}}} \leq \beta_{\mathrm{j}} \leq \hat{\beta}_{\mathrm{j}}+\mathrm{c}_{\frac{\alpha}{2}} \sqrt{\frac{\psi_{\mathrm{jj}}}{\mathrm{n}}} \quad \mathrm{j}=1,2, \ldots, \mathrm{p},
$$

onde $c_{\alpha / 2}$ é valor tabelado da distribuição normal padronizada a um nível $\frac{\alpha}{2}$ de probabilidade.

Para testar a hipótese $\mathrm{H}_{0}: \beta=0$ pode-se utilizar a estatística:

$$
q=n \hat{\beta} \psi^{-1} \hat{\beta}=n \hat{\theta}^{\prime} \Sigma^{-1} X\left(X^{\prime} \Sigma^{-1} X\right)^{-1} X^{\prime} \Sigma^{-1} \hat{\theta}
$$


a qual tem uma distribuição de qui-quadrado com $p$ graus de liberdade.

Para testar a hipótese que o modelo ajusta-se aos dados, pode-se utilizar a estatística:

$$
\left.\mathrm{Q}=\mathrm{n}\left\{\hat{\theta} \Sigma^{-1} \hat{\theta}-\hat{\beta} \psi^{-1} \hat{\beta}\right\}=\mathrm{n} \hat{\boldsymbol{\theta}} \Sigma^{-1} \hat{\theta}-\hat{\theta} \Sigma^{-1} \mathrm{X}\left(\mathrm{X} \Sigma^{-1} \mathrm{X}\right)^{-1} \mathrm{X} \Sigma^{-1} \hat{\theta}\right\}
$$

a qual é comparada com uma distribuição de qui-quadrado com $k$ - $p$ graus de liberdade.

\subsection{Análise de Sensibilidade}

O que se pretende nesse ponto da análise é se os resultados de uma meta-análise são sensíveis à inclusão ou à exclusão de estudos particulares ou, se os resultados são sensíveis à maneira como foi conduzida a análise de dados. A análise de sensibilidade remete à questão: “o que acontece se algum aspecto dos dados ou da análise é mudado?".

Uma questão é se os estudos que são "outliers" potenciais deveriam ser incluídos na análise combinada. "Outliers" potenciais podem ser identificados utilizando um "dot plot" ou um "box plot". Num "dot plot" pode-se verificar se o intervalo de confiança para um determinado estudo coincide com o intervalo de confiança para os estudos combinados. Pode-se utilizar um "box plot" para detectar "outliers" que estão entre as amplitudes dos interquartis.

Para determinar a influência de uma estimativa do tamanho do efeito que é extrema podem-se apresentar os resultados combinados com e sem esses "outliers" potenciais. O procedimento é remover eventuais estudos considerados "outliers", e assim verificar se os resultados sofrem alterações como uma função daquela estimativa do tamanho do efeito daquele estudo.

O diagrama de ramos e folhas mostra a forma da distribuição dos dados, permitindo observar o centro da distribuição, localizar desvios da forma do gráfico 
(como por exemplo a presença de "outliers"). $\mathrm{O}$ "box plot" é um dispositivo que fornece ao observador uma impressão da distribuição dos dados, nele são incorporadas a média, os primeiro e terceiro percentis. Esses dispositivos são úteis para detectar a assimetria na distribuição das estimativas do tamanho do efeito. Numa análise de sensibilidade, podese determinar se os resultados combinados diferem como uma função da transformação dos dados.

Pode-se utilizar um gráfico de funil e um "normal quantile plot" para detectar vícios de publicação. Uma vez detectados os vícios de publicação, deve-se determinar se os resultados da meta-análise são sensíveis ao mecanismo de vício de publicação.

Devem-se também tomar várias decisões sobre os procedimentos da análise, tais como utilizar um modelo de efeitos fixos ou um modelo de efeitos aleatórios e se usar uma média ponderada, ou não, para estimar o tamanho do efeito populacional. Pode-se testar se os resultados da meta-análise são sensíveis a tais decisões. Recomenda-se que o ajuste da meta-análise seja feito tanto para um modelo de efeitos fixos quanto para um de efeitos aleatórios no mesmo conjunto de dados. Se a variação nas estimativas do tamanho do efeito podem ser atribuídas a poucas características dos estudos, o modelo de efeitos fixos é preferivel pois tem maior poder do que o de efeitos aleatórios. Recomenda-se o uso de ponderação média para estimar o tamanho do efeito populacional porque estudos com tamanhos menores da amostra produzem estimativas do tamanho do efeito menos precisas do que estudos com maiores tamanhos da amostra (Wang \& Bushman, 1999).

\subsection{Principais Problemas em Meta-análise}

Apesar de existirem muitos pesquisadores utilizando a meta-análise como uma técnica para reunir estudos independentes, e dos processos nesta área estarem bem desenvolvidos, existem várias questões ainda pendentes em torno da aplicação desse conjunto de técnicas estatísticas para este fim. 


\subsubsection{Seleção dos estudos}

Segundo Costa (1999), o primeiro problema defrontado por alguém que deseja sumarizar um conjunto de pesquisas é a identificação do corpo de trabalhos que, de alguma forma, diz respeito às questões levantadas. Isso requer que o propósito da metaanálise seja claramente articulado. Assim, seja qual for o objetivo da revisão, a seleção dos estudos a serem integrados será o suporte da conclusão procurada.

A seleção é uma questão de inclusão ou exclusão, e os julgamentos requeridos são problemáticos. Existem várias posições com relação a que tipo de estudo deve ser incluído na análise sendo que o problema mais difícil na formação de um critério de inclusão são os estudos provenientes de pesquisas de qualidade duvidosa. Alguns autores consideram que todos os estudos devem ser incluídos, porém, a tendência é adotar uma regra de decisão clara e coerente com os objetivos do pesquisador que utilizará a meta-análise.

\subsubsection{Vícios de publicação}

Outro grande problema relacionado com a realização da meta-análise é o fato de que alguns estudos nunca terem sido publicados. Se a razão para que tais estudos continuem não publicados for o resultado obtido, isso vai acarretar uma meta-análise viesada, por exemplo, estudos com resultados positivos, ou negativos dependendo da resposta esperada, têm maior probabilidade de serem publicados do que aqueles com resultados contrários aos que o pesquisador esperava; estudos que são patrocinados por empresas particulares só serão publicados se os resultados forem de interesse delas e, estudos vindos de grandes centros de pesquisa têm chances maiores de publicação do que os vindo de centros menores (Egger et al., 1997).

Rosenthal (1979) é frequentemente citado como tendo endereçado o problema de arquivar-se artigos com resultados diferentes do esperado inicialmente pelo pesquisador, o chamado "file drawer problem". A solução apresentada pelo autor é combinar os 
resultados experimentais fazendo uma soma de variáveis normal padrão. Outros autores, segundo Costa (1999), sugerem procedimentos distintos do apresentado por Rosenthal.

\subsubsection{População de referência}

De acordo com Costa (1999), algumas condições devem ser postas, ou suposições devem ser assumidas para que uma inferência estatística de qualquer tipo possa ser propriamente legitimada. A principal característica da inferência estatística é o argumento da amostra da população. A amostra deve ser o resultado de um procedimento aleatório e a população deve poder ser identificável. No caso da metaanálise, as duas características não são dadas diretamente.

O ponto principal a ser considerado sobre este tópico é em que extensão os dados de diferentes estudos podem legitimamente ser combinados - o usualmente denominado "problem of apples and oranges" - para se tirar uma conclusão para uma dada população. Segundo Glass (1981) essa resposta é simples: "maçãs e laranjas podem legitimamente ser combinadas no estudo de frutas".

Porém, muitos autores discordam desta afirmação anterior, e, segundo Costa (1999) dois caminhos podem ser apontados para uma solução deste problema. Um é o de buscar fazer a meta-análise tendo estudos individuais bastante homogêneos, com os cuidados de que as suposições de amostra aleatória sejam cumpridas. Outra é o de admitir que o procedimento meta-analítico não precise, necessariamente, trabalhar com amostras aleatórias, e que as inferências a serem feitas sejam mais restritas e que também admitam um certo grau de vagueza e imprecisão. Esse autor sugere que o trabalho com meta-análise inclua, além do tamanho do efeito e dos "p-value", também o tamanho da amostra para a determinação de probabilidades de relevância. 


\subsection{Software}

A quantidade de pacotes estatísticos existentes para realização de uma metaanálise, tanto para serem adquiridos quanto os disponíveis na "internet", é muito grande.

Normand (1995) discute três programas, o DSTAT, o TRUE EPISTAT e o FAST*PRO, sendo que este último tem a vantagem sobre os dois primeiros de realizar tanto uma análise de efeitos fixos quanto de efeitos aleatórios. O DSTAT e o TRUE EPISTAT fazem apenas a aproximação para um modelo de efeitos fixos.

Kirby (1993), propõe a utilização do SYSTAT para realizar uma meta-análise. Este pacote pode ser utilizado tanto no sistema operacional compatível com MS-DOS quanto para MACINTOSH, e com programação adequada, faz os cálculos e gráficos necessários numa análise combinada de dados.

Guveritch \& Hedges (1993), realizaram uma meta-análise, através do EXCEL, com aproximações tanto para um modelo de efeitos fixos quanto para um de efeitos aleatórios utilizando, neste caso o Método dos Momentos e uma análise de subgrupo.

Outros programas como o STATSDIRECT, META Program Information, POWER PRECISION, estes dois últimos disponíveis gratuitamente na "internet" e feitos apenas para a realização da meta-análise, também podem ser utilizados para auxiliar na análise dos dados.

Wang \& Bushman (1999), publicaram um "guia", com programas e macros, para a utilização do pacote estatístico SAS na realização de uma meta-análise. Esses autores consideram que, apesar do SAS não ser especialmente delineado para realizar este tipo de análise, ele é uma das melhores opções, no momento, para se realizar uma metaanálise, já que um bom software para procedimentos meta-analíticos, deve ter capacidade de manejar o banco de dados, realizar os cálculos necessários envolvidos numa meta-análise, usar dispositivos gráficos para ilustrar, apresentar as suposições sobre os procedimentos meta-analíticos e produzir a estimativa resumida dos estudos envolvidos. 


\section{MATERIAL E MÉTODOS}

A Figura 1 apresenta o fluxograma da metodologia empregada para a realização da meta-análise.

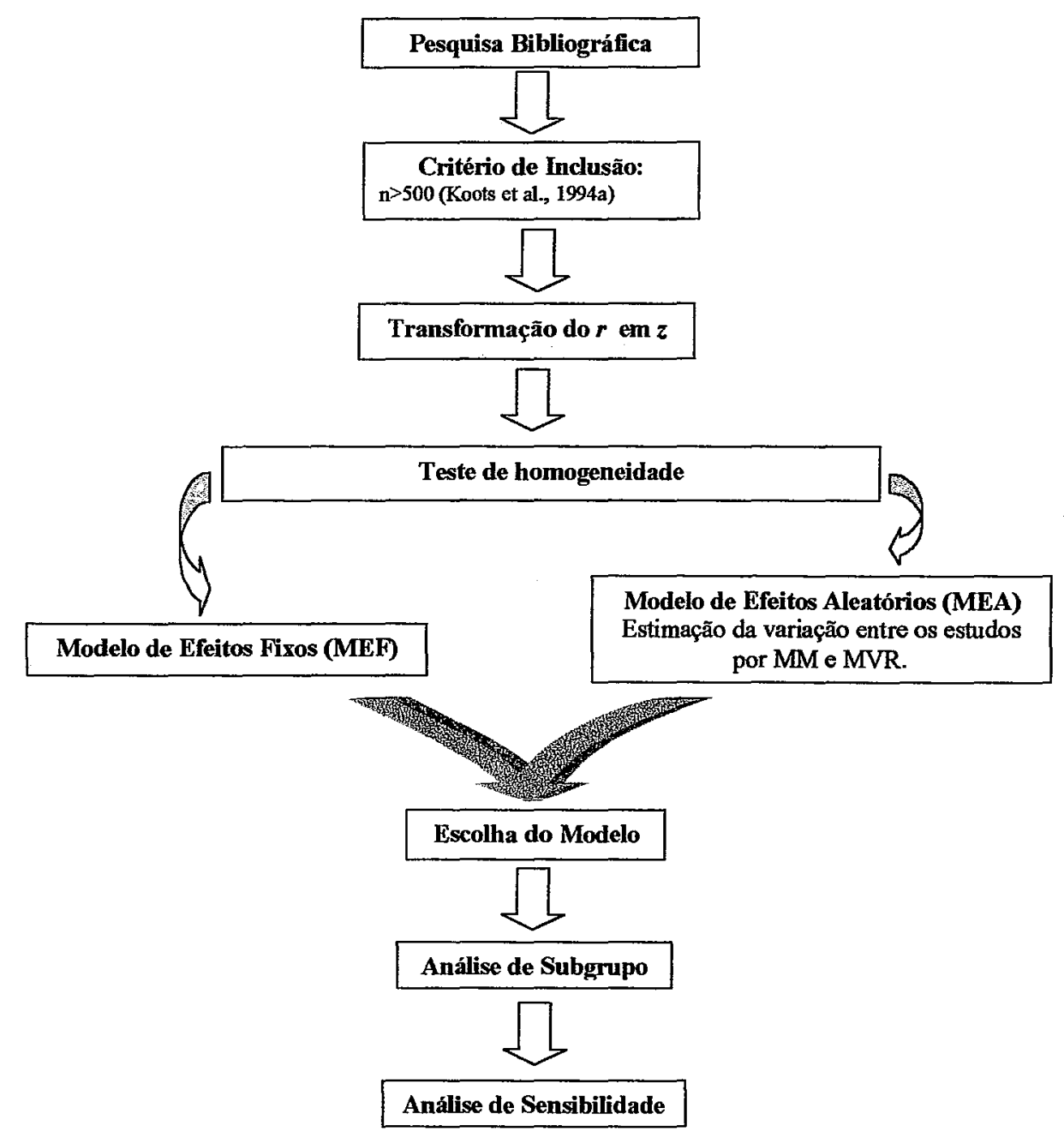

Figura 1. Fluxograma da meta-análise aplicada para as correlações genéticas. 


\subsection{Material}

Os dados utilizados neste exemplo de meta-análise referem-se às estimativas dos coeficientes de correlação genética entre peso ao nascimento e peso à desmama, de bovinos de corte de origem indiana, provenientes de uma revisão realizada por Mercadante et al. (1995) e atualizada até o ano de 2000.

A pesquisa da literatura realizada por Mercadante et al. (1995) foi feita de modo a incluir o máximo possível de estudos sobre o tópico em questão. Para tanto, os autores pesquisaram em anais de congressos e simpósios, trabalhos não indexados, bibliotecas e base de dados catalogados em CD (por exemplo CAB). Deste processo obteve-se 37 estudos, entre os anos de 1968 a 1995.

Para a atualização, de 1996 a 2000, destes dados efetuou-se a pesquisa bibliográfica em anais de congresso e simpósios, biblioteca e na base de dados CAB utilizando as palavras-chave NELORE OR NELLORE OR ZEBU OR BOS INDICUS AND GENETIC CORRELAT* AND HERITABILI* e também NELORE OR NELORE OR ZEBU OR INDICUS AND GENETIC CORRELATION. Entre os anos de 1996 a 2000 foram publicados dois trabalhos sobre o assunto de interesse.

Deste modo, o total de estudos encontrados foi 39, expostos na Tabela 5, em ordem cronológica contendo, o número referente ao estudo, a raça, o país, o número de observações $(\mathrm{N})$, a correlação genética (r) e o subgrupo. Os estudos são provenientes de sete países tropicais, oito raças, com número de observações variando de 193 a 31488 . A estratificação dos estudos foi realizada segundo a década de publicação, em três diferentes subgrupos: " 1 " entre as décadas de 60 e 70 ; " 2 " década de 80 e, “ 3 " década de 90.

A estratificação por década é proposta neste trabalho pois, com o avanço das técnicas de estimação de parâmetros genéticos no decorrer dos anos, aliado à melhoria da quantidade e qualidade dos bancos de dados de desempenho de bovinos, o ano de publicação do estudo pode refletir a qualidade dos resultados.

A representação esquemática das observações, referentes a cada estudo, para os coeficientes de correlação, está apresentado na Tabela 6. 
Tabela 5. Relação completa dos trabalhos sobre correlação genética entre peso ao nascer e desmama em bovinos de corte.

\begin{tabular}{|c|c|c|c|c|c|}
\hline Estudo & Raça & $\mathbf{N}$ & $\mathbf{r}$ & Subgrupo & Referência \\
\hline 1 & Brahman & 1049 & 0,84 & 1 & Berruecos \& Robison (1968) \\
\hline 2 & Nelore & 417 & 0,44 & 1 & Felício et al. (1976) \\
\hline 3 & Guzerá & 399 & 0,26 & 1 & Felício et al. (1976) \\
\hline 4 & Gir & 261 & 1,18 & 1 & Felício et al. (1976) \\
\hline 5 & Nelore & 1580 & 0,81 & 1 & Mortari (1976) \\
\hline 6 & Gir & 193 & 0,21 & 1 & Torres et al. (1979) \\
\hline 7 & Nelore & 1356 & 0,67 & 1 & Pimenta-Filho (1980) \\
\hline 8 & Nelore & 12339 & 0,25 & 2 & Oliveira-Filho \& Duarte (1981) \\
\hline 9 & Nelore & 831 & 0,67 & 2 & Baroni (1982) \\
\hline 10 & Nelore & 998 & 0,40 & 2 & Silva (1983) \\
\hline 11 & Tabapuã & 1857 & 0,76 & 2 & Ledic (1983) \\
\hline 12 & Nelore & 1028 & 0,38 & 2 & Silva et al. (1983) \\
\hline 13 & Guzerá & 659 & 0,53 & 2 & Marques et al. (1983) \\
\hline 14 & Brahman & 2588 & 0,30 & 2 & Verde et al. (1983) \\
\hline 15 & Nelore & 2944 & 0,47 & 2 & Nobre et al. (1985) \\
\hline 16 & Nelore & 4249 & 0,19 & 2 & Milagres et al. (1985) \\
\hline 17 & Nelore & 2282 & 0,99 & 2 & Mariante \& Zancaner (1985) \\
\hline 18 & Guzerá & 485 & 0,73 & 2 & Oliveira et al. (1986) \\
\hline 19 & Gudali & 31488 & 0,81 & 2 & Iloeje (1986) \\
\hline 20 & Nelore & 5701 & 0,40 & 2 & Rosa et al. (1986) \\
\hline 21 & Nelore & 4662 & 0,92 & 2 & Amaral (1986) \\
\hline 22 & Nkone & 1864 & 0,54 & 2 & Tawonezvi et al. (1986) \\
\hline 23 & Nelore & 5483 & 0,34 & 2 & Silva et al. (1987) \\
\hline 24 & Nelore & 2550 & 0,54 & 2 & Cardellino \& Castro (1987) \\
\hline 25 & Boran & 3959 & 0,01 & 2 & Arnason \& Kassa-Mersha (1987) \\
\hline 26 & Nelore & 590 & 0,16 & 2 & Scherré et al. (1988) \\
\hline 27 & Nelore & 574 & $-0,12$ & 2 & Scherré et al. (1988) \\
\hline 28 & Nelore & 18751 & 0,18 & 2 & Eler et al. (1989) \\
\hline 29 & Gobra & 1401 & 0,49 & 2 & Abassa et al. (1989) \\
\hline 30 & Guzerá & 585 & 0,45 & 2 & Martins-Filho \& Lốbo (1989) \\
\hline 31 & Nelore & 2604 & 0,28 & 3 & Ayala et al. (1991) \\
\hline 32 & Guzerá & 748 & 0,64 & 3 & Oliveira et al. (1993) \\
\hline 33 & Nelore & 27549 & 0,23 & 3 & Eler et al. (1994) \\
\hline 34 & Nelore & 18200 & 0,42 & 3 & Lôbo et al. (1995a) \\
\hline 35 & Nelore & 17131 & 0,42 & 3 & Reyes et al. (1995) \\
\hline 36 & Nelore & 3679 & 0,39 & 3 & Salles (1995) \\
\hline 37 & Nelore & 2567 & 0,91 & 3 & Souza \& Ramos (1995) \\
\hline 38 & Nelore & 31114 & 0,63 & 3 & Eler et al. (1996) \\
\hline 39 & Nelore & 688 & 0,83 & 3 & Martins et al. (2000) \\
\hline
\end{tabular}


Tabela 6. Representação esquemática das observações com suas respectivas correlações.

\begin{tabular}{ccccc}
\hline & \multicolumn{4}{c}{ Estudos } \\
\cline { 2 - 5 } & 1 & 2 & $\ldots$ & 39 \\
\hline Observações & $\left(\mathrm{pn}_{1}, \mathrm{pd}_{1}\right)$ & $\left(\mathrm{pn}_{1}, \mathrm{pd}_{1}\right)$ & $\ldots$ & $\left(\mathrm{pn}_{1}, \mathrm{pd}_{1}\right)$ \\
& $\left(\mathrm{pn}_{2}, \mathrm{pd}_{2}\right)$ & $\left(\mathrm{pn}_{2}, \mathrm{pd}_{2}\right)$ & & $\left(\mathrm{pn}_{2}, \mathrm{pd}_{2}\right)$ \\
& $\ldots$ & $\ldots$ & $\ldots$ & $\ldots$ \\
Correlações & $\left(\mathrm{pn}_{1049}, \mathrm{pd}_{1049}\right)$ & $\left(\mathrm{pn}_{417}, \mathrm{pd}_{417}\right)$ & $\ldots$ & $\left(\mathrm{pn}_{688}, \mathrm{pd}_{688}\right)$ \\
\hline
\end{tabular}

Nota: $\mathrm{pn}=$ peso ao nascimento e $\mathrm{pd}=$ peso à desmama.

\subsection{Métodos}

\subsubsection{Critério de inclusão}

Seguindo o critério de inclusão adotado por Koots et al. (1994a), foram descartadas as estimativas da correlação genética obtidas com menos de 500 observações. Não foi feito um estudo sobre a validade deste critério.

\subsubsection{Transformação de $r$ em $z$}

Como os dados utilizados se referem a coeficientes de correlação, procedeu-se a transformação de $r$ na quantidade $z$, proposta por Fisher, citado por Hedges \& Olkin (1985). Para realizar esta transformação utiliza-se a eq. (13),

$$
z=\frac{1}{2} \ln \frac{1+r}{1-r}
$$


Conforme demonstrado por aqueles autores a variável $z$ apresenta distribuição aproximadamente normal com variância $s_{i}^{2}=\sigma_{i}^{2}=1 /(n-3)$.

\subsubsection{Análise Exploratória}

Com a finalidade de verificar a amplitude do intervalo de confiança dos coeficientes de correlação, separadamente para cada estudo, construiu-se um "dot plot", com a utilização do PROC TIMEPLOT (SAS, 1990a), conforme programa proposto por Wang \& Bushman (1999), descrito no Apêndice 2, e eq.(17),

$$
\zeta_{\text {inf. }}=z-\frac{1,96}{\sqrt{n-3}} \text { e } \zeta_{\text {sup. }}=z+\frac{1,96}{\sqrt{n-3}}
$$

A seguir, através de um diagrama de ramos e folhas, de um "box plot" e de estatísticas descritivas, verificou-se a presença ou não de "outliers", a distribuição dos dados, os coeficientes de correlação considerados extremos. Essa análise exploratória foi realizada através do PROC UNIVARIATE (SAS, 1990a), programa apresentado no Apêndice 3.

\subsubsection{Teste de homogeneidade}

O teste de homogeneidade entre os estudos, foi realizado através do PROC GLM (SAS, 1990b) para decidir qual o modelo que explica mais adequadamente os dados, conforme programa proposto por Wang \& Bushman (1999), descrito no Apêndice 4.

A hipótese testada pode ser descrita como,

$\mathrm{H}_{0}: \theta_{1}=\theta_{2}=\ldots=\theta_{\mathrm{k}} \quad$ sendo $\mathrm{k}$ o número de estudos, versus,

$\mathbf{H}_{\mathrm{A}}$ : pelo menos um coeficiente de correlação transformado difere dos demais, 
através da estatística $Q$ calculada pela eq. (18),

$$
\mathrm{Q}_{\text {entre }}=\sum \mathrm{w}_{\mathrm{i}+}\left(\hat{\theta}_{\mathrm{i}+}-\hat{\boldsymbol{\theta}}_{++}\right)^{2}, \quad \mathrm{i}=1,2, \ldots, \mathrm{k} .
$$

A partir deste teste de hipótese, pode-se escolher o modelo mais apropriado para modelar a variação presente nos dados, podendo optar entre um Modelo de Efeitos Fixos (MEF) ou um Modelo de Efeitos Aleatórios (MEA).

\subsubsection{Modelo de Efeitos Fixos (MEF)}

Quando se faz a opção pela aproximação de efeito fixo, o modelo aplicado aos dados de coeficientes de correlação genética, é,

$$
\mathrm{y}_{\mathrm{i}}=\theta+\mathrm{e}_{\mathrm{i}},
$$

onde:

$y_{i}$ representa os coeficientes de correlação genética transformados; sendo $i=1, \ldots, k$;

$\theta$ é a média ponderada das $y_{i}$, dada pela eq. (14),

$$
z_{+}=\frac{\sum_{i=1}^{k} w_{i} z_{i}}{\sum_{i=1}^{k} w_{i}},
$$

como se trata de um modelo fixo a ponderação é,

$$
w_{i}=1 / s_{i}^{2} ;
$$


$\mathrm{e}_{\mathrm{i}}$ é o erro aleatório; apresentando distribuição Normal com média 0 e variância $\sigma_{\mathrm{i}}^{2}$.

Para tamanhos de estudos moderadamente grandes, assume-se que cada $y_{i}$ deve ser normalmente assintoticamente distribuído (pelo teorema central do limite) e aproximadamente não viesado. Assim, pode-se representar:

$$
y_{i} \stackrel{\text { indep. }}{\sim} N\left(\theta, \sigma_{i}^{2}\right) \text { para } i=1,2, \ldots, k
$$

onde: $\sigma_{i}^{2}=1 /(n-3)$.

\subsubsection{Modelo de Efeitos Aleatórios (MEA)}

Por outro lado, caso se opte pela aproximação de efeito aleatório, o modelo aplicável é o modelo hierárquico, assim representado:

$$
\begin{aligned}
& y_{i}=\theta_{i}+e_{i} \\
& \theta_{i}=\theta+\varepsilon_{i}
\end{aligned}
$$

onde:

$y_{i}$ representa os coeficientes de correlação genética transformados; sendo $i=1, \ldots, k$;

$\theta$ é a média ponderada das $y_{i}$, a equação utilizada para realizar esta média é a eq. (14),

$$
z_{+}=\frac{\sum_{i=1}^{k} w_{i}^{*} z_{i}}{\sum_{i=1}^{k} w_{i}^{*}}
$$

e como se trata de um modelo aleatório a ponderação é, $w_{i}^{*}=1 /\left(s_{i}^{2}+\tau^{2}\right)$; 
$\mathrm{e}_{\mathrm{i}}$ é o erro aleatório, apresentando distribuição Normal com média 0 e variância $\sigma_{\mathrm{i}}^{2}$ $\varepsilon_{\mathrm{i}}$ é o erro aleatório, apresentando distribuição Normal com média 0 e variância $\tau^{2}$; $\theta_{\mathrm{i}}$ é dado por:

$$
\hat{\theta}_{i}=\left(1-\hat{B}_{i}\right) y_{i}+\hat{B}_{i} \theta_{+} \text {, }
$$

sendo $\hat{B}_{i}=\frac{\hat{\sigma}_{i}^{2}}{\hat{\sigma}_{i}^{2}+\hat{\tau}^{2}}$.

Em contraste com o modelo de efeitos fixos, a estrutura de efeitos aleatórios pressupõe que cada correlação específica $\theta_{i}$ é retirada de uma superpopulação de efeitos, e $y_{i}$ é também extraída de uma população com média e variância próprias. Assim,

$$
\begin{gathered}
\mathrm{y}_{\mathrm{i}} \mid \theta_{\mathrm{i}}, \sigma_{\mathrm{i}}^{2} \stackrel{\text { indep. }}{\sim} \mathrm{N}\left(\theta_{\mathrm{i}}, \sigma_{\mathrm{i}}^{2}\right) \mathrm{e}, \\
\theta_{\mathrm{i}} \mid \theta, \tau^{2} \stackrel{\text { indep. }}{\sim} \mathrm{N}\left(\theta, \tau^{2}\right) .
\end{gathered}
$$

O valor de $\tau^{2}$ foi estimado pela equação proposta por DerSimonian \& Laird (1986) e representado por $\hat{\tau}_{\mathrm{DL}}^{2}$ e pelo método da Máxima Verossimilhança Restrita (MVR) $\hat{\tau}_{\mathrm{MVR}}^{2}$;

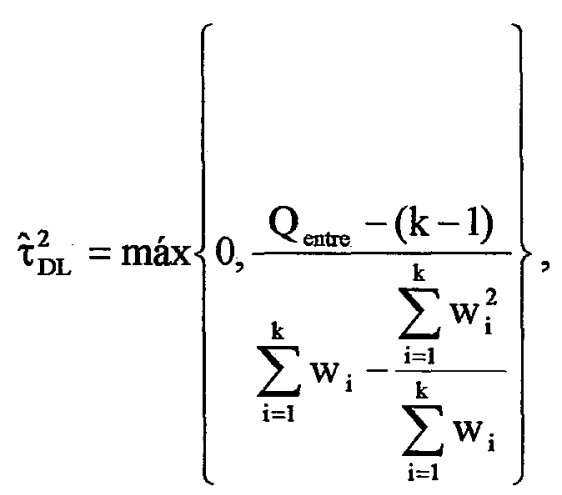




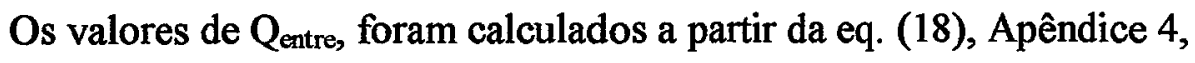
enquanto que,

$$
\hat{\tau}_{M V R}^{2}=\frac{\sum_{i=1}^{k} w_{i}^{2}(\hat{\tau})\left[\frac{k}{k-1}\left(Y_{i}-\hat{\theta}_{M V R}\right)^{2}-\operatorname{Var}\left(\hat{\theta}_{i}\right)\right]}{\sum_{i=1}^{k} w_{i}^{2}(\hat{\tau})} .
$$

Para obter os valores necessários para calcular $\hat{\tau}_{\text {MVR }}^{2}$ utilizou-se o PROC MIXED (SAS, 1996), através do programa proposto por Wang \& Bushman (1999), descrito no Apêndice 4.

\subsubsection{Obtenção da estimativa combinada}

Para obter a estimativa combinada do coeficiente de correlação, utilizou-se a eq. (16),

$$
r_{+}=\frac{\exp \left\{2 z_{+}\right\}-1}{\exp \left\{2 z_{+}\right\}+1}
$$

observando que as ponderações são distintas para o MEF e o MEA, e consequentemente os valores de $z_{+}$e de $r_{+}$.

\subsubsection{Análise de subgrupo}

Para testar a homogeneidade em relação aos subgrupos utilizou-se as macro WITHIN (SAS, 1997) e o programa contendo o PROC FORMAT (SAS, 1990a), propostos por Wang \& Bushman (1999), descritos no Apêndice 6. Sendo que as hipóteses testadas foram, 
$\mathrm{H}_{0}: \theta_{1+}=\theta_{2+}=\theta_{3+}$,

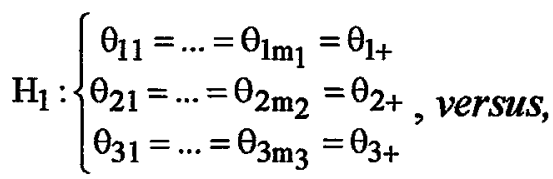

$\mathrm{H}_{\mathrm{A}}$ : pelo menos um coeficiente de correlação transformado difere dos demais.

Para testar a hipótese $\mathrm{H}_{0}$, que não existe variação entre os grupos de estudo, utilizou-se a eq. (18),

$\mathrm{Q}_{\text {entre }}=\sum \mathrm{w}_{\mathrm{i+}}\left(\hat{\theta}_{\mathrm{i+}}-\hat{\theta}_{++}\right)^{2} \quad \mathrm{i}=1,2,3$.

Para testar a hipótese $\mathrm{H}_{1}$, que não existe variação dentro dos grupos de estudo, utilizou-se a eq. (23),

$Q_{\text {dentro }}=\sum_{\mathrm{i}=1}^{\mathrm{k}} \sum_{\mathrm{j}=1}^{\mathrm{m}_{\mathrm{i}}} \mathrm{w}_{\mathrm{ij}}\left(\hat{\theta}_{\mathrm{ij}}-\hat{\theta}_{\mathrm{i}+}\right)^{2}$.

As várias causas de heterogeneidade, que podem estar presentes nesta metaanálise, estão expostas na Tabela 7.

As estimativas combinadas, referentes à variável $r$, foram calculadas executando a macro WAVGZ (SAS, 1997) e o programa contendo o PROC FORMAT (SAS, 1990a), propostos por Wang \& Bushman (1999), descritos no Apêndice 7. 
Tabela 7. Análise da Heterogeneidade entre e dentro dos grupos de estudo.

\begin{tabular}{lcc}
\hline Causas de Heterogeneidade & Estatística Q & Graus de liberdade \\
\hline Entre grupos & $\mathrm{Q}_{\text {entre }}$ & $\mathrm{p}-1$ \\
\hline Dentro de grupos & $\mathrm{Q}_{\text {dentro }}$ & $\mathrm{k}-\mathrm{p}$ \\
Dentro do grupo 1 & $\mathrm{Q}_{\text {dentro 1 }}$ & $\mathrm{m}_{1}-1$ \\
Dentro do grupo 2 & $\mathrm{Q}_{\text {dentro 2 }}$ & $\mathrm{m}_{2}-1$ \\
Dentro do grupo 3 & $\mathrm{Q}_{\text {dentro 3 }}$ & $\mathrm{m}_{3}-1$ \\
\hline Total & $\mathrm{Q}_{\text {total }}$ & $\mathrm{k}-1$ \\
\hline
\end{tabular}

\subsubsection{Análise de Sensibilidade}

Esta etapa da meta-análise consiste em retirar os estudos considerados "outliers", refazer todas os procedimentos, e avaliar o impacto daqueles estudos nas estimativas combinadas do coeficiente de correlação. 


\section{RESULTADOS E DISCUSSÃo}

Neste capítulo, que engloba as várias etapas da meta-análise são apresentados a seleção dos estudos, a transformação utilizada para obtenção do coeficiente de correlação transformado, o teste de homogeneidade, a modelagem da variação sob os modelos de efeitos fixos e aleatórios, uma análise de sensibilidade baseada na análise exploratória dos coeficientes de correlação genético, e uma análise de subgrupo. Seguese a apresentação dos resultados obtidos.

A Tabela 8 relaciona o estudo, a raça, o país, o tamanho da amostra (n) e o coeficiente de correlação ( $r$ ), o coeficiente de correlação transformado (z), após aplicado o critério de inclusão. Nota-se que dos 39 estudos, permaneceram 34. Os coeficientes de correlação genética foram transformados de $r$ para $z$, pela eq. (13), com o objetivo de aproximar normalidade. 
Tabela 8. Estimativas de correlações genéticas entre peso ao nascimento e peso à desmama com a transformação $z$.

\begin{tabular}{|c|c|c|c|c|c|c|c|}
\hline OBS & ESTUDO & RACA & PAIS & $\mathbf{n}$ & $\mathbf{r}$ & $\mathbf{z}$ & $1 / n-3$ \\
\hline 1 & 1 & Brahman & México & 1049 & 0,84 & 1,22117 & 0,0009560 \\
\hline 2 & 5 & Nelore & Brasil & 1580 & 0,81 & 1,12703 & 0,0006341 \\
\hline 3 & 7 & Nelore & Brasil & 1356 & 0,67 & 0,81074 & 0,0007391 \\
\hline 4 & 8 & Nelore & Brasil & 12339 & 0,25 & 0,25541 & 0,0000811 \\
\hline 5 & 9 & Nelore & Brasil & 831 & 0,67 & 0,81074 & 0,0012077 \\
\hline 6 & 10 & Nelore & Brasil & 998 & 0,40 & 0,42365 & 0,0010050 \\
\hline 7 & 11 & Tabapuã & Brasil & 1857 & 0,76 & 0,99622 & 0,0005394 \\
\hline 8 & 12 & Nelore & Brasil & 1028 & 0,38 & 0,40006 & 0,0009756 \\
\hline 9 & 13 & Guzerá & Brasil & 659 & 0,53 & 0,59015 & 0,0015244 \\
\hline 10 & 14 & Brahman & Venezuel & 2588 & 0,30 & 0,30952 & 0,0003868 \\
\hline 11 & 15 & Nelore & Brasil & 2944 & 0,47 & 0,51007 & 0,0003400 \\
\hline 12 & 16 & Nelore & Brasil & 4249 & 0,19 & 0,19234 & 0,0002355 \\
\hline 13 & 17 & Nelore & Brasil & 2282 & 0,99 & 2,64665 & 0,0004388 \\
\hline 14 & 19 & Gudali & Nigéria & 31488 & 0,81 & 1,12703 & 0,0000318 \\
\hline 15 & 20 & Nelore & Brasil & 5701 & 0,40 & 0,42365 & 0,0001755 \\
\hline 16 & 21 & Nelore & Brasil & 4662 & 0,92 & 1,58903 & 0,0002146 \\
\hline 17 & 22 & Nkone & Zimbabue & 1864 & 0,54 & 0,60416 & 0,0005373 \\
\hline 18 & 23 & Nelore & Brasil & 5483 & 0,34 & 0,35409 & 0,0001825 \\
\hline 19 & 24 & Nelore & Brasil & 2550 & 0,54 & 0,60416 & 0,0003926 \\
\hline 20 & 25 & Boran & Etiópia & 3959 & 0,01 & 0,01000 & 0,0002528 \\
\hline 21 & 26 & Nelore & Brasil & 590 & 0,16 & 0,16139 & 0,0017036 \\
\hline 22 & 27 & Nelore & Brasil & 574 & $-0,12$ & $-0,12058$ & 0,0017513 \\
\hline 23 & 28 & Nelore & Brasil & 18751 & 0,18 & 0,18198 & 0,0000533 \\
\hline 24 & 29 & Gobra & Senegal & 1401 & 0,49 & 0,53606 & 0,0007153 \\
\hline 25 & 30 & Guzerá & Brasil & 585 & 0,45 & 0,48470 & 0,0017182 \\
\hline 26 & 31 & Nelore & Brasil & 2604 & 0,28 & 0,28768 & 0,0003845 \\
\hline 27 & 32 & Guzerá & Brasil & 748 & 0,64 & 0,75817 & 0,0013423 \\
\hline 28 & 33 & Nelore & Brasil & 27549 & 0,23 & 0,23419 & 0,0000363 \\
\hline 29 & 34 & Nelore & Brasil & 18200 & 0,42 & 0,44769 & 0,0000550 \\
\hline 30 & 35 & Nelore & Brasil & 17131 & 0,42 & 0,44769 & 0,0000584 \\
\hline 31 & 36 & Nelore & Brasil & 3679 & 0,39 & 0,41180 & 0,0002720 \\
\hline 32 & 37 & Nelore & Brasil & 2567 & 0,91 & 1,52752 & 0,0003900 \\
\hline 33 & 38 & Nelore & Brasil & 31114 & 0,63 & 0,74142 & 0,0000321 \\
\hline 34 & 39 & Nelore & Brasil & 688 & 0,83 & 1,18814 & 0,0014599 \\
\hline
\end{tabular}

Na Figura 2 estão presentes as variáveis: ESTUDO, correspondendo ao número do estudo que foi incluído na meta-análise presente na Tabela 5; EFEITO, referente aos coeficientes de correlação não transformados; e as variáveis INFERIOR e SUPERIOR contendo os valores limites, respectivamente, para o intervalo de confiança a $95 \%$. 


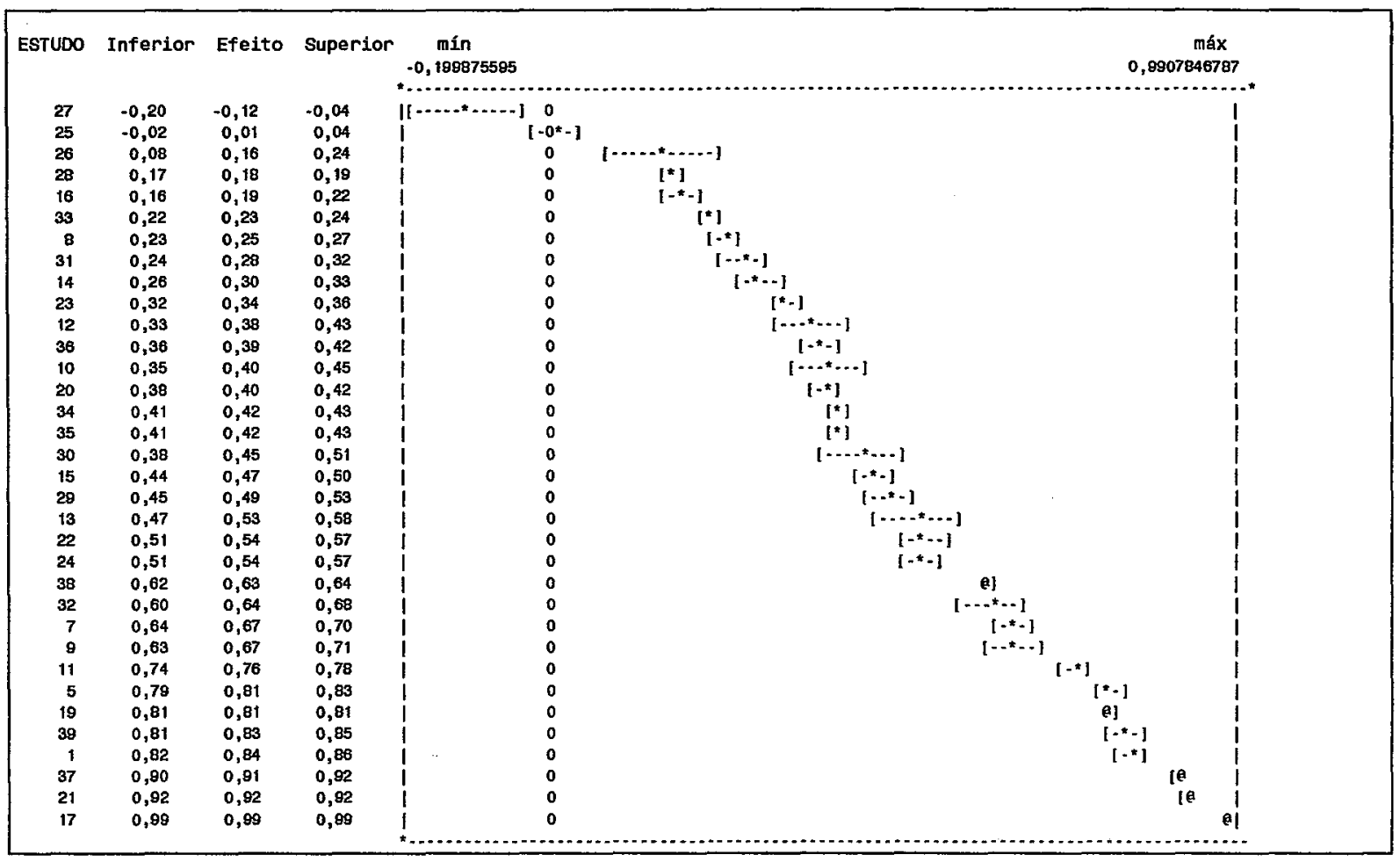

Figura 2. "Dot plot" para a correlação entre peso ao nascimento e peso à desmama.

As estimativas dos coeficientes de correlação foram ordenadas de maneira crescente. Observa-se, pela Figura 2, que o intervalo de confiança para o estudo 27 indica uma correlação significativamente negativa $e$, o intervalo de confiança para o estudo 25 inclui o valor zero. Para os demais estudos, este dispositivo gráfico demonstra que existe uma correlação positiva entre peso ao nascimento e peso à desmama.

Na Figura 2 estão indicados os estudos 17, 21, 25, 27 e 37, considerados "outliers".

Utilizando os coeficientes de correlação transformados na variável $z$, realizou-se o cálculo das estatísticas descritivas, dos quantis, dos extremos, dos gráficos de ramos e folhas e, "box plot", apresentados na Figura 3. 
Para as correlações entre peso ao nascimento e peso à desmama o diagrama de ramos e folhas obtido indica ser unimodal, com a distribuição levemente assimétrica para a direita. Esta observação é confirmada pelo valor positivo de assimetria "skewness", com a presença de "outliers", como observado anteriormente.

O "box plot" geral construído para os dados em questão indica, como no diagrama de ramos e folhas, a presença de "outliers" e uma distribuição levemente assimétrica à direita.

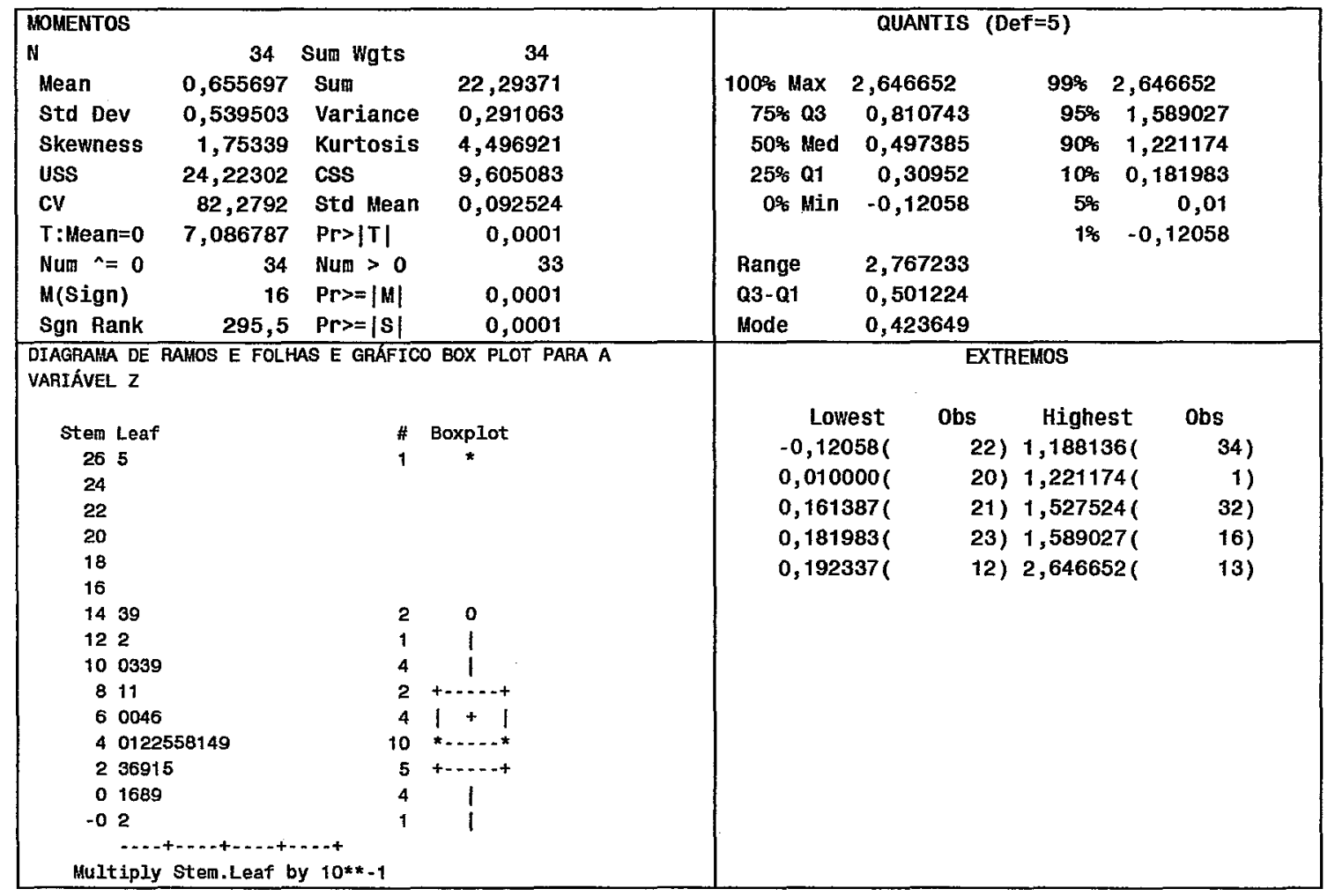

Figura 3. Estatísticas descritivas dos coeficientes de correlação genética transformados.

Os resultados do teste de homogeneidade para determinar se a amostra dos coeficientes de correlação transformados é homogênea, estão apresentados na Tabela 9. Existem fortes evidências para rejeitar a hipótese de nulidade, que apresenta a homogeneidade entre os valores de $z$. 
Tabela 9. Teste de homogeneidade das 34 estimativas transformadas dos coeficientes de correlação entre peso ao nascer e à desmama em bovinos de corte.

\begin{tabular}{llll}
\hline C. H. & G.L. & Estat-Q & "p-value" \\
\hline Erro & 33 & 40105 & 0,000 \\
\hline
\end{tabular}

Nota: C.H. = causa de heterogeneidade

Tabela 10. Estimativa combinada para o modelo de efeitos fixos $\left(w_{i}=1 / s_{i}^{2}\right)$.

\begin{tabular}{|c|c|c|c|c|c|c|c|}
\hline OBS & ESTUDO & $n$ & $r$ & $z$ & $1 / n-3$ & $n-3$ & $(n-3) z_{i}$ \\
\hline 1 & 1 & 1049 & 0,84 & 1,22117 & 0,0009560 & 1046 & 1277,35 \\
\hline 2 & 5 & 1580 & 0,81 & 1,12703 & 0,0006341 & 1577 & 1777,32 \\
\hline 3 & 7 & 1356 & 0,67 & 0,81074 & 0,0007391 & 1353 & 1096,94 \\
\hline 4 & 8 & 12339 & 0,25 & 0,25541 & 0,0000811 & 12336 & 3150,77 \\
\hline 5 & 9 & 831 & 0,67 & 0,81074 & 0,0012077 & 828 & 671,30 \\
\hline 6 & 10 & 998 & 0,40 & 0,42365 & 0,0010050 & 995 & 421,53 \\
\hline 7 & 11 & 1857 & 0,76 & 0,99622 & 0,0005394 & 1854 & 1846,98 \\
\hline 8 & 12 & 1028 & 0,38 & 0,40006 & 0,0009756 & 1025 & 410,06 \\
\hline 9 & 13 & 659 & 0,53 & 0,59015 & 0,0015244 & 656 & 387,14 \\
\hline 10 & 14 & 2588 & 0,30 & 0,30952 & 0,0003868 & 2585 & 800,11 \\
\hline 11 & 15 & 2944 & 0,47 & 0,51007 & 0,0003400 & 2941 & 1500,12 \\
\hline 12 & 16 & 4249 & 0,19 & 0,19234 & 0,0002355 & 4246 & 816,66 \\
\hline 13 & 17 & 2282 & 0,99 & 2,64665 & 0,0004388 & 2279 & 6031,72 \\
\hline 14 & 19 & 31488 & 0,81 & 1,12703 & 0,0000318 & 31485 & 35484,51 \\
\hline 15 & 20 & 5701 & 0,40 & 0,42365 & 0,0001755 & 5698 & 2413,95 \\
\hline 16 & 21 & 4662 & 0,92 & 1,58903 & 0,0002146 & 4659 & 7403,28 \\
\hline 17 & 22 & 1864 & 0,54 & 0,60416 & 0,0005373 & 1861 & 1124,33 \\
\hline 18 & 23 & 5483 & 0,34 & 0,35409 & 0,0001825 & 5480 & 1940,43 \\
\hline 19 & 24 & 2550 & 0,54 & 0,60416 & 0,0003926 & 2547 & 1538,78 \\
\hline 20 & 25 & 3959 & 0,01 & 0,01000 & 0,0002528 & 3956 & 39,56 \\
\hline 21 & 26 & 590 & 0,16 & 0,16139 & 0,0017036 & 587 & 94,73 \\
\hline 22 & 27 & 574 & $-0,12$ & $-0,12058$ & 0,0017513 & 571 & $-68,85$ \\
\hline 23 & 28 & 18751 & 0,18 & 0,18198 & 0,0000533 & 18748 & 3411,81 \\
\hline 24 & 29 & 1401 & 0,49 & 0,53606 & 0,0007153 & 1398 & 749,41 \\
\hline 25 & 30 & 585 & 0,45 & 0,48470 & 0,0017182 & 582 & 282,10 \\
\hline 26 & 31 & 2604 & 0,28 & 0,28768 & 0,0003845 & 2601 & 748,26 \\
\hline 27 & 32 & 748 & 0,64 & 0,75817 & 0,0013423 & 745 & 564,84 \\
\hline 28 & 33 & 27549 & 0,23 & 0,23419 & 0,0000363 & 27546 & 6450,98 \\
\hline 29 & 34 & 18200 & 0,42 & 0,44769 & 0,0000550 & 18197 & 8146,65 \\
\hline 30 & 35 & 17131 & 0,42 & 0,44769 & 0,0000584 & 17128 & 7668,07 \\
\hline 31 & 36 & 3679 & 0,39 & 0,41180 & 0,0002720 & 3676 & 1513,78 \\
\hline 32 & 37 & 2567 & 0,91 & 1,52752 & 0,0003900 & 2564 & 3916,57 \\
\hline 33 & 38 & 31114 & 0,63 & 0,74142 & 0,0000321 & 31111 & 23066,20 \\
\hline 34 & 39 & 688 & 0,83 & 1,18814 & 0,0014599 & 685 & 813,87 \\
\hline \multicolumn{4}{|c|}{$\sum(n-3) z=127491,26$} & \multicolumn{2}{|c|}{$z_{+}=\frac{127491,26}{215546,00} \cong 0,592$} & \multirow{2}{*}{\multicolumn{2}{|c|}{$r_{+}=\frac{e^{2 \times 0,5915}-1}{e^{2 \times 0,5915}+1} \cong 0,531$}} \\
\hline \multicolumn{4}{|c|}{$\sum(n-3)=215546,00$} & & & & \\
\hline
\end{tabular}


Os cálculos e resultados obtidos para o modelo de efeitos fixos estão apresentados na Tabela 10. A estimativa combinada para este modelo foi obtida através da eq. (16) e o resultado foi $r_{+} \cong 0,531$, indicando que as variáveis peso ao nascimento e peso à desmama têm uma associação positiva.

$\mathrm{Na}$ aproximação através do modelo de efeitos aleatórios, para este conjunto de dados, se faz necessário estimar a variância entre os estudos. A estimação do componente de variância pelo Método dos Momentos, proposto por DerSimonian \& Laird, é dada por,

$$
\hat{\tau}_{\mathrm{DL}}^{2}=\frac{40105-(34-1)}{215546-\frac{40373494703}{215546}} \cong 0,204
$$

O resultado da estimação do componente de variância pelo Método da Máxima Verossimilhança Restrita pode ser visto na Tabela 11.

Tabela 11. Estimação do componente de variância pelo MVR, pelo PROC MIXED.

\begin{tabular}{ccccc}
\hline Inf. & Sup. & Método & Estimativa & Nível \\
\hline 0,189 & 0,503 & MVR & 0,291 & 0,95 \\
\hline
\end{tabular}

De posse dos componentes de variância, procedeu-se a análise considerando $\mathbf{w}_{i}^{*}=\frac{1}{s_{i}^{2}+\hat{\tau}^{2}}$ para ponderar os estudos e obter uma estimativa do coeficiente de correlação comum. Os resultados desses cálculos estão apresentados nas Tabelas 12 e 13. 
Tabela 12. Estimativa combinada para o modelo de efeitos aleatórios $\left[\mathrm{w}_{\mathrm{i}}^{*}=1 /\left(\mathrm{s}_{\mathrm{i}}^{2}+\tau_{\mathrm{DL}}^{2}\right)\right]$.

\begin{tabular}{|c|c|c|c|c|c|c|c|}
\hline OBS & ESTUDO & $\mathbf{N}$ & $r$ & z & $1 /(n-3)$ & $\mathbf{w}_{\mathrm{i}}^{*}$ & $w_{i}^{*} z_{i}$ \\
\hline 1 & 1 & 1049 & 0,84 & 1,22117 & 0,0009560 & 4,88858 & 5,9698 \\
\hline 2 & 5 & 1580 & 0,81 & 1,12703 & 0,0006341 & 4,89629 & 5,5183 \\
\hline 3 & 7 & 1356 & 0,67 & 0,81074 & 0,0007391 & 4,89377 & 3,9676 \\
\hline 4 & 8 & 12339 & 0,25 & 0,25541 & 0,0000811 & 4,90958 & 1,2540 \\
\hline 5 & 9 & 831 & 0,67 & 0,81074 & 0,0012077 & 4,88258 & 3,9585 \\
\hline 6 & 10 & 998 & 0,40 & 0,42365 & 0,0010050 & 4,88741 & 2,0705 \\
\hline 7 & 11 & 1857 & 0,76 & 0,99622 & 0,0005394 & 4,89856 & 4,8800 \\
\hline 8 & 12 & 1028 & 0,38 & 0,40006 & 0,0009756 & 4,88812 & 1,9555 \\
\hline 9 & 13 & 659 & 0,53 & 0,59015 & 0,0015244 & 4,87504 & 2,8770 \\
\hline 10 & 14 & 2588 & 0,30 & 0,30952 & 0,0003868 & 4,90222 & 1,5173 \\
\hline 11 & 15 & 2944 & 0,47 & 0,51007 & 0,0003400 & 4,90335 & 2,5011 \\
\hline 12 & 16 & 4249 & 0,19 & 0,19234 & 0,0002355 & 4,90586 & 0,9436 \\
\hline 13 & 17 & 2282 & 0,99 & 2,64665 & 0,0004388 & 4,90098 & 12,9712 \\
\hline 14 & 19 & 31488 & 0,81 & 1,12703 & 0,0000318 & 4,91077 & 5,5346 \\
\hline 15 & 20 & 5701 & 0,40 & 0,42365 & 0,0001755 & 4,90731 & 2,0790 \\
\hline 16 & 21 & 4662 & 0,92 & 1,58903 & 0,0002146 & 4,90637 & 7,7963 \\
\hline 17 & 22 & 1864 & 0,54 & 0,60416 & 0,0005373 & 4,89861 & 2,9595 \\
\hline 18 & 23 & 5483 & 0,34 & 0,35409 & 0,0001825 & 4,90714 & 1,7376 \\
\hline 19 & 24 & 2550 & 0,54 & 0,60416 & 0,0003926 & 4,90209 & 2,9616 \\
\hline 20 & 25 & 3959 & 0,01 & 0,01000 & 0,0002528 & 4,90545 & 0,0491 \\
\hline 21 & 26 & 590 & 0,16 & 0,16139 & 0,0017036 & 4,87078 & 0,7861 \\
\hline 22 & 27 & 574 & $-0,12$ & $-0,12058$ & 0,0017513 & 4,86965 & $-0,5872$ \\
\hline 23 & 28 & 18751 & 0,18 & 0,18198 & 0,0000533 & 4,91025 & 0,8936 \\
\hline 24 & 29 & 1401 & 0,49 & 0,53606 & 0,0007153 & 4,89434 & 2,6237 \\
\hline 25 & 30 & 585 & 0,45 & 0,48470 & 0,0017182 & 4,87044 & 2,3607 \\
\hline 26 & 31 & 2604 & 0,28 & 0,28768 & 0,0003845 & 4,90228 & 1,4103 \\
\hline 27 & 32 & 748 & 0,64 & 0,75817 & 0,0013423 & 4,87937 & 3,6994 \\
\hline 28 & 33 & 27549 & 0,23 & 0,23419 & 0,0000363 & 4,91066 & 1,1500 \\
\hline 29 & 34 & 18200 & 0,42 & 0,44769 & 0,0000550 & 4,91021 & 2,1983 \\
\hline 30 & 35 . & 17131 & 0,42 & 0,44769 & 0,0000584 & 4,91013 & 2,1982 \\
\hline 31 & 36 & 3679 & 0,39 & 0,41180 & 0,0002720 & 4,90499 & 2,0199 \\
\hline 32 & 37 & 2567 & 0,91 & 1,52752 & 0,0003900 & 4,90215 & 7,4882 \\
\hline 33 & 38 & 31114 & 0,63 & 0,74142 & 0,0000321 & 4,91076 & 3,6409 \\
\hline 34 & 39 & 688 & 0,83 & 1,18814 & 0,0014599 & 4,87657 & 5,7940 \\
\hline \multicolumn{3}{|c|}{$\begin{array}{l}\sum w_{i}^{*}{ }^{*}=109,178 \\
\sum w_{i}^{*}=166,493\end{array}$} & $z_{+}^{*}$ & \multicolumn{2}{|c|}{$=\frac{109,178127}{166,4926983} \cong 0,656$} & \multicolumn{2}{|c|}{$\frac{e^{2 \times 0,655753}-1}{e^{2 \times 0,655753}+1} \cong 0,576$} \\
\hline
\end{tabular}

A estimativa combinada para o modelo aleatório é $\mathrm{r}_{+}^{*} \cong 0,576$, tanto para a estimação do componente de variância pelo MM quanto pelo MVR. As ponderações utilizadas $\mathrm{w}_{i}^{*}$ são bastante próximas. 
Tabela 13. Estimativa combinada para o modelo de efeitos aleatórios

$$
\left[w_{i}^{*}=1 /\left(s_{i}^{2}+\tau_{M V R}^{2}\right)\right]
$$

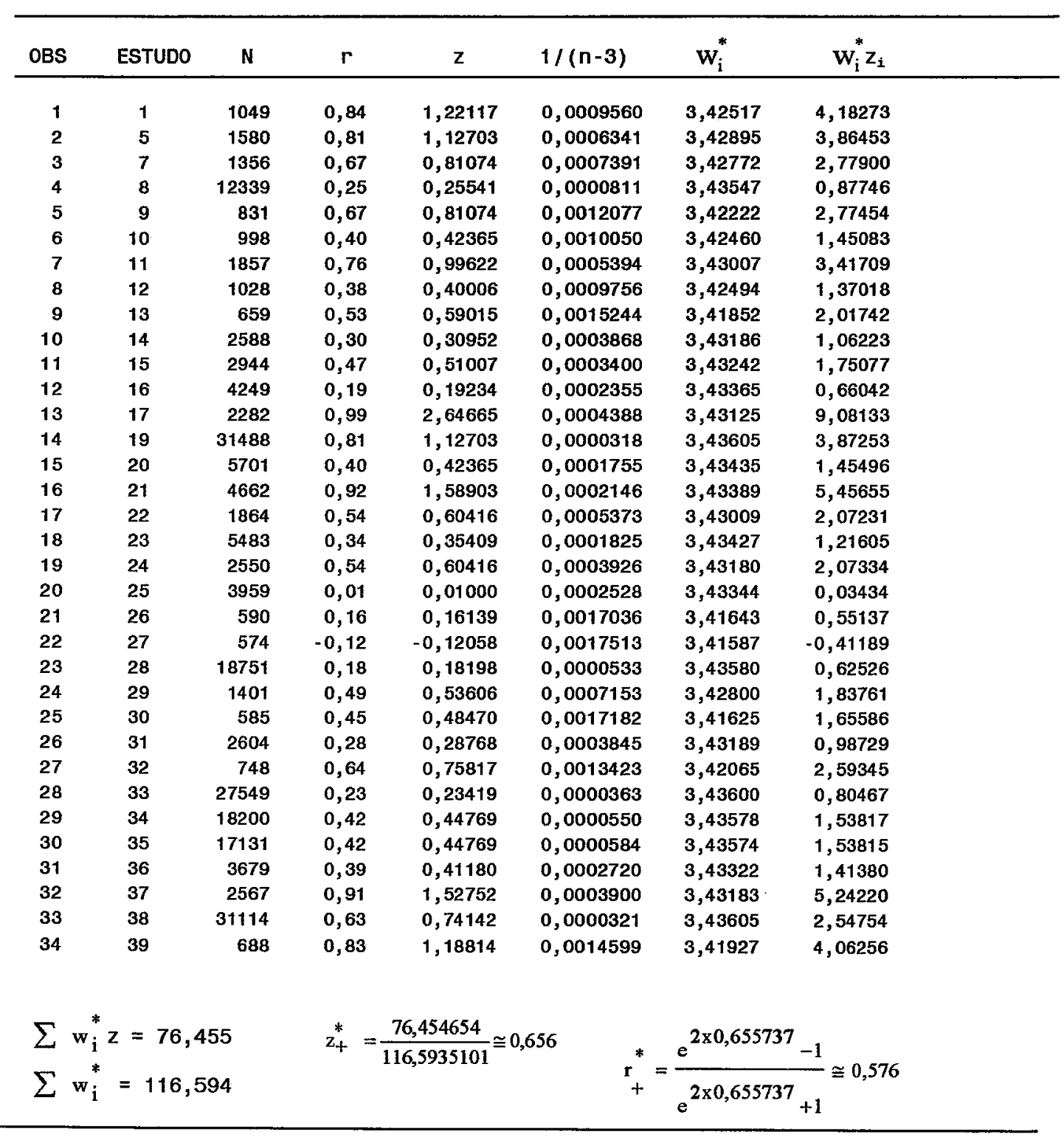

Ficou evidente que existem diferenças substanciais entre os estudos, assim, um modelo de efeito aleatório é mais apropriado para os dados desta meta-análise. Desta maneira, a variância entre os estudos foi de $\hat{\tau}_{\mathrm{DL}}^{2}=0,204$ para o Método dos Momentos e, $\hat{\tau}_{\text {MVR }}^{2}=0,291$ para o Método da Máxima Verossimilhança Restrita. 
O valor combinado do coeficiente de correlação, sob o modelo de efeitos aleatório foi $r_{+}^{*} \cong 0,576$, o qual pode ser considerado alto de acordo com Cohen (1988), indicando que as variáveis peso ao nascimento e peso à desmama são positivamente correlacionadas.

Com o objetivo de comparar a amplitude dos intervalos de confiança obtidas para os modelos de efeito fixo e de efeito aleatório construiu-se um "box plot" (Figura 4). Observa-se, que os intervalos de confiança foram $0,527 \leq r_{+} \leq 0,535$ e $0,442 \leq r_{+}^{*} \leq 0,684$ para o MEF e MEA, respectivamente, indicando uma amplitude maior para o MEA, pelo fato das generalizações serem maiores quando se utiliza este último.

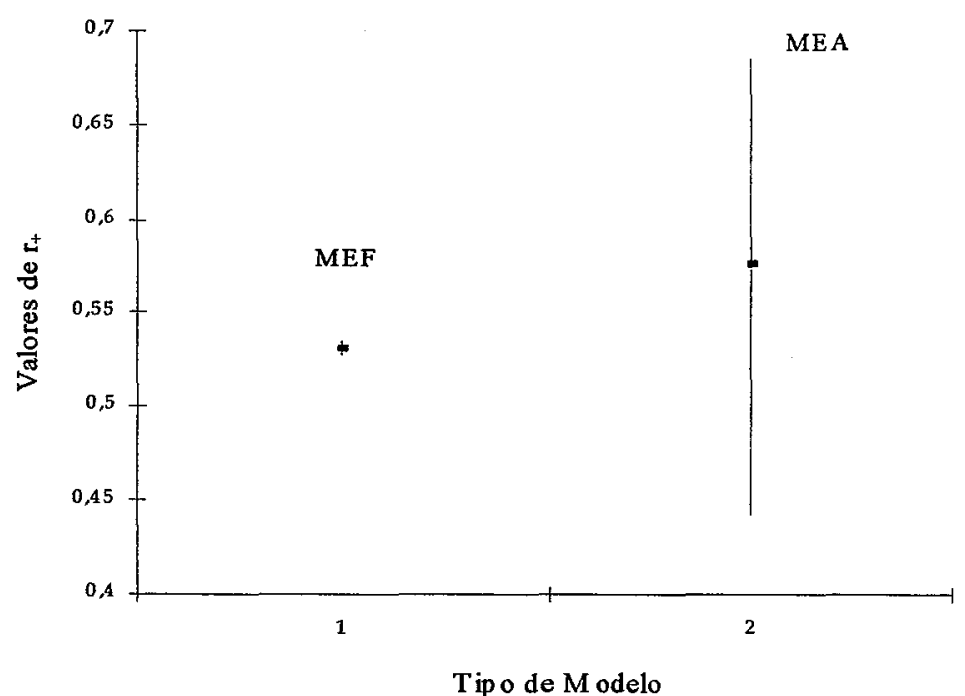

Figura 4. "Box plot" para os intervalos de confiança dos MEF e MEA.

A análise de subgrupo foi realizada incorporando o componente de variância entre os estudos, isto é, a ponderação utilizada tanto para os cálculos dos valores das estatísticas $Q_{\text {entre }}$ e $Q_{\text {dentro, }}$ quanto para os das estimativas combinadas, foi, $w_{i}^{*}=1 /\left(s_{i}^{2}+\tau_{M V R}^{2}\right)$. 
Estão expostos na Tabela 14 os resultados da análise para os três subgrupos de interesse adotados para esta meta-análise.

Tabela 14. Resultado da análise da heterogeneidade para os grupos de estudo.

\begin{tabular}{lrcc}
\hline Causa de Heterogeneidade & GL & ESTAT. Q & "PVALUE" \\
\hline Entre Grupos & 2 & 2006,55 & 0,000 \\
Dentro Grupos & 31 & 38098,2 & 0,000 \\
Dentro(Anos70) & 2 & 117,321 & 0,000 \\
Dentro(Anos80) & 21 & 30903,3 & 0,000 \\
Dentro(Anos90) & 8 & 7077,51 & 0,000 \\
Total & 33 & 40104,7 & 0,000 \\
\hline
\end{tabular}

Pode-se verificar, através dos resultados obtidos na Tabela 14, que existem fortes evidências para rejeitar as hipóteses de nulidade, isto é, tanto entre como dentro dos grupos de estudos não existe homogeneidade para os coeficientes de correlação. $\mathrm{O}$ mesmo pode ser observado para os subgrupos.

As estimativas combinadas para os coeficientes de correlação referentes aos grupos de estudos estão apresentadas na Tabela 15, juntamente com os respectivos intervalos de confiança.

Tabela 15. Resultados das estimativas combinadas para os subgrupos e intervalos de confiança.

\begin{tabular}{lcccc}
\hline Subgrupo & $\mathbf{r}_{+}^{*}$ & Nível & Inf. & Sup. \\
\hline Decada70 & 0,783 & 0,950 & 0,415 & 0,931 \\
Decada80 & 0,534 & 0,950 & 0,354 & 0,675 \\
Decada90 & 0,586 & 0,950 & 0,308 & 0,771 \\
Total & 0,576 & 0,950 & 0,442 & 0,684 \\
\hline
\end{tabular}


O valor da estimativa combinada para a década de 70 pode ser considerado muito alto, e a amplitude do seu intervalo de confiança grande. Tal fato pode ter ocorrido em virtude deste subgrupo envolver estudos mais antigos, indicando, provavelmente, uma qualidade inferior dos dados quando comparados aqueles das outras duas décadas.

Os valores das estimativas combinadas para as décadas de 80 e 90 podem também ser considerados altos. As amplitudes dos seus intervalos de confiança são menores daquelas da década de 70 , fato que pode indicar uma melhor qualidade dos estudos dessas duas últimas décadas em decorrência de uma possível melhoria dos métodos de estimação dos parâmetros genéticos e da qualidade e quantidade dos banco de dados envolvidos.

A análise de sensibilidade foi realizada, com o intuito de verificar se o resultado combinado foi afetado, ou não, pelos estudos considerados "outliers" potenciais.

Como observado anteriormente, por meio do "dot plot" (Figura 2), os estudos que podem ser considerados "outliers" são os de número 17, 21, 25, 27 e 37, e assim, os dados foram analisados sem eles. Os resultados desta análise estão apresentados, de forma resumida, na Tabela 16, e a análise de subgrupo nas Tabelas 17 e 18.

Tabela 16. Resultados resumidos da análise de sensibilidade.

\begin{tabular}{lc}
\hline \multicolumn{1}{c}{ PROCEDIMENTOS } & RESULTADOS \\
\hline Teste de homogeneidade: & $\mathrm{Q}=21565 \mathrm{e}^{\text {"cp-value" }>0,01}$ \\
\hline \multicolumn{1}{c}{ Modelo de Efeitos Fixos } & $\mathrm{r}_{+}=0,498$ \\
Estimativa combinada MEF & \\
\hline Modelo de Efeitos Aleatórios & \\
Estimativa do componente de variância pelo MVR: & $\hat{\tau}_{\mathrm{MVR}}^{2}=0,099$ \\
Estimativa combinada utilizando $\hat{\tau}_{\mathrm{MVR}}^{2}$, sob MEA: & $\mathrm{r}_{+}^{*}=0,518$ \\
Estimativa do componente de variância pelo MM: & $\hat{\tau}_{\mathrm{DL}}^{2}=0,119$ \\
Estimativa combinada utilizando $\hat{\tau}_{\mathrm{DL}}^{2}$, sob MEA: & $\mathrm{r}_{+}^{*}=0,518$ \\
\hline
\end{tabular}


De acordo com teste de homogeneidade para os estudos remanescentes, ainda não existe homogeneidade entre os mesmos ("p-value" > 0,01) para a estatística $Q$, assim, um modelo de efeitos aleatórios é mais apropriado para os dados em questão.

A estimação do componente de variância pelo Método da Máxima Verossimilhança Restrita e Método dos Momentos, proposto por DerSimonian \& Laird (1986) permitiu calcular os resultados combinados para o MEA, pelos quais observa-se que a estimativa combinada obtida para os 29 estudos foi inferior àquela obtida para os 34 estudos.

A retirada dos cinco estudos determinou uma redução importante nos valores de $\hat{\tau}_{\mathrm{MVR}}^{2}$ e $\hat{\tau}_{\mathrm{DL}}^{2}$, proporcionando uma grande redução no intervalo de confiança da estimativa combinada, pelo modelo de efeitos aleatórios, relativamente aos valores originais.

$\mathrm{Na}$ Figura 5 estão apresentados os "box plot" para os MEF e MEA, representando a amplitude para o conjunto de 29 estudos. $O$ intervalo de confiança referente ao MEF e MEA foram $0,494 \leq r_{+} \leq 0,502$ e $0,429 \leq r_{+}^{*} \leq 0,597$, respectivamente, utilizando o componente de variância calculado pelo MVR.

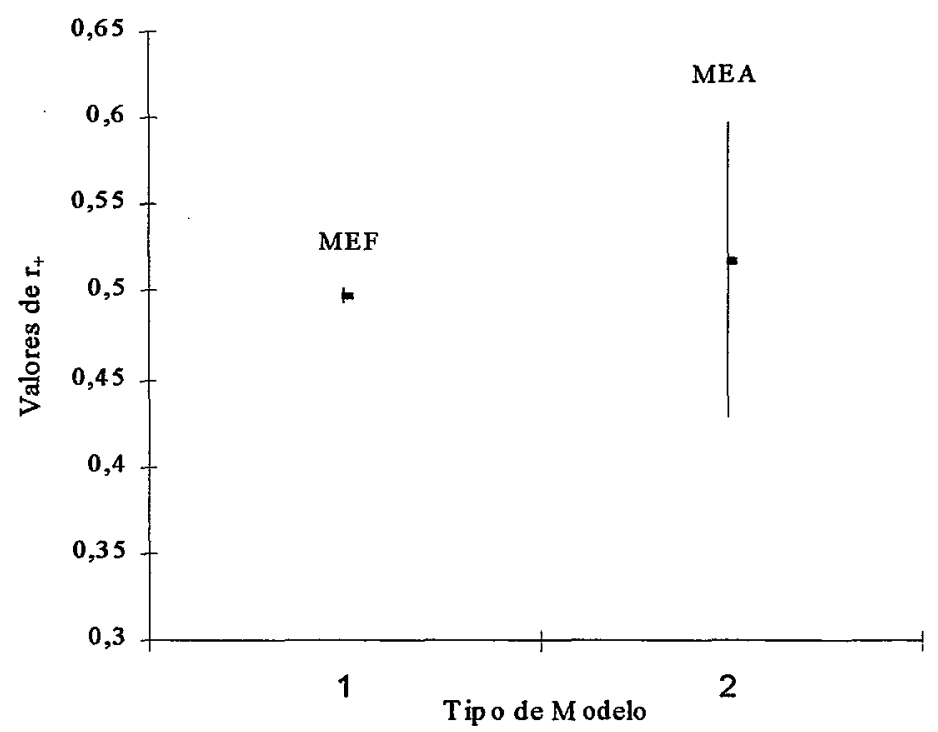

Figura 5. "Box plot" para os IC dos MEF e MEA, para a análise de sensibilidade. 
Assim como o observado para os dados originais, a análise de subgrupo mostrou que não existe homogeneidade entre e dentro dos grupos, assim como dentro dos subgrupos, indicando novamente que esses dados devem ser modelados sob a suposição do modelo de efeitos aleatórios.

Tabela 17. Resultado da análise da heterogeneidade para os grupos de estudo na análise de sensibilidade.

\begin{tabular}{lrcc}
\hline Causa de Heterogeneidade & GL & ESTAT . Q & "PVALUE" \\
\hline Entre Grupos & 2 & 1639,86 & 0,000 \\
Dentro Grupos & 26 & 19925,0 & 0,000 \\
Dentro(Anos70) & 2 & 117,321 & 0,000 \\
Dentro(Anos80) & 17 & 15466,2 & 0,000 \\
Dentro(Anos90) & 7 & 4341,54 & 0,000 \\
Total & 28 & 21564,9 & 0,000 \\
\hline
\end{tabular}

Tabela 18. Resultados das estimativas combinadas para os subgrupos e intervalos de confiança, para a análise de sensibilidade.

\begin{tabular}{lllll}
\hline Subgrupo & $\mathrm{r}_{+}^{*}$ & Nível & Inf. & Sup. \\
\hline Decada70 & 0,783 & 0,950 & 0,601 & 0,888 \\
Decada80 & 0,461 & 0,950 & 0,338 & 0,568 \\
Decada90 & 0,510 & 0,950 & 0,332 & 0,654 \\
Total & 0,518 & 0,950 & 0,429 & 0,597 \\
\hline
\end{tabular}

A extração dos estudos considerados "outliers" acarretou numa redução importante nas estimativas combinadas dos coeficientes de correlação genética, assim como na amplitude de seus intervalos de confiança (Tabela 18) comparativamente aos resultados obtidos para os valores originais (Tabela 15). 
A meta-análise apresenta várias alternativas para combinar resultados de estudos distintos, como no caso presente de estimativas dos coeficientes de correlação genética entre caracteres de bovinos de corte, tomados como exemplo. De modo particular permite modelar a variação entre os resultados de estimativas publicadas e testar a homogeneidade dos estudos, apresentando, ainda, uma flexibilidade para atender situações em que há necessidade ou interesse em agrupar os estudos em subgrupos, como exposto neste trabalho.

No presente trabalho as estimativas de correlação genética foram combinadas nos enfoques dos modelos fixo e aleatório, sendo que sob esta última suposição os estudos foram estratificados segundo a data de publicação. Para todos os enfoques aqui apresentados observou-se a heterogeneidade dos dados, indicando que o modelo de efeitos aleatórios, no qual a variabilidade entre os estudos é incorporada na análise, se faz adequado para obter a estimativa combinada de correlação genética.

Deste modo, em vista dos resultados, considera-se que a utilização da metaanálise é recomendável para sintetizar e combinar resultados de revisão parâmetros genéticos e similares. 


\section{CONCLUSÕES}

As conclusões são baseadas nos desenvolvimentos teóricos e nos resultados de aplicação.

A realização da pesquisa bibliográfica envolvendo, além de trabalhos publicados, também "abstracts", pode reduzir consideravelmente o vício de publicação. Entretanto, dependendo da área do conhecimento envolvida na meta-análise, como no presente trabalho, se faz necessária a busca manual dos trabalhos em Anais de Congresso, pois estes não estão em banco de dados internacionais.

A confiabilidade da meta-análise está tanto na aplicação de técnicas estatísticas apropriadas para sintetizar a informação de dados de estudos distintos, quanto na quantidade e sobretudo qualidade dos mesmos. Portanto, é essencial que a implementação da meta-análise seja planejada, delineada e realizada por profissionais de estatística e por aqueles relacionados à área do conhecimento abordado, dada a sua interdisciplinaridade.

A modelagem da variação entre os diferentes estudos é um procedimento importante na condução de uma meta-análise. Para a situação específica deste trabalho, observou-se que o modelo fixo não foi apropriado em virtude da falta de homogeneidade das estimativas de correlação genética. $\mathrm{O}$ modelo aleatório foi mais eficiente.

O uso de técnicas de meta-análise para sintetizar resultados de revisão de parâmetros genéticos e similares é recomendável. 


\section{REFERÊNCIAS BIBLIOGRÁFICAS}

COHEN, J. Statistical power analysis for the behavioral sciences. 2.ed. New York: Academic Press, 1988, 567p.

COOPER, H. M. Integrating research: a guide for literature reviews. 2.ed. Newbury Park: Sage, 1990. $157 \mathrm{p}$.

COSTA, P. A. B. Um enfoque segundo a teoria de conjuntos difusos para a metaanálise. Florianópolis, 1999. 153p. Tese (Doutorado) - Universidade Federal de Santa Catarina.

DEMPSTER, A. P.; LAIRD, N. M.; RUBIN, D. B. Maximum likelihood from incomplete data via the $E M$ algorithm. Journal of the Royal Statistical Society, v.39, p.1-38, 1977

DerSIMONIAN, R.; LAIRD, N. Meta-analysis in clinical trials. Controlled Clinical Trials, v.7, p.177-188, 1986.

DICKERSIN, K.; BERLIN, J.A. Meta-analysis: state-of-the-science. Epidemiologic Reviews, v.14, p.154-176, 1992.

EGGER, M.; SMITH, G.D. Meta-analysis: potentials and promise. British Journal of Medicine, v.315, 1371-1374, 1997. 
EGGER, M.; SMTTH, G.D. Meta-analysis: bias in location and selection of studies. British Journal of Medicine, v.316, 61-66, 1998.

EGGER, M.; SMITH, G.D.; PHILLIPS, A.N. Meta-analysis: principles and procedures. British Journal of Medicine, v.315, 1533-1537, 1997.

FAGARD, R. H.; STAESSEN, J. A.; THIJS, L. Advantages and disadvantages of the meta-analysis approach. Journal of Hypertension, v. 14, suppl.2, p.9-13, 1996.

FISHER, R.A. Statistical methods for research worker. 4.ed. London: Oliver and Boyde, 1932. 307p.

GAVER, J. R.; DRAPER, D. P.; GOEL, P. K.; GREENHOUSE, J. B.; HEDGES, L. V.; MORRIS, C. N.; WATERNAUX, C. Panel on statistical issues and opportunities for research in the combination of information. Washington: National Academic Press, 1992. 217p.

GLASS, G. V. Primary, secundary, and meta-analysis of research. Educational Researcher, v.6, p.3-8, 1976.

GLASS, G. V.; McGRAW, B.; SMITH, M. L. Meta-analysis in social research. Beverly Hills: Sage Publ., 1981. 280p.

GUREVITCH, J.; HEDGES, L. V. Meta-analysis: combining the results of independent experiments. In: SCHEINER, S. M.; GUREVITCH, J. Design and analysis of ecological experiments. New York: Chapman \& Hall, 1993. cap. 17, p.378-398.

HEDGES, L. V. Estimation of effect size from a series of independent experiments. Psyhological Bulletin, v.92, n.2, p.490-499, 1982. 
HEDGES, L.V.; OLKIN, I. Regression models in research synthesis. The American Statistician, v.37, n.2, p.137-140, 1983.

HEDGES, L.V.; OLKIN, I. Statistical methods for meta-analysis. London: Academic Press, 1985. 369p.

HOUWELINGEN, H.C.V. The future of biostatistics: expecting the unexpected. Statistics in Medicine, v.16, p.2773-2784, 1997.

HWANG, M.; THORN, R. G. The effect of user on system success: a meta-analytical integration of research findings. Information \& Management, v.35, p.229-236, 1999.

KIRBY, K. N. Advanced data analysis with SYSTAT. New York: Van Nostrand Reinhold, 1993. 475p.

KOOTS, K.R.; GIBSON, J.P.; SMITH, C.; WILTON, J.W. Analyses of publised genetic parameter estimates for beef production traits. 1. Heritability. Animal Breeding Abstracts, v.62, n.5, p. 309-338, May 1994a.

KOOTS, K.R.; GIBSON, J.P.; SMITH, C.; WILTON, J.W. Analyses of publised genetic parameter estimates for beef production traits. 2. Phenotypic and genetic correlations. Animal Breeding Abstracts, v.62, n.11, p. 826-853, Nov. 1994b.

LAU, J.; IOANNIDIS, P.A; SMITH, C.H. Quantitative synthesis in systematic reviews. Annals of Internal Medicine, v.127, n.9, p.820-826, 1997.

MERCADANTE, M.E.Z.; LÔBO, R.B.; REYES, A. Parámetros genéticos para características de crescimiento en cebuínos de carne. Archivo Latinoamericano Producción Animal, v. 3, n. 1, p.45-89, 1995. 
MOHIUDDIN, G. Estimates of genetic and phenotypic parameters of some trais in beef cattle. Animal Breeding Astracts, v.61, n.8, p.495-522, 1993

NORMAND, S.T. Meta-analysis software: a comparative review. The American Statistician, v.49, n.3, p.298-309, 1995.

NORMAND, S.T. Tutorial in biostatistics meta-analysis: formulating, evaluating, combining, and reporting. Statistics in Medicine, v.18, p.321-359, 1999.

OLKIN, I. Meta-analysis: reconciling the results of independent studies. Statistics in Medicine, v. 14, p.457-472, 1995.

PICKARD, L. M; KITCHENHAM, B. A.; JONES, P. W. Combining empirical results in software engineering. Information and Software Technology, v.40, p.811-821, 1998.

ROSENTHAL, R. Meta-analytic procedures for social research. Beverly Hills: Sage Publ., 1984. 150p.

SAS INSTITUTE. SAS procedures guide. Version 6, 3.ed., Cary, 1990a.

SAS INSTITUTE. SAS/STAT user's guide. Version 6, 4.ed., Cary, 1990b. 846p.

SAS INSTITUTE. SAS/STAT software: changes and enhancements through release 6.07. 6.12. Cary, 1996 .

SAS INSTITUTE. SAS macro language. 1.ed., Cary, 1997.

WANG, M. C.; BUSHMAN, B. J. Integration results: through meta-analytic review using SAS software. Cary: SAS Institute, 1999. 400p. 


\section{REFERÊNCIAS BIBLIOGRÁFICAS UTILIZADAS NA META-ANÁLISE}

ABASSA, K.P.; WILCX, C.J.; OLSON, T.A. Genetic aspects of growth in Gobra zebu cattle. Revista Brasileira de Genética., v.4, p.795-801, 1989.

AMARAL, C.O. Efeito da endogamia sobre a reprodução e crescimento de bovinos da raça nelore. Ribeirão Preto, 1986. 114p. Dissertação (Mestrado) - Faculdade de Medicina de Ribeirão Preto, Universidade de São Paulo.

ARNASON, Th.; KASSA-MERSHA, H. Genetic parameters of growth of Ethiopian Boran cattle. Animal Production, v.44, p.201-208, 1987.

AYALA, J.M.N.; PEREIRA, J.C.C.; OLIVERA, H.N. Efeitos genéticos e não genéticos sobre características ponderais de 2 populações da raça nelore. Arquivo Brasileiro de Medicina Veterinária e Zootecnia, v.43, n.1, p.81-91, 1991.

BARONI, E.B.Q. Efeitos maternais sobre os pesos de bovinos nelore até a desmama e as estimativas de correlações genéticas até os 12 meses de idade. Ribeirão Preto, 1982. 45p. Dissertação (Mestrado) - Faculdade de Medicina de Ribeirão Preto, Universidade de São Paulo.

BERRUECOS, J.M.; ROBISON, O.W. Preweaning growth in Brahmans. Journal of Animal Science, v.27, n.2, p.1124, 1968. /Apresentada ao 60. Annual Meeting of the American Society of Animal Science - Abstracts/ 
CARDELLINO, R.A.; CASTRO, L.F.S. Herdabilidade e correlações genéticas de peso e ganho de peso em bovinos da raça nelore. Revista da Sociedade Brasileira de Zootecnia, v.16, n.1, p.28-39, 1987.

ELER, J.P.; FERRAZ, J.B.S.; SILVA, P.R. Estimação simultânea de parâmetros genéticos para características de importância econômica na raça nelore, com a utilização de modelos animais. In: REUNIÃO ANUAL DA SOCIEDADE BRASILEIRA DE ZOOTECNIA, 33., Fortaleza, 1996. Anaïs. Viçosa: SBZ, 1996.

ELER, J.P.; FERRAZ, J.B.S.; LÔBO, R.B. Estimação de correlações genéticas, fenotípicas e ambientais na raça nelore, com uso de modelo animal multivariado. In: REUNIÃO ANUAL DA SOCIEDADE BRASILEIRA DE ZOOTECNIA, 31., Maringá, 1994. Anais. Viçosa: SBZ, 1994. p.169.

ELER, J.P.; LÔBO, R.B.; ROSA, A.N. Influência de fatores genéticos e de meio em pesos de bovinos da raça Nelore criados no Estado de São Paulo. Revista da Sociedade Brasileira de Zootecnia, v.18, n.2, p.103-111, 1989.

FELÍCIO, P.E.; LIMA, F.L.; GONÇALVES, L.S. Aspectos fenotípicos, genéticos e ambientais dos pesos ao nascer, aos 120 e aos 210 dias, das raças nelore, guzerá e gir, da Estação Experimental de Zootecnia de Sertãozinho. Boletim de Indústria Animal, v.33, n.1, p.19-69, 1976.

ILOEJE, M.V. Components of variance for growth traits among zebu and South Devon beef cattle in southeasten Nigeria. Livestock Production and Science, v.14, p.231-238, 1986.

LEDIC, I.L. Efeitos de meio e estimativas de parâmetros genéticos do crescimento prédesmama de bezerros da raça Tabapuã. Belo Horizonte, 1983. 125p. Dissertação (Mestrado) - Escola Veterinária, Universidade Federal de Minas Gerais. 
LÔBO, R.N.B; MADALENA, F.E.; VIEIRA, A.R. Average estimates of genetic parameters for beef and dairy cattle in Tropical regions. Animal Breeding Abstracts, v.68, p.433-462, 2000.

LÔBO, R.B.; REYES, A. de los; BEZERRA, L.A.F.; PIMENTA, C.M.S.J.; SILVA, J.A. II de V.; TAVARES, H. de F. Parâmetros fenotípicos e genéticos de pesos e perímetro escrotal às idades-padrão em animais da raça Nelore. In: REUNIÃo ANUAL DA SOCIEDADE BRASILEIRA DE ZOOTECNIA, 32., Brasília, 1995. Anais. Viçosa: SBZ, 1995. p.625-627.

MARIANTE, AS.; ZANCANER, A. Crescimento e reprodução em gado nelore: visão do criador e do pesquisador. São Paulo: Ed. dos Criadores, 1985. 152p.

MARQUES, L.F.A.; MILAGRES, J.C.; SILVA, M.A.; CASTRO, A.C.G. Fatores genéticos que influenciam o crescimento de gado guzerá em regiões do Espírito Santo e Minas Gerais. Revista da Sociedade Brasileira de Zootecnia, v.12, n.2, 1983.

MARTINS, G.A; MARTINS FILHO, R.; LIMA, F.A.M.; LÔBO, R.N.B. Influência dos fatores genéticos e de meio sobre o crescimento de bovinos da raça Nelore no estado do Maranhão. Revista Brasileira de Zootecnia, v.29, n.1, p. 103-107, 2000.

MARTINS FILHO, R.; LÔBO, R.B. Aspectos genéticos e de meio associados a peso ao nascer, a desmama e aos 205 dias, em rebanho Guzerá. In: REUNIÃO ANUAL DA SOCIEDADE BRASILEIRA DE ZOOTECNIA, 26., Porto Alegre, 1989. Anais. Viçosa: SBZ, 1989. p.375.

MERCADANTE, M.E.Z.; LÔBO, R.B.; REYES, A. Parámetros genéticos para características de crescimiento en cebuínos de carne. Archivo Latinoamericano Producción Animal, v. 3, n. 1, p.45-89, 1995. 
MILAGRES, J.C.; SILVA, L.O.C. da; NOBRE, P.R.C.; ROSA, A.N. Influência de fatores de meio e herança sobre pesos de animais da raça Nelore no Estado de Minas Gerais. Revista da Sociedade Brasileira de Zootecnia, v.14, n.4, p.463-484, 1985.

MORTARI, N. Estudo genético-quantitativo de características ponderais do período pré-desmame em gerações sucessivas de um rebanho nelore. Ribeirão Preto, 1976. 127p. Dissertação (Mestrado) - Faculdade de Medicina de Ribeirão Preto, Universidade de São Paulo.

NOBRE, P.R.C.; ROSA, A.N.; SILVA, L.O.C. da. Influência de fatores genéticos e de meio sobre os pesos de gado Nelore no Estado da Bahia - Brasil. Revista da Sociedade Brasileira de Zootecnia, v.14, n.3, p.338-357, 1985.

OLIVEIRA, J.A. de; LÔBO, R.B.; GONÇALVES, A.A.M. Estimativas de parâmetros genéticos e fenotípicos de pesos e ganhos em peso do nascimento aos 365 dias de idade em um rebanho da raça Guzerá. Boletim de Indústria Animal, v.50, p.119. $123,1993$.

OLIVEIRA, J.A. de; PEREIRA, G.T.; BERGAMASCHINE, A.F.; FAGLIARI, J.J. Fatores de meio e herança que afetam os pesos e o ganho de peso de bezerros guzerá na fase de aleitamento. Arquivo Brasileiro de Medicina Veterinária e Zootecnia, v.38, n.5, p.761-771, 1986. 
OLIVEIRA FILHO, E.B.; DUARTE, F.A.M. Correlações genéticas, fenotípicas e ambientes entre etapas do crescimento de bezerros nelore. In: REUNIÃO ANUAL DA SOCIEDADE BRASILEIRA DE ZOOTECNIA, 18., Goiânia, 1981. Anais. Viçosa: SBZ, 1981. p.253.

PIMENTA FILHO, E.C. Fatores genéticos e de meio que influenciam os pesos e ganhos de peso de animais nelore na caatinga litorânea da Paraíba. Viçosa, 1980. 92p. Dissertação (Mestrado) - Universidade Federal de Viçosa.

REYES, A. de los; LÔBO, R.B; OLIVEIRA, H.N. de; TONHATI, H.; MARTINS FILHO, R.; BEZERRA, L.A.F. Estimation de (co)varianzas y DEP's por modelo animal bicaracter para pesos y perimetro escrotal de ganado nelore en Brasil. Revista Argentina de Producción Animal, v.15, n.3/4, p.926-930, 1995.

ROSA, A.N.; SILVA, L.O.C. da; NOBRE, P.R.C. Avaliação do desempenho de animais nelore em controle de desenvolvimento ponderal no Estado de Mato Grosso do Sul, Brasil. Revista da Sociedade Brasileira de Zootecnia, v.15, n.6, p.515532, 1986.

SALLES, P.A. Critérios de seleção para características de crescimento em machos da raça nelore. Ribeirão Preto, 1995. 69p. Dissertação (Mestrado) - Faculdade de Medicina de Ribeirão Preto, Universidade de São Paulo.

SCHERRÉ, J.F.; CARNEIRO, G.G.; FONSECA, C.G.; PEREIRA, C.S.; SAMPAIO, I.B.M. Estudo genético-quantitativo de pesos de bezerros ao nascimento, aos 90 e 205 dias de idade num rebanho nelore no trópico semi-árido. Arquivo Brasileiro de Medicina Veterinária e Zootecnia, v.40, n.3, p.205-223, 1988. 
SILVA, J.S. Efeitos de meio e de herança sobre o peso ao nascimento, aos 90 dias de idade e à desmama (205 dias) de um rebanho nelore da Zona da Mata de Pernambuco. Belo Horizonte, 1983. 61p. Dissertação (Mestrado) - Escola de Veterinária, Universidade Federal de Minas Gerais.

SILVA, L.O.C.; MILAGRES, J.C.; SILVA, M.A.; REGAZZI, A.J.; EUCLIDES, R.F. Análise genética de pesos de animais nelore em várias idades. Revista da Sociedade Brasileira de Zootecnia, v.12, n.2, p.177-186, 1983.

SILVA, L.O.C.; ROSA, A.N.; NOBRE, P.R.C.; MILAGRES, J.C.; EVANGELISTA, S.R.M. Análise de pesos de bovinos nelore criados a pasto no Estado de São Paulo, Brasil. Pesquisa Agropecuária Brasileira, v.22, n.11/12, p.1245-1256, 1987.

SOUZA, J.C.; RAMOS, A.A. Efeitos de fatores genéticos e do meio sobre os pesos de bovinos da raça nelore. Revista da Sociedade Brasileira de Zootecnia, v.24, p.164 - 172, 1995.

TAWONEZVI, H.P.R.; BROWNLEE, L.W.I.; WARD, H.K. Studies on growth of Nkone cattle. Zimbabwe Journal of Agricultural Research, v.24, n.1, 1986.

TORRES, R.A.; SILVA, M.A.; TORRES, J.R. Fatores de meio e herança que afetam os pesos e ganho de peso de bezerros gir na fase de aleitamento. Revista da Sociedade Brasileira de Zootecnia, v.8, n.3, p.488-496, 1979.

VERDE, O.; PLASSE, D.; BASTARDO, J; HOOGESTEIJN, R.; BASTIDAS, P. Parâmetros geneticos de tres pesos en un rebaño Brahman registrado bajo seleccion. ALPA, Mem., v.18, p.161, 1983. 
APÊNDICE 
APENDICE 1. Programa SAS referente ao critério de inclusão e transformação do $r$ em $z$.

data dados;

input estudo $n R$;

$z=0.5^{\star} \log ((1+r) /(1-r))$;

$v z=1 /(n-3)$;

if $n<=500$ then delete;

cards;

$\begin{array}{lll}1 & 1049 & 0.84\end{array}$

$\begin{array}{lll}1 & 417 & 0.44\end{array}$

$3 \quad 399 \quad 0.26$

$4 \quad 261 \quad 1.18$

$5 \quad 1580 \quad 0.81$

$6 \quad 193 \quad 0.21$

$\begin{array}{lll}7 & 1356 & 0.67\end{array}$

$8 \quad 12339 \quad 0.25$

$\begin{array}{lll}9 & 831 & 0.67\end{array}$

$\begin{array}{lll}10 & 998 & 0.40\end{array}$

$\begin{array}{lll}11 & 1857 & 0.76\end{array}$

$\begin{array}{lll}12 & 1028 & 0.38\end{array}$

$\begin{array}{lll}13 & 659 & 0.53\end{array}$

$14 \quad 2588 \quad 0.30$

$15 \quad 2944 \quad 0.47$

$16 \quad 4249 \quad 0.19$

$\begin{array}{lll}17 & 2282 & 0.99\end{array}$

$18 \quad 485 \quad 0.73$

$19 \quad 31488 \quad 0.81$

$20 \quad 5701 \quad 0.40$

$21 \quad 4662 \quad 0.92$

$22 \quad 1864 \quad 0.54$

$23 \quad 5483 \quad 0.34$

$24 \quad 2550 \quad 0.54$

$25 \quad 3959 \quad 0.01$

$26 \quad 590 \quad 0.16$

$27 \quad 574 \quad-0.12$

$28 \quad 18751 \quad 0.18$

$29 \quad 1401 \quad 0.49$

$30 \quad 585 \quad 0.45$

$31 \quad 2604 \quad 0.28$

$32 \quad 748 \quad 0.64$

$33 \quad 27549 \quad 0.23$

$34 \quad 18200 \quad 0.42$

$35 \quad 17131 \quad 0.42$

$\begin{array}{lll}36 & 3679 & 0.39\end{array}$

$\begin{array}{lll}37 & 2567 & 0.91\end{array}$

$\begin{array}{lll}38 & 31114 & 0.63\end{array}$

$\begin{array}{lll}39 & 688 & 0.83\end{array}$

;

proc print;

run;

A saída deste programa está apresentada na Tabela 7. 
APÊNDICE 2. Programa SAS referente a construção do "dot plot".

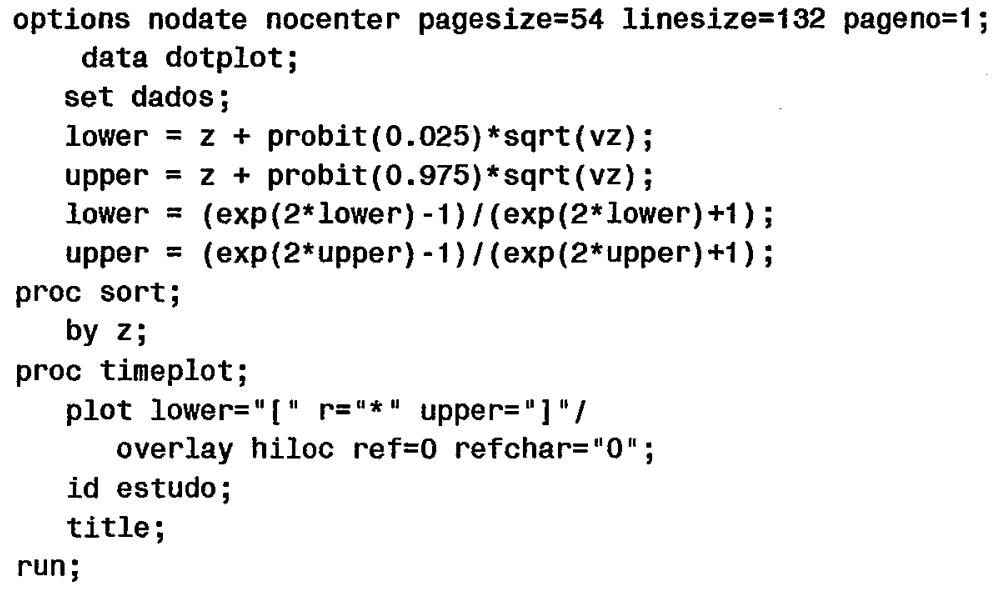

A saída deste programa está apresentada na Figura 2. 
APÊNDICE 3. Programa SAS referente à análise exploratória dos dados.

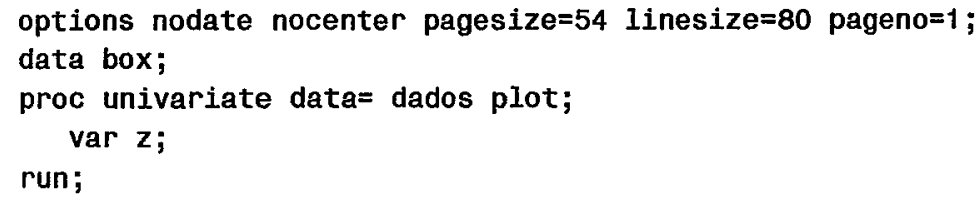

A saída deste programa está apresentada de maneira resumida na Figura 3. Segue abaixo saida completa.

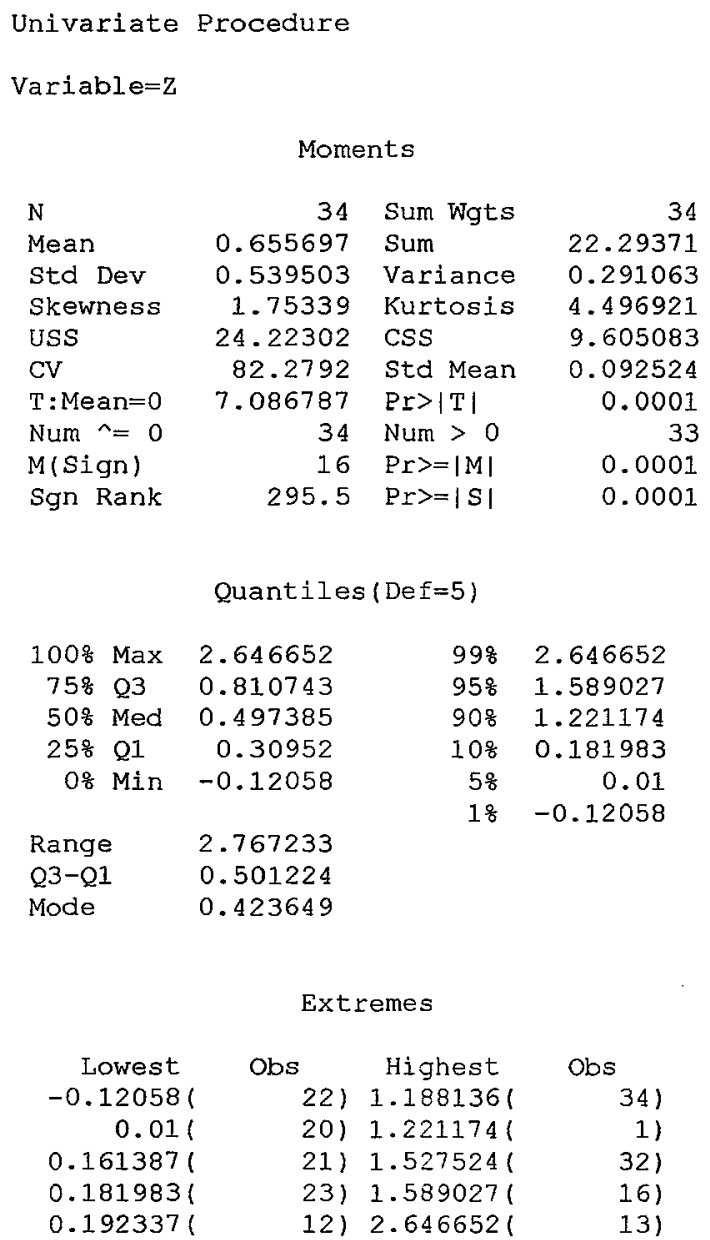

$$
\begin{array}{rr}
998 & 2.646652 \\
958 & 1.589027 \\
90 \% & 1.221174 \\
108 & 0.181983 \\
58 & 0.01 \\
18 & -0.12058
\end{array}
$$

Extremes

Lowest
-0.120581
0.011
$0.161387 !$
$0.181983 !$
0.192337

Obs Highest

22) 1.188136(

Obs

20) 1.221174(

21) 1.527524(

23) 1.589027(

12) 2.646652( 


\section{Univariate Procedure}

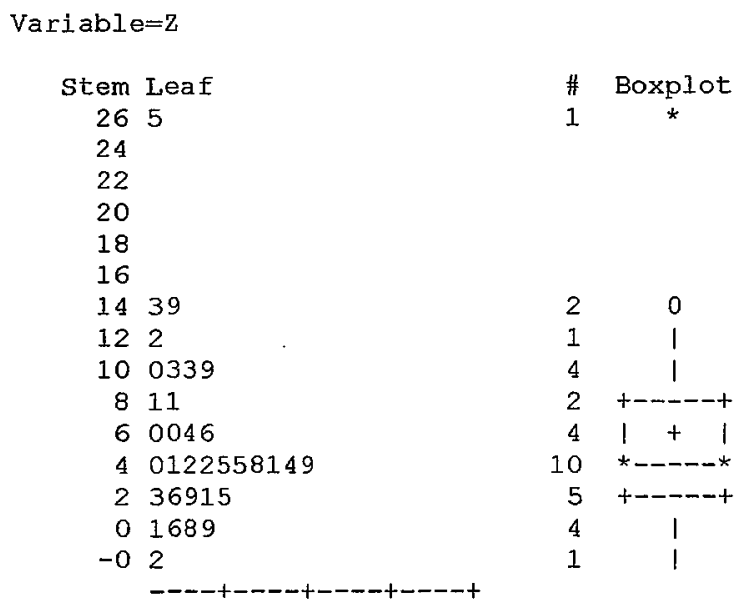

Multiply Stem. Leaf by $10 * *-1$

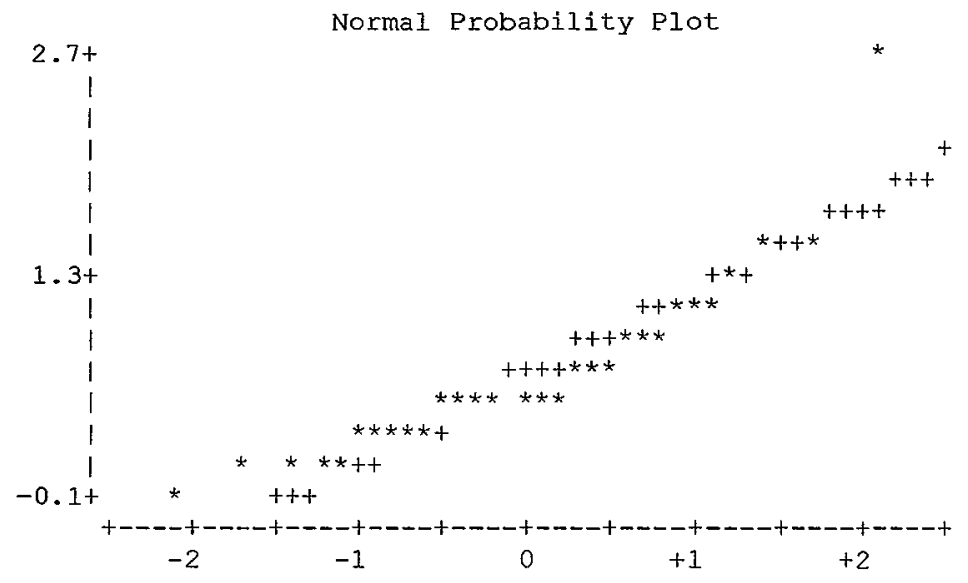




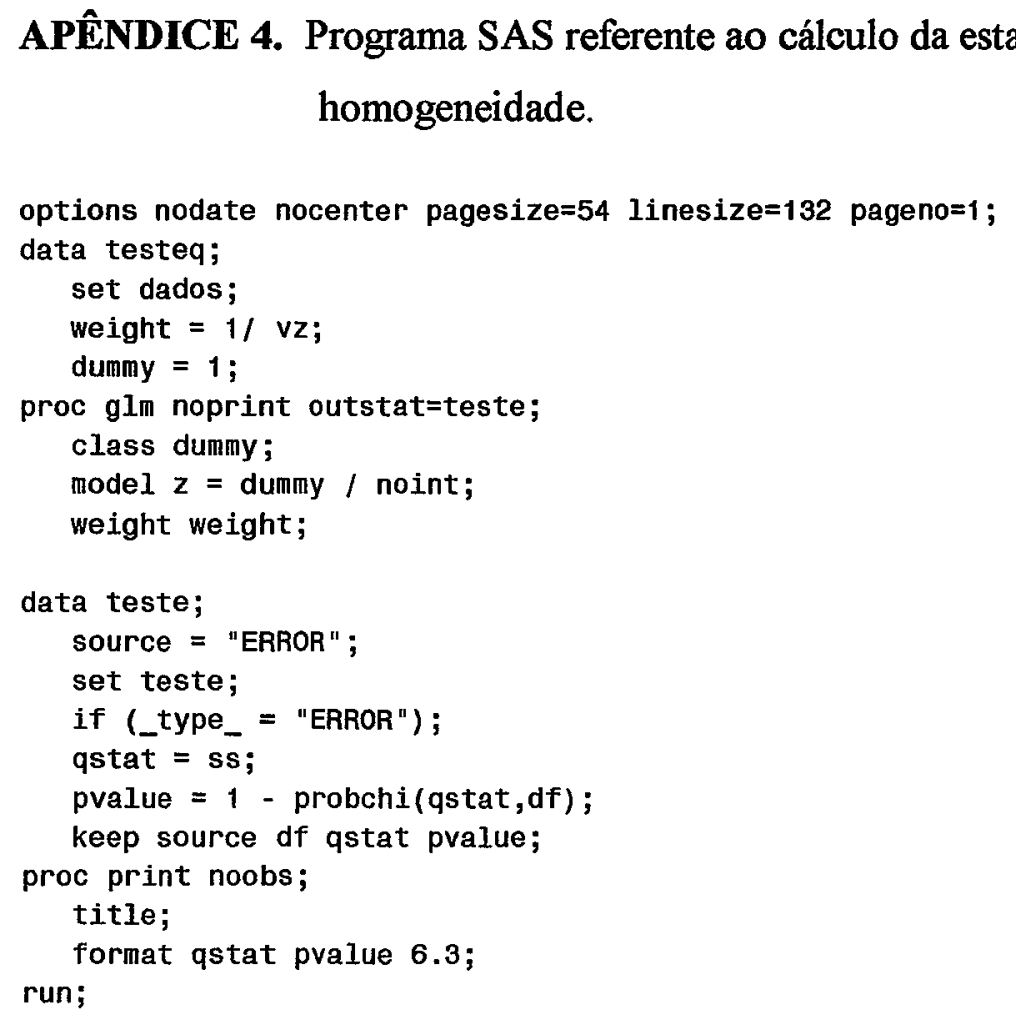

A saída deste programa está apresentada na Tabela 8. 


\section{APÊNDICE 5. Programa SAS referente a estimação do componente de variância}

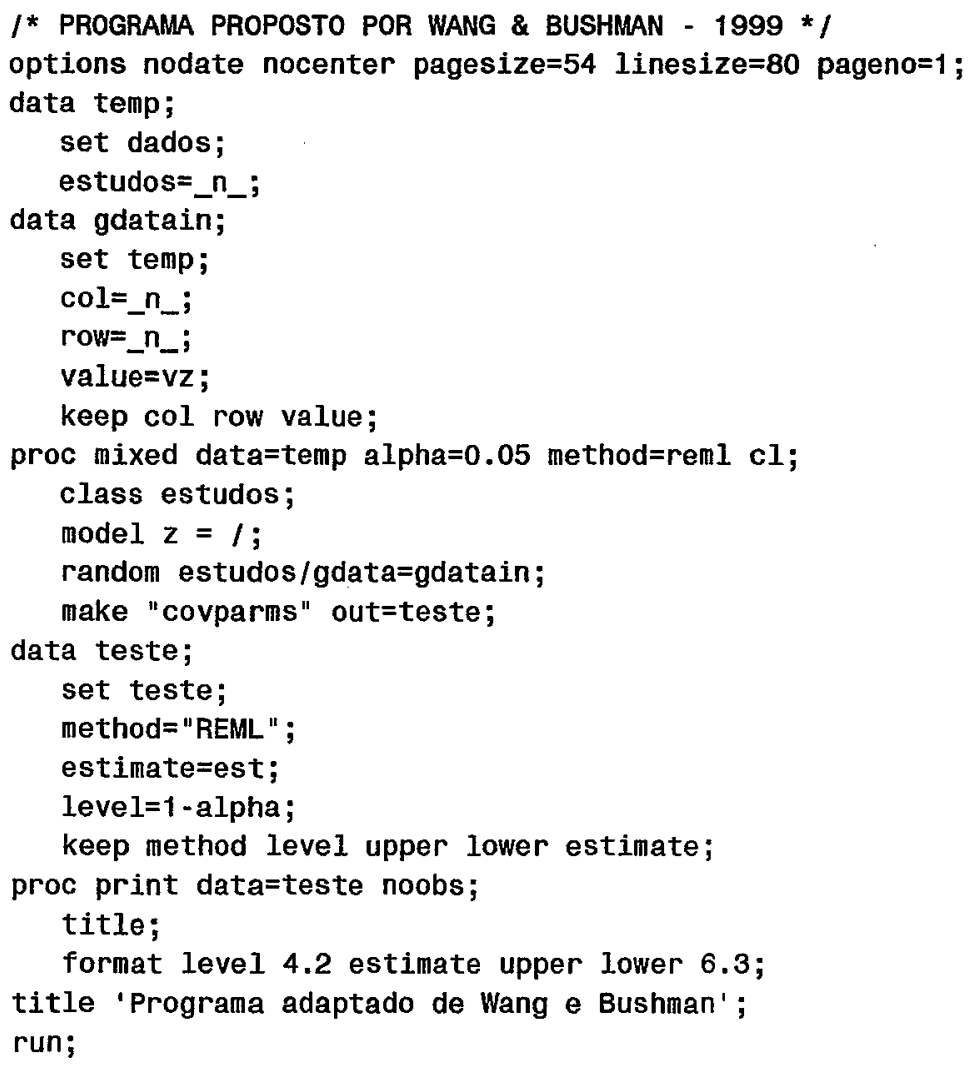

A saída resumida deste programa está apresentada na Tabela 10. A saída completa segue abaixo.

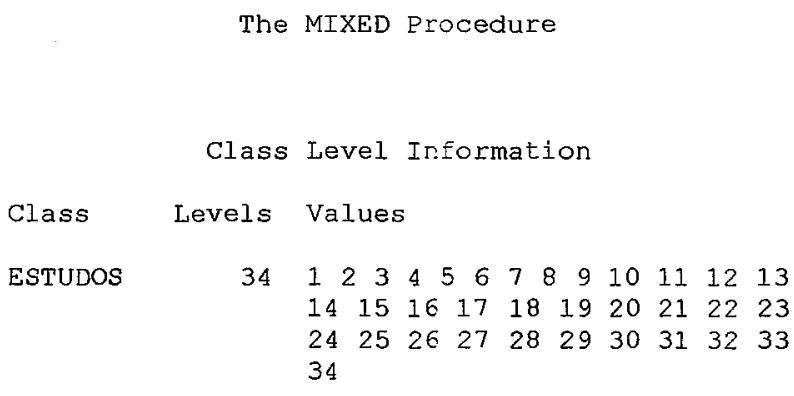


REML Estimation Iteration History

\begin{tabular}{|c|c|c|c|c|c|c|}
\hline & & ration & Evaluations & Objective & & fiterion \\
\hline & & 0 & 1 & -4.20273902 & & \\
\hline & & 1 & 5 & -4.19481029 & & 00000000 \\
\hline Conver & ce crite & ia met. & riance Parame & er Estimates & $s$ (REN & \\
\hline & Co & Parm & Estimate & Alpha & Lower & Upper \\
\hline & $\operatorname{Re}$ & idual & 0.29052111 & 0.05 & .1890 & 0.5034 \\
\hline & & $\mathrm{M}$ & odel Fitting & nformation & for $z$ & \\
\hline & & Descr & iption & & & Lue \\
\hline & & Obser & vations & & 34. & 200 \\
\hline & & Res I & og Likelihood & & -28 & 276 \\
\hline & & Akaik & e's Informati & n Criterion & -29 & 276 \\
\hline & & Schwa & rz's Bayesian & Criterion & -29 & 758 \\
\hline & & $-2 R e$ & s Log Likelih & & & \\
\hline Progran & adaptado & de Wang & e Bushman & & & \\
\hline LOWER & UPPER & METHO & ESTIMATE & LEVEL & & \\
\hline 0.189 & 0.503 & REMI & 0.291 & 0.95 & & \\
\hline
\end{tabular}


APÊNDICE 6. Macro e programa SAS utilizados para testar a homogeneidade na análise de subgrupo sob um modelo de efeito aleatório.

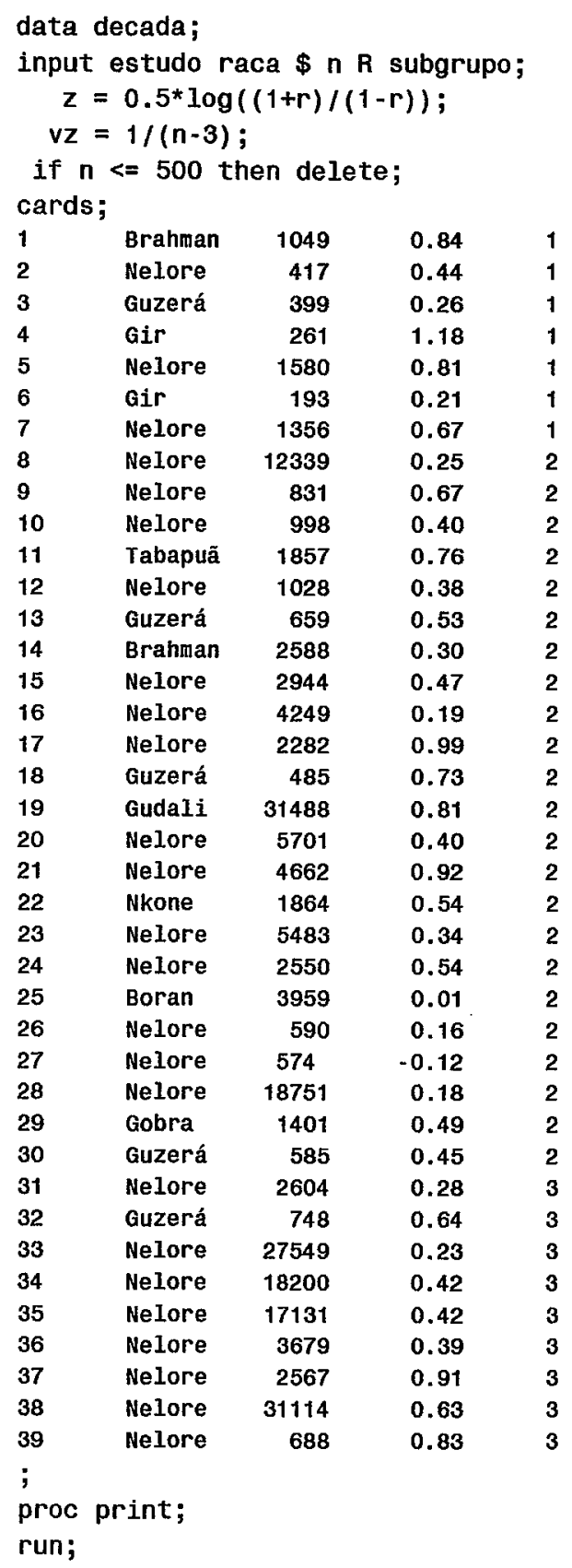




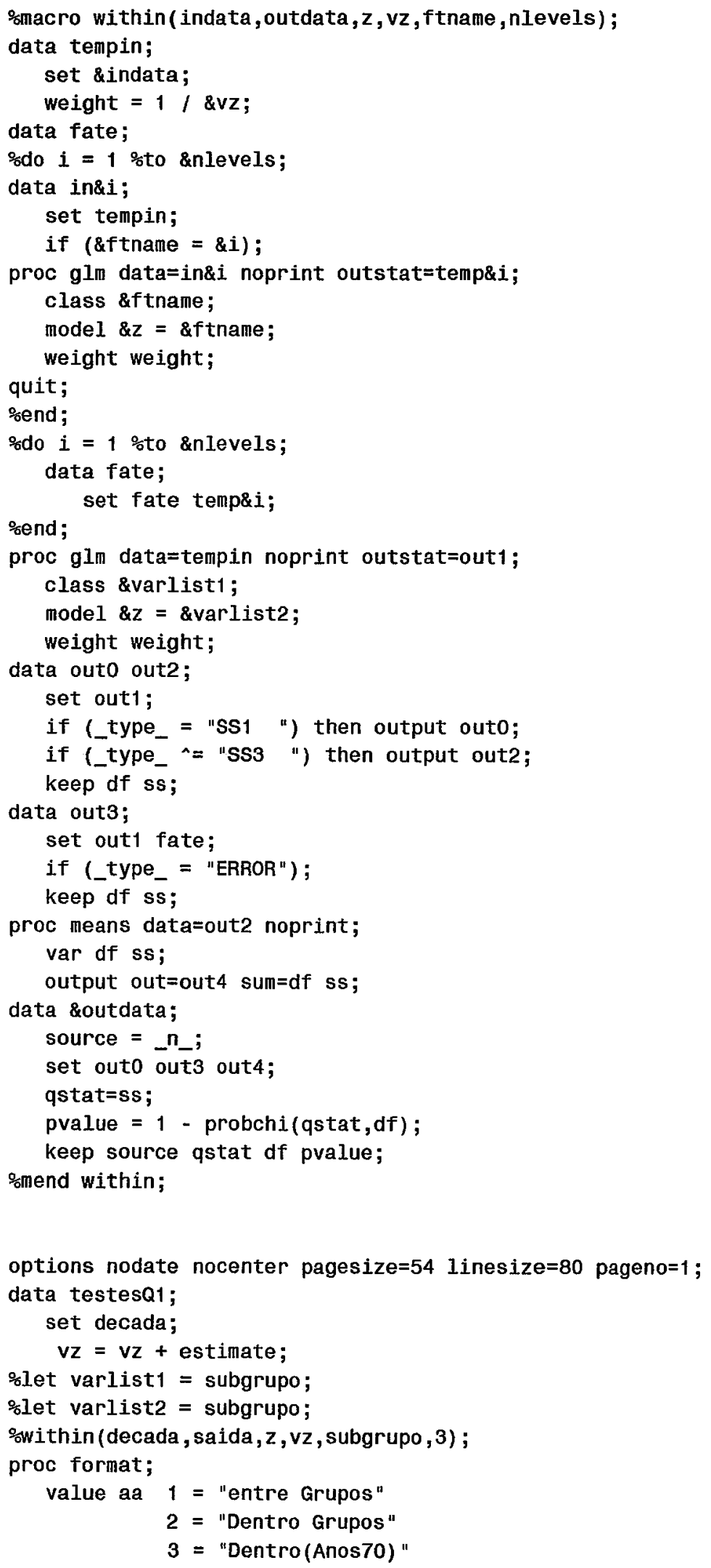




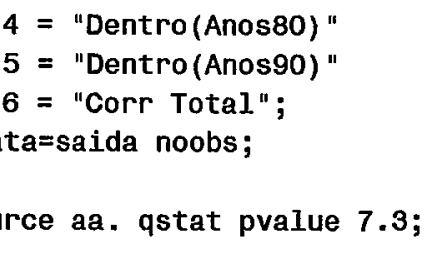

run;

A saída deste programa está apresentada na Tabela 14. 
APÊNDICE 7. Macro e programa SAS utilizados para calcular os coeficientes de correlação combinados e seus respectivos intervalos de confiança, sob um modelo de efeito aleatório.

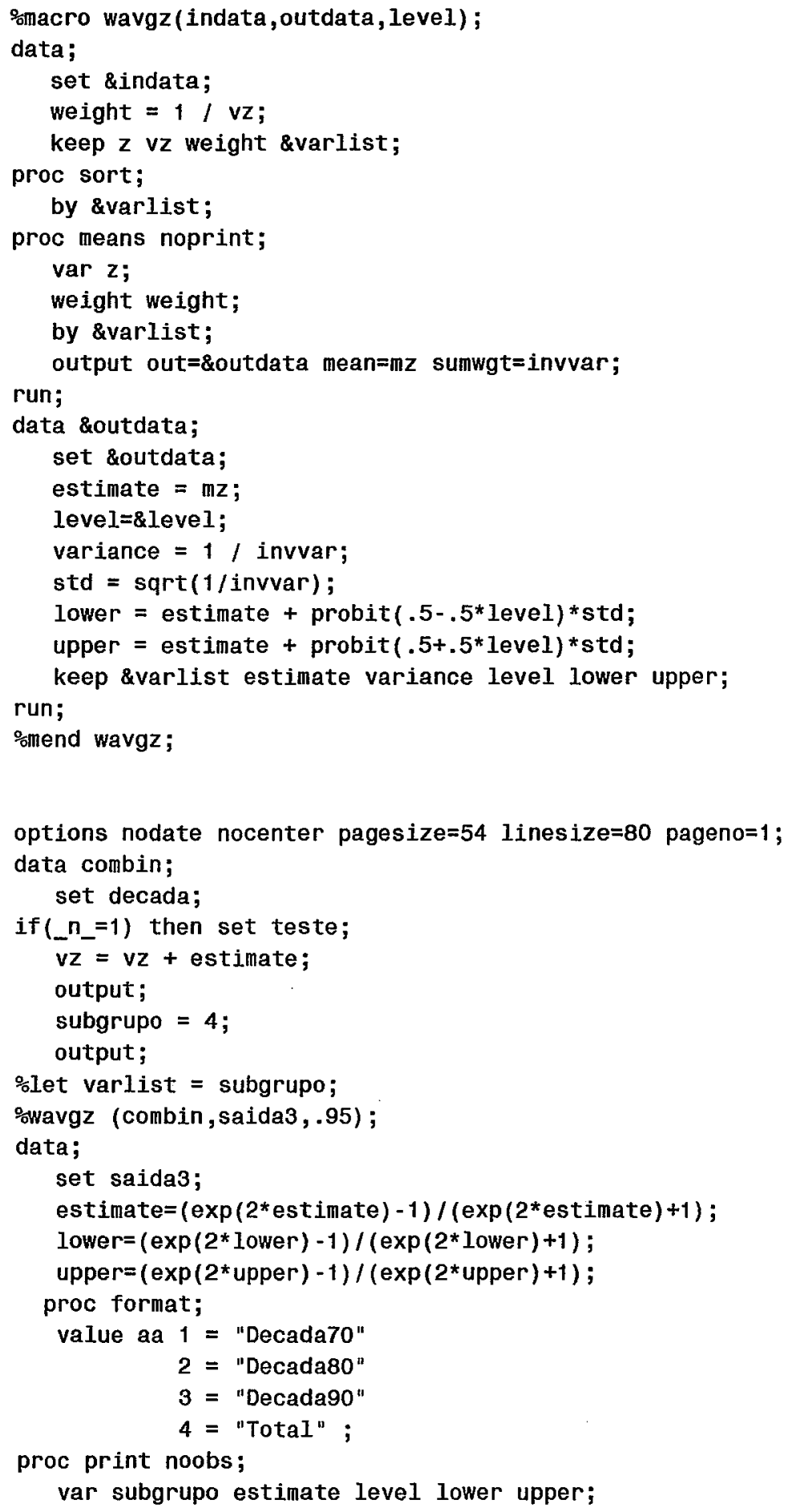


format subgrupo aa. estimate level lower upper 6.3;

run;

A saída deste programa está apresentada na Tabela 15 . 